\title{
Implementing Strategies for Drying and Pressing Wood Without Emissions Controls
}

Final Report for Project DE-FC36-96ID13439

Supported by the US Department of Energy

by

Sujit Banerjee

Institute of Paper Science and Technology

School of Chemical \& Biomolecular Engineering Georgia Institute of Technology

$50010^{\text {th }}$ Street, NW, Atlanta, GA 30332-0620

and

Terrance E. Conners

Department of Forestry

University of Kentucky

Lexington, KY 40546-0073

September 2007 


\section{Executive Summary}

Drying and pressing wood for the manufacture of lumber, particleboard, oriented strand board (OSB), veneer and medium density fiberboard (MDF) release volatile organic compounds (VOCs) into the atmosphere. These emissions require control equipment that are capitalintensive and consume significant quantities of natural gas and electricity. The objective of our work was to understand the mechanisms through which volatile organic compounds are generated and released and to develop simple control strategies.

Of the several strategies developed, two have been implemented for OSB manufacture over the course of this study. First, it was found that increasing final wood moisture by about 2-4 percentage points reduced the dryer emissions of hazardous air pollutants by over $70 \%$. As wood dries, the escaping water evaporatively cools the wood. This cooling tapers off wood when the wood is nearly dry and the wood temperature rises. Thermal breakdown of the wood tissue occurs and VOCs are released. Raising the final wood moisture by only a few percentage points minimizes the temperature rise and reduces emissions.

Evaporative cooling also impacts has implications for VOC release from wood fines. Flaking wood for OSB manufacture inevitable generates fines. Fines dry out rapidly because of their high surface area and evaporative cooling is lost more rapidly than for flakes. As a result, fines emit a disproportionate quantity of VOCs. Fines can be reduced in two ways: through screening of the green furnish and through reducing their generation during flaking. The second approach is preferable because it also increased wood yield. A procedure to do this by matching the sharpness angle of the flaker knife to the ambient temperature was also developed.

Other findings of practical interests are as follows.

- Dielectric heating of wood under low-headspace conditions removes terpenes and other extractives from softwood.

- The monoterpene content in trees depend upon temperature and seasonal effects.

- Method 25A emissions from lumber drying can be modeled from a knowledge of the airflow through the kiln.

- A heat transfer model shows that VOCs released during hot-pressing mainly originate from the surface of the board.

- Boiler ash can be used to adsorp formaldehyde from air streams. 


\section{CONTENTS}

Page

Executive Summary

Overview 3

VOC extraction from softwood through low-headspace heating $\quad 8$

Microwave-enhanced transport of chemicals into

$\begin{array}{ll}\text { green wood under low-headspace conditions } & 22\end{array}$

$\begin{array}{ll}\text { HAPs release from wood drying } & 27\end{array}$

Seasonal variation in Southern pine terpenes 36

Mechanisms of terpene release during sawdust and flake drying $\quad 46$

Flake drying temperature affects mat properties during pressing 56

Mechanism of VOC release from high-temperature Southern $\begin{array}{ll}\text { pine lumber drying } & 66\end{array}$

Method for lowering the VOCs emitted during drying of wood products 71

Method for distributing chemicals through a fibrous material $\begin{array}{ll}\text { using low-headspace dielectric heating } & 72\end{array}$

Heat transfer model for estimating pinene emissions from $\begin{array}{ll}\text { hot-pressing softwood flakeboard } & 75\end{array}$

Controlling formaldehyde emissions with boiler ash 85

Process-based control of HAPs emissions from drying wood flakes 95

Influence of knife angle and ambient temperature $\begin{array}{ll}\text { on fines generation from flakers } & 104\end{array}$

Temperature effects on fines generation during wood flaking 115

$\begin{array}{lr}\text { List of publications and presentations } & 122\end{array}$ 


\section{Overview}

This report is divided into several sections each of which has been published or accepted for publication in the peer-reviewed literature. A summary of each section is as follow.

VOC extraction from softwood through low-headspace heating

This paper was published in Holzforschung, 53, 641-647 (1999).

Two approaches are reported to control VOC release: heating green wood, or irradiating it with microwave energy, both in a low-headspace environment where evaporation is minimized. Low-headspace heating of green flakes (for OSB manufacture) releases VOCs but proportionately much less water. Hence, it is feasible to extract and collect the VOCs from green wood prior to drying, and to then dry it with lowered emissions. Irradiating flakes with microwave leads to contrasting behavior. Water is released with very little VOC loss if the flakes are microwaved in an open container. Microwaving under low-headspace conditions removes the VOCs, but retains the water in the wood.

The water trapped in the wood because of the low-headspace restriction drives the VOCs out of the hydrophobic regions (e.g., resin canals) where they are principally located, into hydrophilic zones. Movement out of the hydrophilic environment and out of the wood is then quite rapid. Hence, either VOC or water release can be targeted by adjusting the headspace during microwaving. Most of the VOCs lost during drying originate from the surface, and low-headspace microwaving releases this surficial material. Hydrogen isotope exchange work shows that microwaving increases water access to the exchangeable protons in dry, or partially dry, wood tissue. The terpenes are carried out with the small amount of steam generated. Similar results are obtained with low-headspace radiofrequency (RF) irradiation of lumber; RF treatment does not induce a significant change in strength.

Microwave-enhanced transport of chemicals into green wood under low-headspace conditions

This paper was published in Holzforschung, 54 (2000) 331-333.

Dye studies showed that microwaving a green wood under low-headspace conditions led to greater ingress of the dye into the structure of wood than would be expected on the basis of heat alone. The study complements a previous finding where turpentine was preferentially released from green softwood through dielectric heating under low-headspace conditions. It was hypothesized that since the water was unable to leave the wood because of the low-headspace restriction, it dissolved the turpentine from hydrophobic regions within the wood. Once dissolved, these hydrophobic materials moved rapidly outside. The practical implication of this separation of turpentine from green wood is that the turpentine, which normally represents an air pollutant during drying, is now extracted as a product. The turpentine-depleted wood can then be dried with much reduced emissions.

\section{HAPs release from wood drying}

This paper was published in Environ. Sci. Technol., 34, 2280 (2000).

Hazardous Air Pollutant (HAP) profiles from drying softwood and hardwood flakes (for the manufacture of oriented strand board) are very similar, indicating that they originate through 
a common mechanism, the breakdown of wood tissue. Hence, the strategies employed to reduce VOC (volatile organic compound) emissions from hardwood can also be extended to decreasing HAPs from softwood. Drying aspen flakes in the field and in the laboratory gives rise to different VOC species, and direct extension of laboratory data to the field may prove difficult. Formaldehyde emissions from drying fresh aspen flakes are lower than those from stored material; the opposite effect occurs for methanol and the other aldehydes. HAPs evolved from drying pine flakes surge sharply at 5-10\% moisture content during drying at $130-160^{\circ} \mathrm{C}$. Emissions of methanol, formaldehyde, pentanal, and hexanal all begin simultaneously, with the release of methanol and formaldehyde being the most sensitive to dryer temperature. Hence, the nature of the VOC mix will be at least partly governed by the dryer temperature. Pine and aspen give rise to similar HAPs profiles during either drying or pressing flakes that are already dried.

\section{$\underline{\text { Seasonal Variation In Southern Pine Terpenes }}$}

This paper was published in Forest Products J., 51(6), 89 (2001).

Monoterpene and volatile organic compound (VOC) concentrations measured at some mills have large swings of a seemingly seasonal nature and a great amount of variability is evident. The question to be resolved is whether these differences are attributable to wood handling and mill operations or to biological factors associated with tree growth. Information in the available literature primarily describes monoterpene production and release associated with foliage, not wood. This paper describes the results of a study comparing the amounts of VOCs released from drying southern pine wood to the amount of monoterpenes collected from loblolly pine (Pinus taeda) increment cores. Handling and storage have been shown to potentially affect quantitative results, but it appears that more monoterpenes are produced in trees in response to higher temperatures and increased precipitation. At least for reasonably fresh material, measurements of monoterpenes and VOC concentrations at mills probably reflect climatically-affected patterns of tree development.

\section{Mechanisms of Terpene Release During Sawdust and Flake Drying}

This paper was published in Holzforschung, 55, 413 (2001).

The water and $\alpha$-pinene released during sawdust and flake drying were simultaneously measured. For sawdust, the drying profiles for water and pinene are very different at oven temperatures of $105^{\circ} \mathrm{C}$, but are similar at $200^{\circ} \mathrm{C}$. There is an initial burst of pinene very early in the process, which is mainly attributed to the loss of pinene dissolved in surface water. Later, the pinene and water are released in a near-constant ratio, which is ascribed to water mobilizing pinene from the interior of the wood matrix to the wet line. The surfactants present in wood are believed to solubilize pinene into water. Finally, pinene is lost through evaporation when the wood is almost dry. Hence, at least three mechanisms are operative for the movement and release of $\alpha$-pinene and other terpenes from wood.

\section{Flake Drying Temperature Affects Mat Properties During Pressing}

This paper was published in Holzforschung, 56, 558 (2002).

The contact angle of water on wood rises sharply as the wood approaches dryness. The general shape of the rise can be reproduced through thermodynamic calculations that consider 
the presence of extractives on the surface. SEM work confirms that extractives move progressively to the surface with increasing drying temperature. Other factors such as pore closure also contribute to surface hydrophobicity. The temperature profile within a stack of flakes during accelerated pressing shows a break at $100^{\circ} \mathrm{C}$ when flakes dried at high temperature are processed. Moisture is known to be driven from the outer layers of the stack to the core during early pressing. If the flake surface is hydrophobic then this moisture would film on the surface rather than penetrate into the flake. Subsequent evaporation of the moisture would lead to high pressure. Hence, flakes dried at high temperature should be more prone to delamination. Hightemperature drying also promotes VOC emissions and there should be operational and environmental benefits to drying at lower temperature.

Mechanism Of VOC Release From High-Temperature Southern Pine Lumber Drying This paper was published in Wood Fiber Sci., 34, 666 (2002)

Hydrocarbon (Method 25A) emissions from drying southern pine lumber have been measured in full-scale experiments. The mechanism proposed comprises three components: release of turpentine dissolved in the surface layer of water on the wood, water-mediated transport of turpentine from the interior of the wood to the surface, and evaporation of turpentine during the falling rate period. The result allows the total Method 25A release to be estimated without knowledge of the airflow through the kiln. Full-scale Method 25A emissions from lumber can be predicted from laboratory work on sawdust, indicating that the mechanism is independent of the type of furnish.

Method for lowering the VOCs emitted during drying of wood products

This material issued as US patent 6,365,240 (2002)

The present invention is directed to a method for removal of VOCs from wood products prior to drying the wood products. The method of the invention includes the steps of providing a chamber having an opening for receiving wood and loading the chamber with green wood. The wood is loaded to an extent sufficient to provide a limited headspace in the chamber. The chamber is then closed and the wood is heated in the chamber for a time and at a temperature sufficient to saturate the headspace with moisture and to substantially transfer VOCs from the wood product to the moisture in the headspace.

Method for distributing chemicals through a fibrous material using low-headspace dielectric heating

This material issued as US patent 6,436,486 (2002).

System and method for diffusing chemicals rapidly and evenly into and through fibrous material, such as wood. Chemicals are introduced into the fibrous material by applying the chemicals to the fibrous material. After treating the fibrous material with the chemicals, the fibrous material is maintained under low-headspace conditions. Thermal energy or dielectric heating, such as microwave or radio frequency energy, is applied to the fibrous material. As a result, the chemicals are able to distribute evenly and quickly throughout the fibrous material. 
Heat Transfer Model for Estimating Pinene Emissions from Hot-Pressing Softwood Flakeboard This paper was published in Holzforschung, 58, 384 (2004).

A heat transfer model for estimating pinene emissions from hot-pressing strand for the manufacture of flakeboard has been constructed from first principles and validated. The model predicts $\alpha$-pinene emissions of $0.4 \mathrm{~kg} / 1000 \mathrm{~kg}$ for a 0.95 - $\mathrm{cm}$ board, which is within the $0.3-0.6$ $\mathrm{kg} / 1000 \mathrm{~kg}$ range reported for commercial operations. Most of the emissions originate from the hot 1-mm layer of wood adjoining the platen surface. As a result, residual pinene in the board is depleted at the surface for both commercial and laboratory-prepared boards. Emissions are drastically reduced when the mat is surfaced with a layer of aspen.

Controlling Formaldehyde Emissions with Boiler Ash

This paper was published in Environ Sci. Technol. 39, 5101 (2005).

Fluidized wood ash reduces formaldehyde in air from about 20 to less than 1 ppmv. Methanol is removed to a much lower extent. The efficiency of formaldehyde reduction increases with increasing moisture content of the ash. Sorption of formaldehyde to ash can be substantially accounted for by partitioning to the water contained in the ash followed by ratecontrolling binding to the ash solids. Adsorption occurs at temperatures of up to $165^{\circ} \mathrm{C}$; oxidation predominates thereafter. It is proposed that formaldehyde could be stripped from an air stream in a fluidized bed containing ash, which could then be returned to a boiler to incinerate the formaldehyde.

\section{Process-Based Control of HAPs Emissions From Drying Wood Flakes}

This paper was published in Environ. Sci. Technol., 40, 2438 (2006).

Industrial wood drying generates methanol, formaldehyde, and other Hazardous Air Pollutants (HAPs). A simple theoretical model shows that particles smaller than $400 \mu \mathrm{m}$ will begin to thermally degrade and release disproportionately large quantities of HAPs. This is confirmed in full-scale practice where particles smaller than $500 \mu \mathrm{m}$ show visible signs of charring. Laboratory measurement of the activation energy for the breakdown of wood tissue into methanol and formaldehyde led to a value of about $17 \mathrm{kcal} / \mathrm{mole}$. The apparent activation energy measured in the field was higher. This result was obtained under non-isothermal conditions and is biased high by the fines fraction of the furnish which is exposed to elevated temperatures. It is proposed that a combination of screening out the fines fraction smaller than $500 \mu \mathrm{m}$ and reducing dryer inlet temperature will substantially reduce emissions, possibly to the point where control devices can be downsized or eliminated. Our findings allow these HAPs reductions to be semiquantitatively estimated.

Influence of Knife Angle and Ambient Temperature on Fines Generation from Flakers

This paper was published in Forest Products J., 56(10) 86 (2006).

The production of fines from a flaker at a commercial southern pine OSB mill was found to be correlated with the log storage temperature and the cutting angle of the knife. Knife angle changes were able to significantly decrease the amount of fines produced, and the knife angle could be optimized for different wood temperatures. Twenty-nine degree knife angles produce 
fewer fines than knives with 26 or 31 degree knife angles when log storage temperatures are cool. Similar results were obtained using a pilot plant strander. Optimizing knife angles to reduce fines will not only increase production efficiency but will also reduce VOCs during wood drying.

\section{Temperature Effects on Fines Generation during Wood Flaking}

This manuscript has been accepted by Appita $J$.

The amount of fines produced by flaking green logs into strands for oriented strandboard depends on a combination of temperature and the knife sharpness angle. In winter, a larger knife angle reduces the fines significantly. Two conditions are necessary for this phenomenon to occur: the fines must be created by (at least) two different processes, and the two processes must have different temperature dependencies. During flaking, a piece of wood is removed from a log through a combination of splitting and cutting. Results from two full-scale facilities suggest that the splitting component is temperature-dependent because lignin softens with increasing temperature. Laboratory results indicate that the cutting action is insensitive to temperature. These data provide a working hypothesis for the practice of reducing flaker fines by adjusting the knife sharpness angle in response to log temperature. A similar approach should also apply to reducing fines from chipping wood for pulping, although the significance would be smaller given that far fewer fines are generated during chipping than in flaking. 


\title{
VOC Extraction from Softwood Through Low-Headspace Heating
}

\author{
Holzforschung, 53, 641-647 (1999).
}

\author{
Wei Su${ }^{1}$, James R. Boerner ${ }^{1}$, Usha Hooda ${ }^{1}$, Hui Yan ${ }^{1}$, Sujit Banerjee ${ }^{1}$, Rubin Shmulsky ${ }^{2}$, Leo- \\ nard L. Ingram ${ }^{2}$, Terrance E. Conners ${ }^{2}$ \\ ${ }^{1}$ Institute of Paper Science and Technology, Atlanta, GA, USA \\ ${ }^{2}$ Mississippi State University, Mississippi State, MS, USA
}

\section{Summary}

Volatile organic compounds (VOCs), principally terpenes, released during wood drying face present or potential regulation. Two approaches are reported to control VOC release: heating green wood, or irradiating it with microwave energy, both in a low-headspace environment where evaporation is minimized. Low-headspace heating of green flakes (for OSB manufacture) releases VOCs but proportionately much less water. Hence, it is feasible to extract and collect the VOCs from green wood prior to drying, and to then dry it with lowered emissions. Irradiating flakes with microwave leads to contrasting behavior. Water is released with very little VOC loss if the flakes are microwaved in an open container. Microwaving under low-headspace conditions removes the VOCs, but retains the water in the wood. The water trapped in the wood because of the low-headspace restriction drives the VOCs out of the hydrophobic regions (e.g., resin canals) where they are principally located, into hydrophilic zones. Movement out of the hydrophilic environment and out of the wood is then quite rapid. Hence, either VOC or water release can be targeted by adjusting the headspace during microwaving. Most of the VOCs lost during drying originate from the surface, and low-headspace microwaving releases this surficial material. Hydrogen isotope exchange work shows that microwaving increases water access to the exchangeable protons in dry, or partially dry, wood tissue. The terpenes are carried out with the small amount of steam generated. Similar results are obtained with low-headspace radiofrequency $(\mathrm{RF})$ irradiation of lumber; RF treatment does not induce a significant change in strength.

Keywords:

Microwave, Radiofrequency, Flakes, Lumber, Particle, Pinene, Terpene, VOC, Low-headspace, Recovery 


\section{Introduction}

Environmental regulations in the United States impose controls on wood drying facilities. Regenerative Thermal Oxidation units (Yeo 1993; Grzanka 1996; Matros et al. 1996) are most often employed, but they are capital-intensive, and are associated with substantial operating and maintenance costs. $\mathrm{CO}_{2}$ and $\mathrm{NO}_{\mathrm{x}}$ emissions from the control units are additional negatives. The reliance on control devices would be minimized if emissions could be reduced through process changes. In previous papers, we outlined strategies for reducing VOCs (principally terpenes) by changing drying practices without adding significant new capital equipment (Banerjee et al. 1998; Su et al. 1999). We now demonstrate the principle of a new process whereby softwood VOCs can be substantially recovered from wood prior to drying.

When green wood is heated in a low-headspace environment (one where evaporation is minimized), energy is transferred to both wood tissue and the entrained water. Since most of the water is unable to leave because of the low-headspace restriction, its movement or rate of mixing within the wood matrix, should increase. Wood constituents that are at least partially soluble in water should also be better mixed as a result. Alexiou et al. (1990) have shown that pre-steaming under saturation conditions mobilizes Eucalyptus heartwood extractives, probably by allowing water greater access to cell walls. A similar effect should occur for turpentine in softwood, since the turpentine components are principally localized in specific hydrophobic regions in wood (resin canals). Low-headspace heating should even out their concentrations, and help move them to the surface, from which they can more easily leave the wood. As a result, some of the turpentine should be removed from green wood, which can then be dried conventionally with reduced emissions. In this paper we apply this concept to the extraction of turpentine from softwood.

\section{Materials and Methods}

The purpose of these experiments was to determine the suitability and efficacy of steam and of dielectric heating in a low-headspace enclosure to remove terpenes from wood particles, flakes, and lumber. The two methodologies are functionally dissimilar; unlike thermal (steam) heating where the heat moves from the surface of the wood to the interior, dielectric heating (e.g., microwave or RF heating) transfers energy to the entire wood matrix. Loblolly pine (pinus taeda) particles and flakes were solicited from three mills in the southern U.S., wrapped in plastic and placed in cold storage for use within a few days. Unseasoned lumber was obtained and handled similarly.

\section{Steaming trials with particles}

Particles were steamed in a low-headspace cylinder, a $10.2 \mathrm{~cm}$ (outside diameter) x 69 $\mathrm{cm}$ long sealed stainless steel vessel with a quick disconnect union at one end for sample loading and unloading. The cylinder accepts up to $100 \mathrm{~g}$ of furnish, and is illustrated in Figure 1. Steam can be fed into the vessel at pressures ranging from 1-3.5 atmospheres. The unit is fitted with a steam vortex meter with pressure and temperature outputs, needle valves to retain the steam in the vessel after injection, and a pressure relief valve. Heating tape is wrapped around the vessel to minimize condensation inside the cylinder. Steam times and temperatures were varied to determine whether these variables had any effect on VOC recovery. Steaming times ranging from 15 to 60 minutes were used, and the steam temperatures ranged from 119 to $179^{\circ} \mathrm{C}$. The steam was vented through a methanol trap to recover the VOCs. 
The steamed particles were dried in a $3.8 \mathrm{~cm}$ diameter ceramic tube furnace at $130^{\circ} \mathrm{C}$ for 30 minutes. The furnish was placed in a ceramic boat in the center of the tube, a $3.8 \mathrm{~cm}$ midsection of which was electrically heated. Air was metered to the tube inlet at $2 \mathrm{lpm}$, and the furnace emissions were drawn into a JUM Model VE7 flame ionization analyzer (FIA) through its builtin pump. This unit is used in US EPA Method 25A for monitoring VOC emissions (Anonymous 1995). The results are reported on an "as propane" ppm basis in air. Terpenes and resin acids were analyzed by GC-FID; the resin acids were derivatized by trimethylanilinium hydroxide prior to injection.

\section{Steaming trials with lumber}

To evaluate the feasibility of removing VOCs from lumber by steaming it in a low headspace environment, an experimental pilot-scale kiln $\left(0.33 \mathrm{~m}^{3}\right.$ capacity $)$ at Mississippi State University was fitted with a steam spray. Two kiln runs were made with end-matched samples of southern pine. Wood $\left(0.085 \mathrm{~m}^{3}\right)$ with an average specific gravity of 0.42 was used for each run. One set was steamed for 5 hours (under saturation conditions) in a $0.42 \mathrm{~m}^{3}$ steamer, and then kiln-dried for 18 hours to a final moisture content of $6 \%$ on an oven-dry basis, while the other served as a control and was only kiln-dried. Steaming was done at $100^{\circ} \mathrm{C}$; the kiln temperature was $118^{\circ} \mathrm{C}$, and the wet-bulb temperature during drying was approximately $82^{\circ} \mathrm{C}$, but was not controlled. Total hydrocarbon data were collected with an FIA throughout the entire drying cycle. The lumber was dried in the pilot kiln after steaming, and the VOCs emitted during drying were measured by Method 25A.

For strength testing, twenty five $3.8 \mathrm{~cm} \times 14 \mathrm{~cm}$ x $244 \mathrm{~cm}$ southern pine boards were machined into $10 \mathrm{~cm}$ wide pieces, and further cut in half into side-matched pairs. One of the paired pieces was wrapped in plastic (to impose low-headspace conditions) and irradiated with RF. After the board reached $100^{\circ} \mathrm{C}$, which took about 40 minutes of irradiation, it was maintained at about $100^{\circ} \mathrm{C}$ for an additional 30 minutes by cycling the power. The other board served as a control. Both sets were subsequently dried using a conventional temperature-time based schedule to a final average $\mathrm{MC}$ of $15 \%$. After drying, the lumber was equilibrated to about $12 \% \mathrm{MC}$. Two boards from each charge warped during drying and were not tested.

\section{Dielectric heating of flakes}

For each trial, three paired sets of flakes (2-3 g) were prepared by breaking individual pieces in half to form two equivalent furnish samples. One set from each pair was microwaved in a Teflon cylinder ( $4.4 \mathrm{~cm}$ diameter $\times 10.2 \mathrm{~cm}$ length) fitted with a screw cap containing a small opening that accommodated a fiber optic thermocouple. Damp sponge inserts were positioned at both ends of the cylinder to prevent moisture loss during treatment. Both microwaved and control flakes were subsequently dried similarly to the particles in the steaming experiment (in the tube furnace at $130^{\circ} \mathrm{C}$ ). The microwave units used were a Panasonic NN-6405A oven, and a Cober Electronics, Dimension 3 system. 


\section{Dielectric heating of lumber}

Radiofrequency work was done with the Strayfield dryer located at Georgia Power's Technology Application Center in Atlanta, GA. The irradiation frequency was $27.12 \mathrm{MHz}$. at $0.6 \mathrm{~A}$, but water loss was high at the longer treatment times, possibly due to leakage For the first experiments, low-headspace conditions were achieved by simply wrapping the charge $(5 \mathrm{~cm} \times 10$ $\mathrm{cm} \times 60 \mathrm{~cm}$ pieces of southern pine) in plastic. These experiments demonstrated that approximately $50-60 \%$ of the VOCs could be removed during two- to six-minute RF treatment at $0.6 \mathrm{~A}$, but water loss was high at the longer treatment times, possibly due to leakage through the plastic wrapper. Confirmatory experiments using longer boards were run with the vessel shown in Figure 2 . The unit is a $1.2 \mathrm{~m}$. long by $11.4 \mathrm{~cm}$ (outside diameter) polyethylene tube with a polyethylene flange heat-welded at one end and a plate welded at the opposite end. Teflon shutoff valves were installed at both ends. A trap containing water was connected to one end of the extraction vessel. Omega HHTFO-1 fiber-optic thermocouples were used to determine the surface and internal temperatures of the charge during irradiation. The internal temperature was obtained by inserting the thermocouple into a pre-drilled hole in the wood, which reached the board centerline.

To define the efficiency of VOC collection from the headspace, the trap in Figure 2 was filled with $250 \mathrm{~mL}$ of methanol in an ice bath. Lumber $(2.7 \mathrm{~kg}$., $4.4 \mathrm{~cm} \times 8.3 \mathrm{~cm} \times 112 \mathrm{~cm})$ was irradiated in the Strayfield dryer at 1.1 amps with power cycling to keep the external wood temperature at about $100^{\circ} \mathrm{C}$. The wood was removed after 30 minutes of irradiation, the condensed steam inside the vessel was collected, and the vessel was then rinsed with $250 \mathrm{~mL}$ of methanol. Pine boards $(5 \mathrm{~cm} \times 10 \mathrm{~cm} \times 120 \mathrm{~cm})$ were treated using RF energy under the following conditions: (i) 30 minutes of continuous RF treatment at $0.8 \mathrm{amps}$; (ii) 30 minutes of intermittent RF treatment at $1.1 \mathrm{amps}$, with the power being manually cycled on and off to maintain the surface temperature at just below $100^{\circ} \mathrm{C}$; (iii) repetition of the above treatment for 15 minutes; and (iv) $\mathrm{RF}$ treatment until pressure built up in the vessel indicating the release of steam. For condition (i) the interior temperature increased linearly to about $100^{\circ} \mathrm{C}$ over 15 minutes and then held steady. The surface temperature climbed linearly to $100^{\circ} \mathrm{C}$ over 30 minutes. The four conditions are labeled $\mathrm{C}, \mathrm{F}, \mathrm{H}$, and $\mathrm{A}$ in Table 4.

\section{Isotopic measurements}

Green pine blocks $(5 \mathrm{~cm} \times 2.5 \mathrm{~cm} \times 2.5 \mathrm{~cm})$ were dried to different moisture levels at $120^{\circ} \mathrm{C}$, immersed in $\mathrm{D}_{2} \mathrm{O}$ ( $>99 \%$ isotopic content) at room temperature for various periods, and were then cut in halves. One half was wrapped in plastic and microwaved at $110 \mathrm{~W}$ for 30 minutes until the internal temperature (as measured by a fiber-optic thermometer) reached $100^{\circ} \mathrm{C}$. The field was then shut off for 15 minutes, and the cycle was repeated until the wood experienced 30 minutes of actual microwaving. The wrap retained the water in the wood. The other half of the $\mathrm{D}_{2} \mathrm{O}$-soaked wood served as a control. Fibers taken from just inside the wet surface from five regions along the length of the piece were then analyzed by mass spectrometry with a direct insertion probe. The ion chromatograms of the three isotopic forms of water, namely $\mathrm{H}_{2} \mathrm{O}$, $\mathrm{HOD}$, and $\mathrm{D}_{2} \mathrm{O}$, were "parallel" to one another. In other words, the $\mathrm{H}_{2} \mathrm{O}: \mathrm{HOD}: \mathrm{D}_{2} \mathrm{O}$ proportion remained constant throughout, indicating that all three forms of water were bound equally strongly to the wood. 


\section{Results and Discussions}

Extraction of VOCs from particle through low-headspace steaming

VOCs from particles were measured during 30 minutes of drying, and the results are shown in Table 1. The difference in VOCs released between the control and the steamed flakes reflects the VOCs removed during steaming. Compared to the control samples, over $45 \%$ of the VOCs were removed during steaming at high temperature $\left(>150^{\circ} \mathrm{C}\right)$. Increasing the steaming time from 30 to 60 minutes did not increase the VOCs extracted to any substantial extent, but the furnish turned noticeably darker. Smaller amounts of VOCs were extracted during lowtemperature steaming. The final column in Table 1 is the pinene recovered in the methanol trap as a percentage of total VOC lost from the wood as measured by Method 25A. Although Method 25A measures all the VOCs emitted during drying, pinene is the major VOC constituent (Cronn et al 1983). The VOC recovery from steaming was lower than anticipated, probably because of material left in the vessel.

The above experiments were conducted under pressure since the steam was introduced under atmospheric pressure, and the sealed unit was then heated. To separate the effects of temperature and pressure, particles were steamed at about $167^{\circ} \mathrm{C}$ for 10 minutes under sealed conditions (with the valve closed), and then for 20 minutes with the needle valve cracked slightly open. The steamed wood was then heated in the tube furnace for 30 minutes at $130^{\circ} \mathrm{C}$, and the VOCs measured. Substantial VOC (73\%) loss occurred during steaming. Runs were also made where the needle valve was partially opened immediately after the vessel was charged with steam, i.e., the material was steamed continuously at near-atmospheric pressure. A sixty seven percent VOC removal was realized. These results demonstrate that high temperature, and not high pressure, is the key to VOC extraction, and that steaming particles at elevated temperature is a viable means of extracting VOCs. Extraction of VOCs from lumber through low-headspace steaming

Two VOC emission peaks are usually observed when wood is dried. The first peak is associated with near-surface VOCs. Later, when drying is quite advanced and the wood is no longer evaporatively cooled, the temperature rises and mobilizes the VOCs in the interior to give rise to the second peak (Banerjee et al. 1995). The level of VOC emissions from the control material used in this experiment was typical, with the VOC surges occurring when expected. The profile from the control essentially lagged that of the steamed material by about 2 hours. Total hydrocarbon data collected during the 18-hour kiln cycles are illustrated in Figure 3. Steaming reduced the area of the initial peak much more than it did the second (later) peak, indicating that the VOCs closer to the surface are preferentially removed by this procedure. Emissions from the control lumber were $1.5 \mu \mathrm{g} / \mathrm{g}$ (dry basis), and emissions from the pre-steamed/kiln-dried material were $1.4 \mu \mathrm{g} / \mathrm{g}$ (dry basis), i.e. less than $10 \%$ of the total VOCs were removed from the lumber. Considering the increased kiln residence time required, this reduction is too small for the process to be commercially viable.

\section{Low-headspace microwaving of flakes}

VOCs released during drying wood microwaved under low-headspace conditions are compared to a control in Table 2. Clearly, emissions from the microwaved wood are greatly reduced, indicating that the VOCs were released during microwaving. Hence, brief microwaving under low-headspace conditions extracts much of the VOCs while retaining the water in the wood. As observed with steam, microwaving reduces the intensity of the initial VOC signal, indicating that the VOCs closest to the surface are preferentially removed. 
Trials in which microwaving was attempted under open conditions, i.e. without the lowheadspace restriction, resulted in the loss of water, but the VOCs were mostly retained in the wood. Since the major difference between the low-headspace and the open experiments is the retention of water in wood in the former, water must assist VOC removal under low-headspace conditions. Simply put, the hot water confined in the wood by the low-headspace constraint promotes VOC release from wood. Water strongly absorbs microwave energy, whereas energy absorption by wood is much weaker. We hypothesize that without the headspace limitation, the water or steam moves out of the flake quickly before it is able to extract the VOCs from the wood. Hence, either VOC or water release can be selected by keeping the headspace open or closed, respectively. We do not imply that VOCs can only be removed through interaction with water; simple evaporation must also be a mechanism.

To ensure that the better performance of the microwave treatment was not just due to a higher flake temperature, one of a paired set of flakes was microwaved, and the other was immersed in boiling water. A thermocouple was placed inside the Teflon cylinder for the boiling water experiments, and the temperature was monitored continuously. For the microwave work the temperature was taken just after microwaving. The flakes reached about $90^{\circ} \mathrm{C}$ after either 5 minutes of immersion in boiling water or 2 minutes of microwaving at $600 \mathrm{~W}$. Both sets were then dried and their VOCs measured. The comparison in Table 3 demonstrates that more VOCs are released during microwaving. Hence, the decrease in VOCs during drying shown in Tables 2 and 3 are induced by the microwave irradiation, and not just by the attendant increase in temperature. The temperature and pressure gradients created by microwaving possibly increase the internal mixing of water to promote VOC release.

\section{Low-headspace RF-treatment of lumber}

Table 4 summarizes the results from the drying runs conducted at different time and power combinations. The RF time reflects the actual irradiation time, while the total time, includes the additional period the wood was kept in the cylinder, regardless of whether or not the RF unit was on. The VOC profiles illustrated in Figure 4 clearly illustrate the potential for VOC reduction available through RF-pretreatment.

Entries $\mathrm{F}$ and $\mathrm{H}$ in Table 4 received the same amount of radiation (12 minute exposures) but the former was kept in the unit for 30 minutes instead of 15 minutes, and the wood was consequently exposed to saturated headspace conditions for a longer period. Not surprisingly, increasing power (compare $\mathrm{C}$ and $\mathrm{F}$ ) and exposure period ( $\mathrm{H}$ and $\mathrm{A}$ ) increased the amount of VOCs removed. VOC reduction of $79 \%$ was observed in the best case (F). Importantly, this was achieved with minimal water loss, which opened the possibility of driving out and collecting VOCs through low-headspace RF treatment and then drying the wood conventionally with much lower releases. The power requirement should be quite low since the RF field is not used to evaporate water, but only to maintain the wood at a set temperature.

\section{Mechanism of microwave-induced VOC release from wood}

The VOCs lost from wood maintained under low-headspace conditions under a microwave field originate from the periphery of the furnish. Consider the profiles in Figure 5, which correspond to the first pair of entries in Table 2 (microwaved at $600 \mathrm{~W}$ for 3 minutes). Note that 
the reduction in VOCs for the microwaved wood occurs early in the process. The first VOC peak reflects surficial material, which is released when the wood is initially heated (Banerjee et al. 1995). The second broader band arises when the wood is mostly dry, and originates from the interior of the furnish. The wood dries in approximately 25 minutes in the Figure 5 experiment, i.e., during the rise of the second peak. Since microwaving affects this second signal minimally, if at all, it is clear that only the surface VOCs are released during microwaving. Much of the mass in a piece of wood resides near the surface. For example, consider a cube of length $l$. Its volume is then $l^{3}$. The volume of wood lying within a distance of $0.1 l$ of the surface is $0.49 l^{3}$. Hence, depending upon the sample dimensions, the "surface" can represent a large proportion of the wood.

\section{Collection of VOCs from low-headspace RF treatment of lumber}

The material trapped in methanol was released during irradiation, and the VOCs in this fraction are referred to as trapped emissions in Table 5. The condensate and rinsate are collectively called condensate/rinsate. The milky condensate/rinsate was clarified through addition of a 1:1 methanol: ether solution. Most of the terpenes (about $0.4 \mu \mathrm{g} / \mathrm{g}$, green basis) were found in the trapped emissions. While this is by no means optimized, it is roughly comparable to the difference between the control and RF-treated values in Table 4. Hence, much of the VOCs removed from wood by RF are recoverable.

\section{Effect of RF-irradiation on strength}

Specimen data were first tested for normality using the Shapiro-Wilk test at $\alpha=0.05$, then used to test the null hypothesis that there were no differences between control and RF-treated specimens using paired two-sided t-tests with $\alpha=0.5$. One group of tension specimens had a pvalue less than 0.05 , so the paired two-sample Wilcoxon signed rank test was used in place of the t-test for this group. The null hypothesis was not rejected for the following tests: modulus of elasticity, compression, tension, shear and toughness. The modulus of rupture results proved to be different for the two sets of data; the group of RF-treated specimens had MOR values approximately $90 \%$ of the control group. We conclude that RF treatment does not significantly affect mechanical properties.

\section{Isotopic measurements}

The water released from green wood (MC: 125\%) soaked in $\mathrm{D}_{2} \mathrm{O}$ had the same isotopic composition (Table 6) regardless of whether or not the wood was microwaved. This indicates that the exchangeable protons in green wood are able to interact with the $\mathrm{D}_{2} \mathrm{O}$, and that microwaving does not enhance the process. However, with the use of progressively drier wood, the water released from fibers taken from the microwaved wood was of lower isotopic content, which means that more of the $\mathrm{D}_{2} \mathrm{O}$ was retained in the wood through isotopic exchange. Presumably, microwaving opened up the wood structure and increased access of $\mathrm{D}_{2} \mathrm{O}$ to the exchangeable protons in wood tissue. The exchangeable protons in dried wood are mostly those situated on hydroxyl groups, and the difference in isotopic exchange is the greatest for the dried wood. This suggests that most of the protons in green wood are exchangeable with the isotope under ambient conditions; i.e. the wood structure is open. As the wood dries, internal hydrogen bonding restricts access of the $\mathrm{D}_{2} \mathrm{O}$ to some of the hydroxyl protons. It would seem that the energy transferred to water upon microwaving is sufficient to, at least partially, overcome this barrier. The effect resembles the hysteresis that occurs for moisture sorption to green and dried 
wood. Analogous isotope exchange work with $\mathrm{D}_{2} \mathrm{O}$ has been previously conducted (Bikales and Segal, 1971; Gordeev et al 1991; Jeffries 1964; Kamide et al 1984; Krassig 1977, 1979, 1984; Mann and Marrinan 1956) to determine the accessibility of water to cellulose.

\section{Conclusions}

Energy transferred to water constrained in wood is probably dissipated through thermal motion of the water within the wood matrix. The isotopic work illustrates this quite well; under irradiation, $\mathrm{D}_{2} \mathrm{O}$ is able to access hydrogen-bonded areas in partially dried wood that are otherwise excluded. The contrast between open and low-headspace microwaving demonstrates that hot water, when forced to remain in the wood through the low-headspace restriction, aids in removing the VOCs out of wood. Thus, there must be at least two means of VOC removal from wood during conventional drying. Water must be at least partially responsible for VOC loss from green wood during early drying. VOC removal from dry wood must be driven by vapor pressure considerations (Banerjee et al. 1995, 1998).

The VOC material is concentrated in hydrophobic regions within the wood matrix. We believe that transferring energy to water while constraining it to remain in the wood promotes transport of the VOCs to hydrophilic zones from which they can rapidly move out of wood. Alexiou et al. (1990) have shown that pre-steaming Eucalyptus mobilizes heartwood extractives, probably by allowing water greater access to cell walls. Irradiating wood under low-headspace conditions appears to promote this access. Also, the sapwood is likely to heat up more rapidly than heartwood during microwaving owing to its higher water content, and the resulting temperature and pressure gradients may promote mixing.

The physics of VOC removal is not presently known, and is under study. However, the only apparent difference between VOC extraction through steaming and microwaving is that the latter occurs much more quickly. Since water absorbs microwave energy much more easily than does wood, the wood is principally heated by the water, and the wood-water interaction should, therefore, be more closely coupled during microwaving (or RF-treatment), than during steaming. This, in turn, should transfer more VOC material into the aqueous phase.

The practical implications of the process is that brief microwaving or treatment with radiofrequency energy draws out the VOCs from the wood, which can then be collected when the small amount of steam released is condensed (Banerjee et al. 1999). The vapor pressure of $\alpha-$ pinene at $100^{\circ} \mathrm{C}$ is 0.14 atmospheres (TRC 1989), which means that $1.2 \mathrm{~g}$ of pinene should be removed with every gram of steam. The VOC-depleted wood can then be dried with muchreduced control costs. Although both RF and thermal heating are able to remove VOCs, RF is far

more efficient. Terpenes are driven out from the low-headspace vessel when the small amount of steam is vented, and should be recoverable when the steam is condensed. Heavier organics such as resin acids remain in the vessel. Irradiation did not induce any significant deterioration in strength. It is important to recognize that the wood is not dried with electrical energy, but merely maintained at a set temperature for a short period. Thus the high electric power costs typically associated with microwave or radiofrequency drying are not incurred.

\section{Acknowledgements}


We thank the US Department of Energy for funding most of the study, and Georgia Power Co. for lending us the Cober microwave unit, and for providing us access to their Strayfield RF unit.

\section{References}

Alexiou, P.N., A.P. Wilkins and J. Hartley. 1990. Effect of pre-steaming on drying rate, wood anatomy and shrinkage of regrowth Eucalyptus pilularis Sm., Wood Sci. Technol. 24,103-110.

Anonymous. 1995. Method 25A - Determination of total gaseous organic concentration using a flame ionization analyzer, 40CFR Part 60, 870-872, August 1, 1995.

Banerjee, S., M. Hutten, W. Su and L. Otwell. 1995. Release of water and volatile organics from wood drying, Environ. Sci. Technol. 29, 1135-1136.

Banerjee, S., W. Su, M.P. Wild, L.P. Otwell, M.E. Hittmeier and K.M. Nichols. 1998. Wet line extension reduces VOCs from softwood drying. Environ. Sci. Technol. 3, 1303-1307.

Banerjee, S., J. Boerner, and W. Su. 1999. Method for lowering the VOCs emitted during drying of wood products, US patent pending.

Bikales, M. and L. Segal. 1971. Cellulose and cellulose derivatives, Part IV, Wiley, New York.

Cronn, D.R., S.G. Truitt and M.J. Campbell. 1983. Chemical characterization of plywood veneer drying emissions. Atmos. Environ., 17, 201-211.

Gordeev, G., A. Maslennikov, M. Ioelovitch and Y. Grunin. 1991. Investigation of the interreltionship between cellulose degree of crystallinity and parameters of free induction NMR signal. Chim. Drev. (Wood Chem.), 3, 27-30.

Grzanka, R. April 1996. Facing the EPA cluster rules: the RTO option for emission control. Paper Age pp. 14-15.

Jeffries, R. 1964. The amorphous fraction of cellulose and its relation to moisture sorption. J. Appl. Polym. Sci., 8, 1213-1220.

Kamide, K., K. Okajima, T. Matsul, and K. Kowsaka. 1984. Study on the solubility of cellulose in aqueous alkali solution by deuteration IR and 13-C NMR. Polymer J., 16, 857-866.

Krassig, H. 1984. Structure and reactivity of cellulose fibres. Papier, 38, 571-582.

Krassig, H. 1977. New structural studies on cellulose fibers using methods of molecular characterisation: infra-red spectroscopy. Lenzinger Ber., 43, 141-151.

Krassig, H. 1979. New structural aspects for cellulose. Papier, 33, V9-20.

Mann, J. and H.J. Marrinan, 1956. The reaction between cellulose and heavy water: Part I. A qualitative study by infrared spectroscopy. Trans. Faraday Soc., 52, 481-497.

Matros, Y.S., G.A Bunimovich, S.E. Patterson and S.F. Meyer. 1996. Is it economically feasible to use heterogeneous catalysts for VOC control in regenerative oxidizers? Catalysis Today, 2, 307-313.

Method 25A. 1995 Determination of total gaseous organic concentration using a flame ionization analyzer. 40CFR Part 60, 870-872, August 1, 1995.

National Forest Products Association. 1986. National Design Specifications, Appendix Q. 87

Su, W., H. Yan, S. Banerjee, L.P. Otwell, and M.E. Hittmeier. April 1999. Field-proven strategies for reducing VOCs from hardwood drying. Environ. Sci. Technol., in press.

TRC Vapor Pressure Database, 1989. Texas Thermodynamic Research Center, College Station, TX.

Yeo B. 1993. Regenerative Unsteady State Catalytic Oxidation: An Emerging Technology for VOC Oxidation, AIChE Annual Meeting, St. Louis, Missouri. 


\begin{tabular}{|c|c|c|c|c|}
\hline \multicolumn{5}{|c|}{ high temperature steaming } \\
\hline $\begin{array}{l}\text { steam time } \\
\text { (min) }\end{array}$ & $\begin{array}{c}\text { steam } \\
\text { temp }\left({ }^{\circ} \mathrm{C}\right)\end{array}$ & $\begin{array}{l}\text { VOC }(\mu \mathrm{g} / \mathrm{g}, \\
\text { dry basis) }\end{array}$ & $\mathbf{n}$ & $\begin{array}{l}\text { VOC recovered in } \\
\text { the trap }(\%)^{3}\end{array}$ \\
\hline 0 (control) & & $1300 \pm 200$ & 8 & not determined \\
\hline 15 & 174 & $580 \pm 30$ & 4 & 81 \\
\hline 30 & 179 & $490 \pm 10$ & 4 & 112 \\
\hline 30 & 174 & $510 \pm 40$ & 4 & 89 \\
\hline 30 & 178 & $690 \pm 30$ & 4 & 32 \\
\hline 30 & 152 & $720 \pm 80$ & 3 & not determined \\
\hline 60 & 172 & $490 \pm 80$ & 4 & 76 \\
\hline 60 & 178 & $510 \pm 40$ & 4 & not determined \\
\hline \multicolumn{5}{|c|}{ low temperature steaming } \\
\hline 30 & 119 & $830 \pm 10$ & 4 & 18 \\
\hline 30 & 122 & $810 \pm 50$ & 4 & 12 \\
\hline
\end{tabular}




\begin{tabular}{|c|c|}
\hline $\begin{array}{l}\text { microwave } \\
\text { conditions }\end{array}$ & $\begin{array}{c}\text { VOC }(\mu \mathrm{g} / \mathrm{g}) \\
\text { (green basis) }\end{array}$ \\
\hline control & 536 \\
\hline $600 \mathrm{~W}, 3 \mathrm{~min}$. & 329 \\
\hline control & 857 \\
\hline $1200 \mathrm{~W}, 1 \mathrm{~min}$. & 145 \\
\hline control & 767 \\
\hline $1200 \mathrm{~W}, 1 \mathrm{~min}$. & 266 \\
\hline at $130^{\circ} \mathrm{C}$ over 6 & ites \\
\hline
\end{tabular}

\begin{tabular}{|c|c|c|}
\hline $\begin{array}{c}\text { microwave treatment } \\
(600 \mathrm{~W})\end{array}$ & $\begin{array}{c}\text { boiling water } \\
\text { treatment }\end{array}$ & $\begin{array}{c}\text { VOC }(\mu \mathrm{g} / \mathrm{g})(\text { green } \\
\text { basis })\end{array}$ \\
\hline \multirow[t]{2}{*}{2 min. } & & 239 \\
\hline & $5 \mathrm{~min}$. & 352 \\
\hline \multirow[t]{2}{*}{$2 \mathrm{~min}}$. & & 424 \\
\hline & $5 \mathrm{~min}$. & 799 \\
\hline \multirow[t]{2}{*}{$2 \mathrm{~min}}$. & & 215 \\
\hline & $5 \mathrm{~min}$. & 514 \\
\hline
\end{tabular}

\begin{tabular}{|c|c|c|c|c|}
\hline Table 4. VOCs from RF-treated lumber \\
\hline ID & $\begin{array}{c}\text { RF time/total } \\
\text { time (min) }\end{array}$ & RF amps & $\begin{array}{c}\text { weight loss } \\
\mathbf{( \% )}\end{array}$ & $\begin{array}{c}\text { VOC } \\
(\boldsymbol{\mu g} / \mathbf{g})\end{array}$ \\
\hline control & 0 & na & na & 1,680 \\
\hline C & $30 / 30$ & 0.8 & 2.8 & 760 \\
\hline F & $12 / 30$ & 1.1 & 4.0 & 350 \\
\hline H & $12 / 15$ & 1.1 & 3.8 & 820 \\
\hline A & $9 / 9$ & 1.1 & 2.2 & 1,000 \\
\hline \multicolumn{5}{|l|}{} \\
\hline green basis
\end{tabular}




\begin{tabular}{|l|c|c|c|c|}
\hline Table 5. Analysis of trapped emissions and condensate/rinsate \\
\hline & $\begin{array}{c}\alpha-p i n e n e \\
\left(\mu \mathbf{g} / \mathbf{g}^{\mathbf{1}}\right)\end{array}$ & $\begin{array}{c}\beta \text {-pinene } \\
\left(\mu \mathbf{g} / \mathbf{g}^{\mathbf{1}}\right)\end{array}$ & $\begin{array}{c}\text { total VOCs } \\
\left(\mu \mathbf{g} / \mathbf{g}^{\mathbf{1}}\right)\end{array}$ & $\begin{array}{c}\text { total resin } \\
\mathbf{a c i d s}\left(\boldsymbol{\mu g} / \mathbf{g}^{\mathbf{1}}\right)\end{array}$ \\
\hline trapped emissions & 250 & 187 & 518 & 0 \\
\hline condensate/rinsate & 0.45 & 0.46 & 6.4 & $520^{2}$ \\
\hline \multicolumn{5}{|c|}{} \\
\hline $\begin{array}{l}{ }^{1} \text { green basis, analysis by gc; }{ }^{2} \text { resin acid distribution: pimaric }(5 \%) ; \text { unknown } \\
(17 \%) ; \text { isopimaric }(28 \%) ; \text { dehydroabietic }(9 \%) ; \text { abietic }(27 \%) ; \text { neoabietic }(14 \%)\end{array}$ \\
\hline
\end{tabular}

\begin{tabular}{|c|c|c|c|}
\hline \multicolumn{4}{|c|}{ Table 6. Isotopic content of water released from wood } \\
\hline MC (\%) & $\begin{array}{c}\text { soaking pe- } \\
\text { riod (days) }\end{array}$ & $\begin{array}{c}\text { percent deuterium }(\boldsymbol{\sigma})^{\mathbf{2}} \\
\text { control }\end{array}$ \\
\hline 125 & 5 & $48(15)$ & $47(8)$ \\
\hline 44 & 10 & $56(16)$ & $47(5)$ \\
\hline 24 & 2 & $60(4)$ & $49(7)$ \\
\hline 0 & 5 & $61(7)$ & $45(3)$ \\
\hline \multicolumn{4}{|c|}{} \\
\hline $\begin{array}{l}{ }^{1} \text { dry basis MC of the wood being microwaved; }{ }^{2} \text { averaged from } \\
5 \text { samples; the bracketed values are standard deviations }\end{array}$ \\
\hline
\end{tabular}

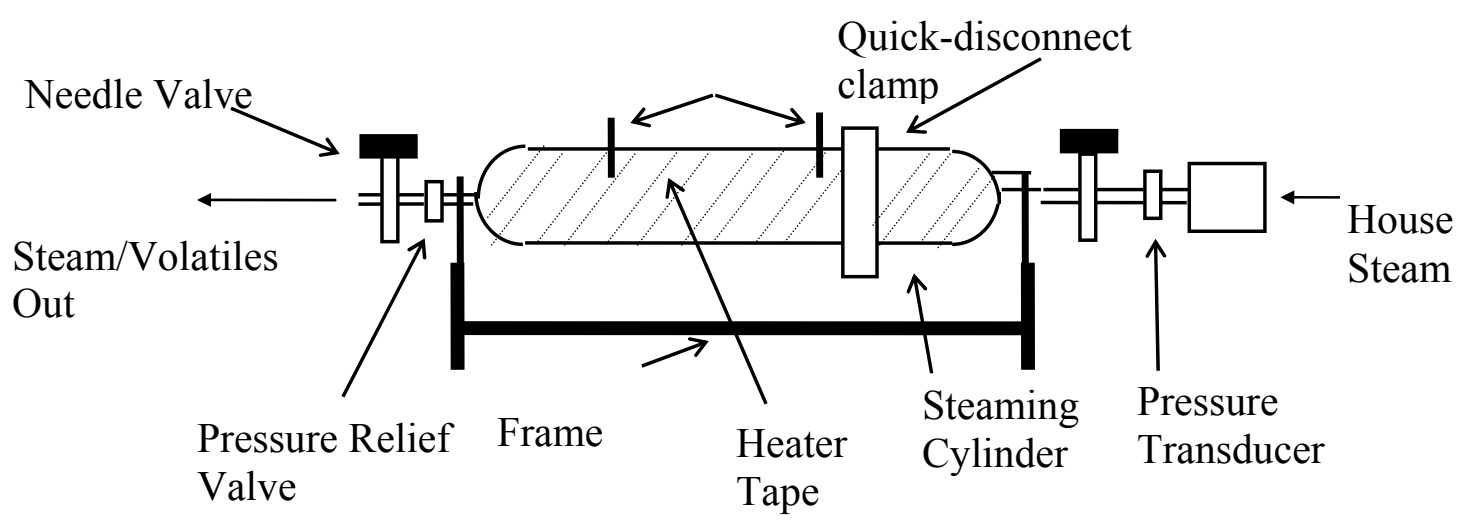

Fig. 1. Schematic of a low-headspace steaming unit. 


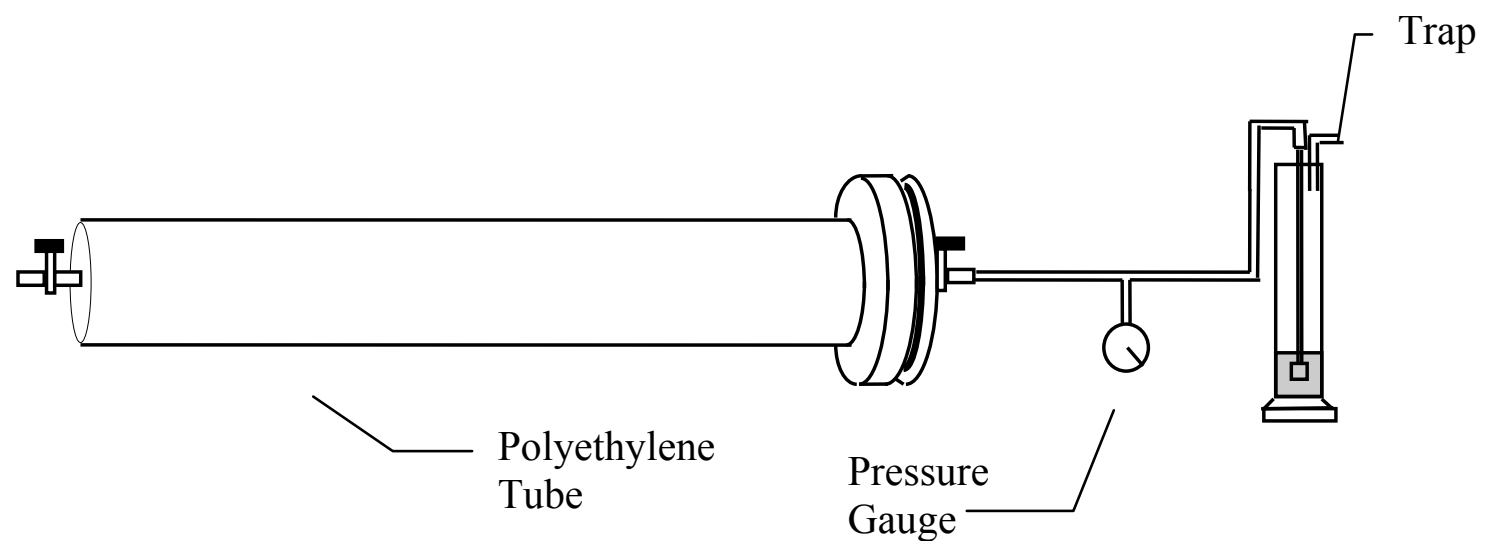

Fig. 2. Schematic of a low-headspace unit for use in a RF dryer.

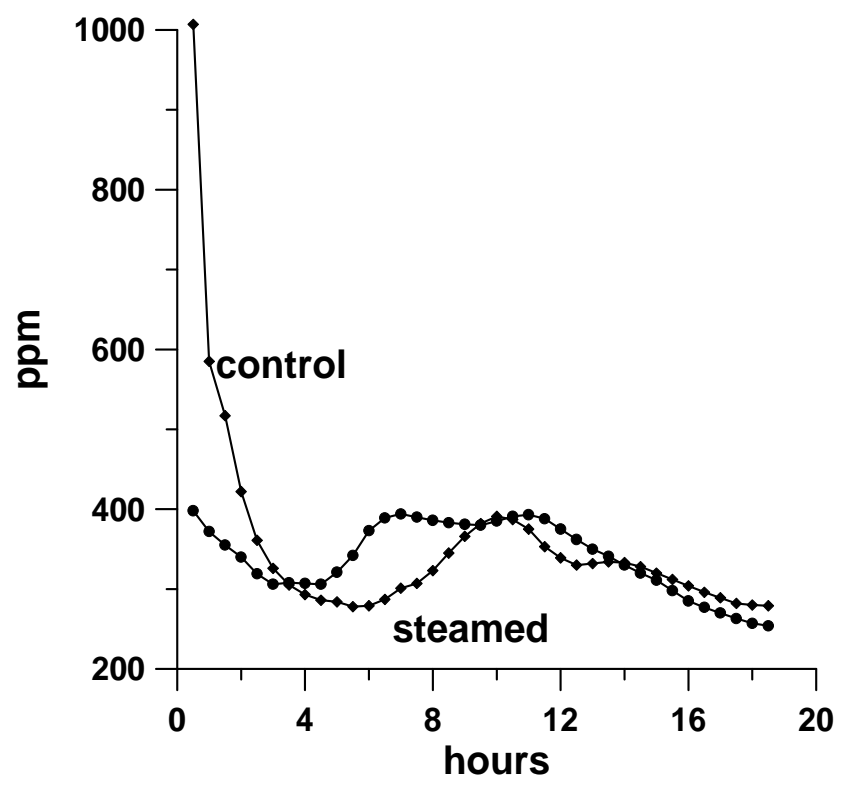

Fig. 3. VOCs from control and steamed lumber. 


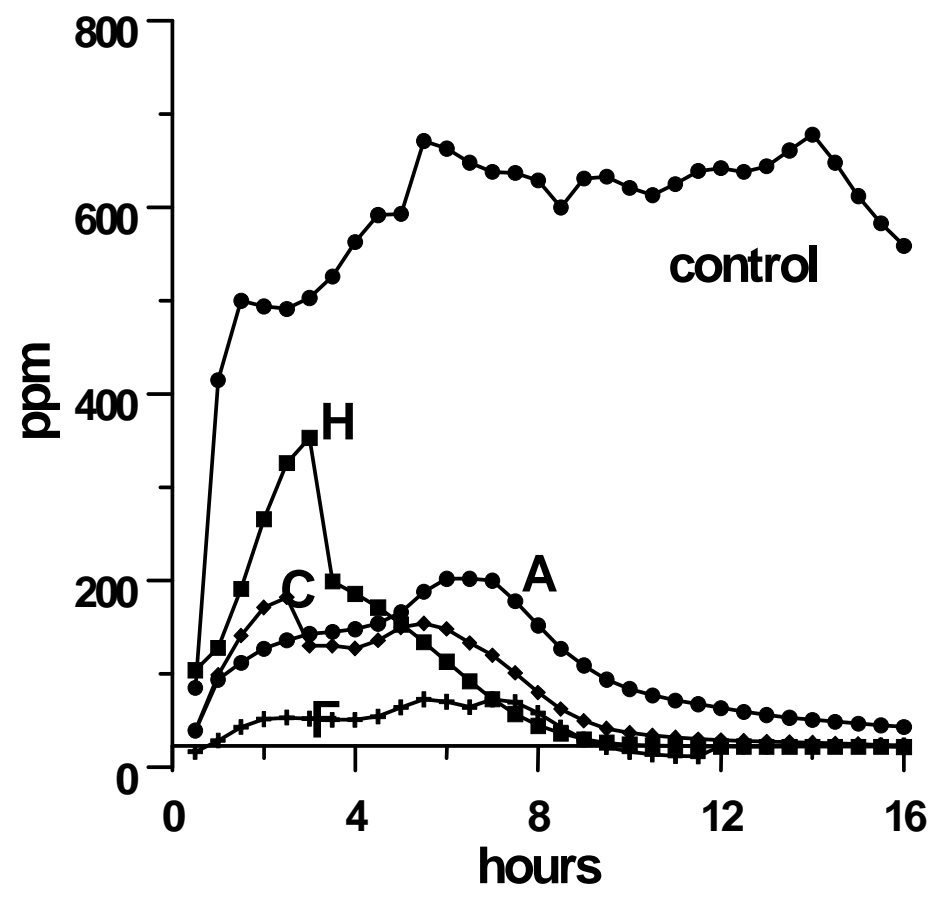

Fig. 4. VOCs from low-headspace RF-treated lumber.

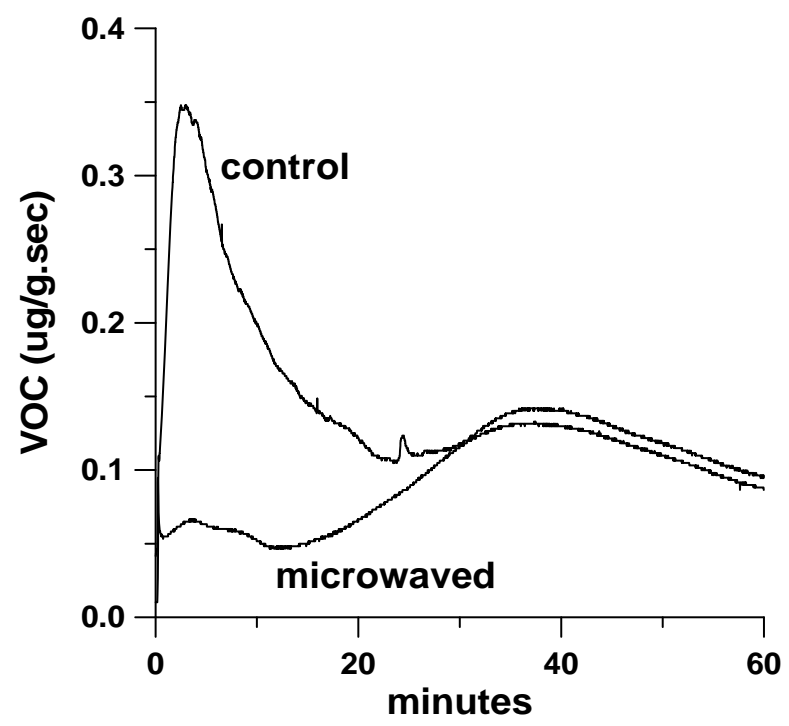

Fig. 5. VOC profiles from control and microwaved OSB flakes. 


\title{
Microwave-Enhanced Transport of Chemicals into
}

\section{Green Wood under Low-Headspace Conditions}

Holzforschung, 54 (2000) 331-333

\author{
Usha Hooda and Sujit Banerjee \\ Institute of Paper Science and Technology, Atlanta, GA, USA
}

Keywords: Dielectric, Diffusion, Dye, Headspace, Microwave, Mixing, Rate, Wood.

\section{Introduction}

The introduction of chemicals into green wood is industrially important in processes such as chemical pulping (Chen 1992; Parthasarathy 1996; Parthasarathy et al. 1996). We previously found that placing green pine flakes or board in a microwave or radiofrequency (RF) field in a low-headspace environment extracts pinenes and other organics from the wood while removing very little water (Su et al. 1999). Since the volume of the headspace is low, the water is unable to evaporate, and is forced to remain in the wood. Without this restriction, the microwave energy would dry out the wood, and the movement of chemicals within the wood would not occur. Since water absorbs microwave energy much more readily than does wood, the wood is principally heated by the water. The enhanced wood-water interaction forced by the low-headspace condition mobilizes the VOCs, and moves them out of the wood. In this paper we report the opposite effect - the introduction of chemicals from the surface into the wood matrix through dielectric heating.

\section{Materials and Methods}

Wafers (30 x $34 \mathrm{~mm}$ area, 2-14 mm thick) were cut against the grain from green pine sapwood, with care being taken to exclude knots and visible imperfections. The pieces were spotted with $5.0 \mu$ of Versatint purple II (a water-soluble chemical obtained from Milliken Chemicals, Inman, SC), tightly wrapped with plastic to ensure low-headspace conditions, and microwaved at $60 \mathrm{~W}$ in a Cober model LBM unit operating at $2.45 \mathrm{GHz}$. A thermocouple was attached to one surface of the wafer, and the power was cycled to maintain the surface temperature at $80-95^{\circ} \mathrm{C}$ for 1 minute. The lightness of the wood surface before and after spotting with the dye was measured spectrophotometrically (Anon 1994). The lightness, $\mathrm{L}^{*}$, is assigned a value of zero for black, and 100 for white, and is a measure of the concentration of the dye on the surface. Bourbois et al. (1991) have described an application where L ${ }^{*}$ parameters were related to the concentration of a constituent.

A $130 \mathrm{~mm}^{2}$ in the region of the spot was analyzed before and after microwaving, as was the area on the reverse face of the wafer directly opposite the spot. The initial area of the spot was approximately $250 \mathrm{~mm}^{2}$, but spreading occurred in some experiments. For control experiments where the wood was oven-heated, the wafer was wrapped in aluminum foil and heated such that the wood surface temperature reached $80-95^{\circ} \mathrm{C}$ for 1 minute. The results reported are 
for the individual wafers. A small weight loss of about 3\% was incurred during either microwaving or heating.

\section{Results and Discussion}

$\mathrm{L}^{*}$ values of the spotted regions of the face and reverse side of microwaved and ovenheated wafers are compared in Figure 1 for wood specimens of varying thicknesses. Note that L* for the face increases with microwaving, while that for the reverse side decreases, demonstrating movement of the dye. In contrast, $\mathrm{L}^{*}$ for the oven-heated pieces is relatively unchanged after treatment, indicating that microwaving mobilizes the dye to a much greater extent than does heat alone. The size of the dye spot varies somewhat due to sample non-uniformity, and causes occasional anomalies. For instance, the back face $\mathrm{L}^{*}$ for the $5 \mathrm{~mm}$ oven-dried sample decreases significantly upon heating, in exception to all the other data. The surface area of the microwavetreated spotted area also grows much more in comparison to the heat-treated sample, as shown in Figure 2. The area of the microwaved sample grows the most for the thinnest piece, since zdirectional movement is more limited.

The rate of ingress of the dye into several $10 \mathrm{~mm}$ wafers was monitored during both microwaving and oven-heating, and the results are illustrated in Figures 3 and 4, respectively. The "initial" value at zero seconds refers to the value obtained when the wafer was first spotted. The "final" value at zero seconds related to the wafer after it reached $80^{\circ} \mathrm{C}$. The face lightens and the back surface darkens during microwaving. The corresponding changes are much smaller during oven-heating. Hence, all the evidence points to enhanced mixing of chemicals from the surface into the matrix of the wood.

Gibson et al. (1988) described a related application where the diffusion of ethylene oxide in polyvinyl chloride was enhanced by microwave. They compared diffusion rates in an oven to those in a cycled microwave field, and found that the activation energy for diffusion was lowered considerably during irradiation. A similar phenomenon likely occurs in our case. Microwaving enhances the diffusion of water, probably by disrupting the association between water and wood surfaces. The low-headspace restriction is a necessity, since, without it, the water would simply evaporate, and the wood would dry out (Chen et al. 1990; Zhang et al. 1997). Under lowheadspace conditions, the water is forced to remain in the wood, and its diffusion rate (or mixing) within the wood increases. As a result, the movement of materials dissolved in water is also enhanced. This is, of course, an oversimplification; other interactions are also affected. For example, the dye has its own association with wood, and the wood-water, wood-dye and dye-water relationships must all be altered.

These results complement those of a study reported earlier (Su et al. 1999) where turpentine was preferentially released from green softwood through dielectric heating under lowheadspace conditions. It was hypothesized that since the water was unable to leave the wood because of the low-headspace restriction, it dissolved the turpentine from hydrophobic regions within the wood. Once dissolved, these hydrophobic materials moved rapidly outside. The practical implication of this separation of turpentine from green wood is that the turpentine, which normally represents an air pollutant during drying, is now extracted as a product. The turpentine-depleted wood can then be dried with much reduced emissions. Our work here extends this 
theme; instead of moving organics from the inside out, we describe the opposite process. The implications of this to chemical pulping are being explored.

\section{Acknowledgements}

This study was funded by the US Department of Energy through contract DE-FCO796IDI343. We thank Georgia Power for loaning us the Cober microwave unit.

\section{References}

Anonymous, 1994. T 524 om-94. Color of paper and paperboard ( $45^{\circ} / 0^{\circ}$ geometry), TAPPI Press, Atlanta, GA.

Bourbois, P.J., G. Janin and R. Guyonnet. 1991. La Mesure de couleur: une methode d'etude et d'optimisation des transformation chimiques du bois thermolyse. Holzforschung. 45, 377-382.

Chen, G.C. 1992. Application of a surfactant as a Kraft pulping additive. Proceedings, TAPPI Pulping Conference. 513-517.

Chen, P., P. Schmidt and M. Sanio. 1990. An exploratory study of microwave heating in drying of hardwood veneer. International Microwave Power Institute. 25, 54-73.

Gibson, C., I. Matthews and A. Samuel. 1988. Microwave enhanced diffusion in polymeric materials. International Microwave Power Institute 23, 17-28.

Parthasarathy, V.R. 1996. Soda-AQ pulping and chlorine free bleaching of loblolly pine - total system approach to sulfur free pulping and chlorine free bleaching of softwood. Proceedings, TAPPI Environmental Conference. 559-573.

Parthasarathy, V.R, R.C. Grygotis, K.W. Wahoske and D.M. Bryer. 1996. A sulfur-free chlorinefree alternative to kraft pulping. Tappi J. 79(6), 189-198.

Su, W., J.R. Boerner, U. Hooda, H. Yan, S. Banerjee, R. Shmulsky, L.L. Ingram and T.E. Conners. 1999. VOC extraction from softwood through low-headspace heating, Holzforschung, in press.

Zhang, L., S. A. Avramidis and S.G. Hatzikiriakos. 1997. Moisture flow characteristics during radiofrequency vacuum drying of thick lumber. Wood Sci. Technol. 31, 265-277.

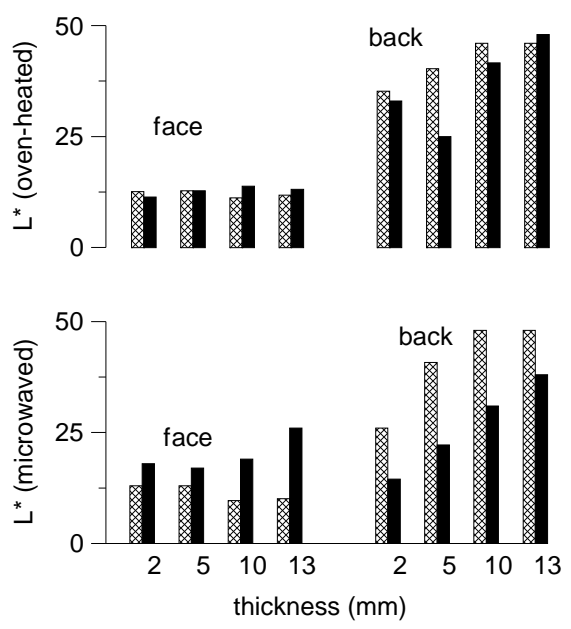

Fig 1. Lightness $\left(\mathrm{L}^{*}\right)$ values of microwaved and oven-heated wafers. The hatched and dark bars represent pre- and post-treatment, respectively. 


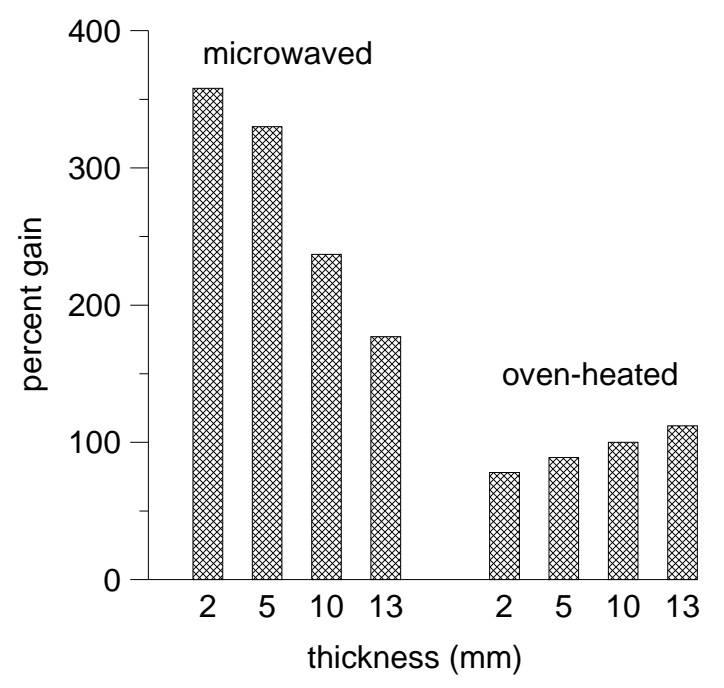

Fig 2. Gain in surface area of the spot (face side) after low-headspace microwaving and oven-heating.
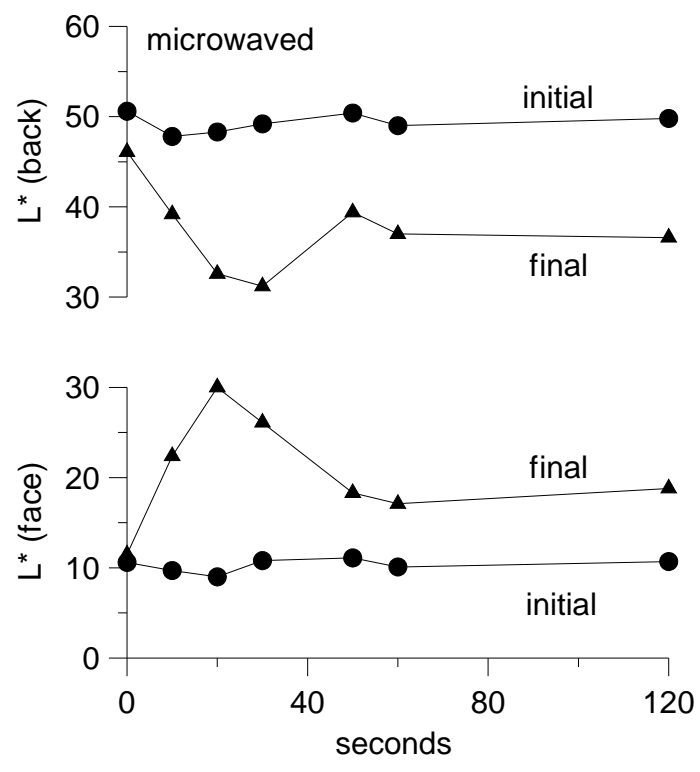

Fig 3. Rate of ingress of dye during microwaving. 

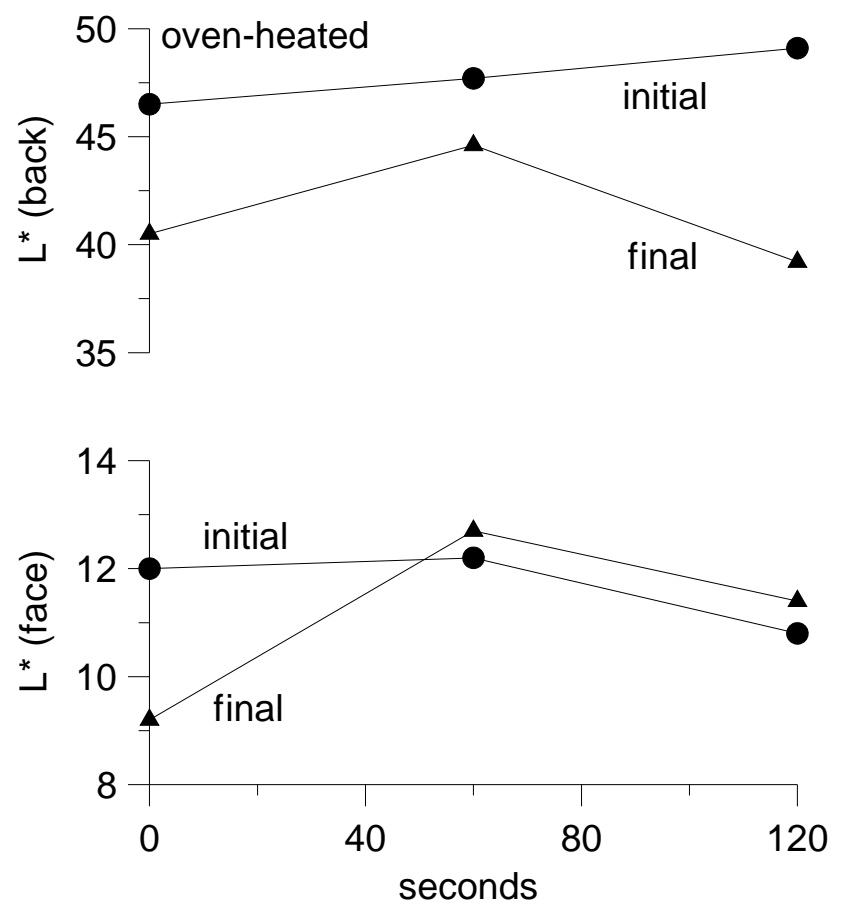

Fig 4. Rate of ingress of dye during oven-heating. 


\title{
HAPs Release From Wood Drying
}

\author{
Environ. Sci. Technol., 34, 2280 (2000) \\ Lawrence P. Otwell, Michael E. Hittmeier \\ Georgia-Pacific Corporation \\ PO Box 105605 \\ Atlanta, GA 30348 \\ Usha Hooda, Hui Yan, Wei Su, Sujit Banerjee \\ Institute of Paper Science and Technology \\ 500 Tenth Street NW \\ Atlanta, GA 30318
}

\begin{abstract}
Hazardous Air Pollutant (HAP) profiles from drying softwood and hardwood flakes (for the manufacture of oriented strand board) are very similar, indicating that they originate through a common mechanism, the breakdown of wood tissue. Hence, the strategies employed to reduce VOC (volatile organic compound) emissions from hardwood can also be extended to decreasing HAPs from softwood. Drying aspen flakes in the field and in the laboratory gives rise to different VOC species, and direct extension of laboratory data to the field may prove difficult. Formaldehyde emissions from drying fresh aspen flakes are lower than those from stored material; the opposite effect occurs for methanol and the other aldehydes. HAPs evolved from drying pine flakes surge sharply at $5-10 \%$ moisture content during drying at $130-160^{\circ} \mathrm{C}$. Emissions of methanol, formaldehyde, pentanal, and hexanal all begin simultaneously, with the release of methanol and formaldehyde being the most sensitive to dryer temperature. Hence, the nature of the VOC mix will be at least partly governed by the dryer temperature. Pine and aspen give rise to similar HAPs profiles during either drying or pressing flakes that are already dried.
\end{abstract}

\section{Introduction}

VOCs released from hardwood and softwood differ both in the nature and in the quantities of material evolved. Hardwood VOCs are principally degradation products that arise from the thermal breakdown of wood. They include methanol, formaldehyde, and other compounds designated by the U.S. EPA as Hazardous Air Pollutants, or HAPs (1). Softwood releases a much larger quantity of VOCs, most of which are terpenes (2). However, since wood tissue may also be subject to thermal breakdown during softwood drying, the same suite of VOCs evolved from hardwood may also be evolved from softwood. In other words, in addition to its predominantly terpene load, softwood VOCs may also include HAPs.

We have shown that drying hardwood to final moistures of 5\% or more (as opposed to the much lower values that is common industry practice) can lead to a dramatic decrease in 
VOCs (3). Wood is evaporatively cooled by the departing moisture as it dries. The cooling effect is lost late in the process when the water is mostly gone, the wood tissue temperature rises, wood decomposition begins, and VOCs are evolved. The VOCs rise very sharply indicating that the decomposition is associated with a high activation energy (3); increasing the final moisture content (MC) from $2 \%$ to $5 \%$ can reduce VOCs by over $60 \%$. These findings have been independently confirmed for formaldehyde, whose evolution increases rapidly with drying temperature (4).

The VOC-dryer temperature curve is more gradual for softwood since pinene, the principal VOC constituent, is released more through vapor pressure and Henry's Law considerations, and not from wood breakdown (2). Hence, while the dependence of the total VOCs from softwood on dryer temperature may be quite moderate, that of the smaller HAP subgroup should be just as sensitive as that from hardwood. Given that HAPs are under regulation (5), it is important to understand the factors that govern the release of these compounds.

\section{Experimental}

Pine flakes for the production of oriented strand board were obtained from the GeorgiaPacific Dudley, NC, mill; aspen flakes were provided by the Potlatch Grand Rapids, MN, facility and the Georgia-Pacific, Woodland, ME, mill. The flakes were dried at $105^{\circ} \mathrm{C}$ for work that required dry furnish. The tube furnace used for drying flakes in the laboratory has been described earlier $(2,3)$. Briefly, air $(0.25 \mathrm{~L} / \mathrm{min})$ is directed over $4-7 \mathrm{~g}$. of furnish placed in an aluminum foil boat in a heated ceramic tube, and the VOCs are stripped from the air stream in either chilled water (for the determination of methanol and formaldehyde) or in a methanol trap (for collecting the other organics).

Formaldehyde recoveries were first established by heating a known amount of formaldehyde $(12.5 \mu \mathrm{g} / \mathrm{mL})$ in the tube furnace at $160^{\circ} \mathrm{C}$ for $0.5 \mathrm{hr}$, collecting the emissions in $20 \mathrm{~mL}$ of either chilled water or $1 \%$ sodium bisulfite solution, and analyzing the trapped material by the chromotropic acid method (6). Water was used in situations where the trapped material was also analyzed by gc for other components; an interference was observed in the presence of bisulfite. Formaldehyde recoveries were $95 \%$ in water and $103 \%$ in bisulfite. Methanol was determined by gc, and its recovery through the oven/trap assembly was $95 \%$. Since formaldehyde was inseparable from methanol under our gc conditions, the two were quantified together and the methanol determined by subtracting out the independently-measured formaldehyde, after normalizing for differences in gc response factors. Pentanal and hexanal were collected in chilled methanol; their recoveries were 90-94\%. All emissions data are reported on a dry basis.

Flake temperature was measured during drying in a $160^{\circ} \mathrm{C}$ oven by attaching a thermocouple to the surface and measuring the time-temperature curve. The section of the thermocouple not in contact with the wood was insulated. Since flake weight loss and temperature could not be simultaneously measured, equivalent batches of flakes were dried under similar conditions for varying periods and a time-MC curve was determined. The temperature-MC curve was then obtained by combining the two sets of data.

VOCs were collected in the field (Woodland, ME, during August 26-28, 1998), by insert-

ing a heated sample probe into the center of the dryer stack. A heated sample pump and line was 
used to convey the gases to chilled impingers, each containing $20 \mathrm{~mL}$ of water. Two impingers connected in parallel were used; one contained organics-free water for methanol collection, while $1 \%$ sodium bisulfite was used in the other for trapping formaldehyde. Each collection was run in duplicate for 30 minutes. A second sampling assembly was used to simultaneously record total hydrocarbon emissions through a Method 25A determination (7). The flow through each impinger was controlled at $0.4 \mathrm{~L} / \mathrm{min}$, with the flow meters connected after the impingers to prevent deposition in the flow meter.

VOCs released during pressing operations originate from both the wood and the applied resin. In order to determine volatiles released from wood alone, resin was not added, and flakes were placed in a steel foil bag (0.002 in. thick 309 high-chromium stainless steel) with inlet and outlet tube connections. The bag was then placed between the top $\left(200^{\circ} \mathrm{C}\right)$ and lower platens $\left(90^{\circ} \mathrm{C}\right)$ of an electrohydraulic press $(8)$ and pressed at 1,000 psi for 3 minutes to a thickness of $1 / 8$-inch, which corresponds to approximately $48 \mathrm{lb} / \mathrm{ft}^{3}$. Air passed through the bag at $0.5 \mathrm{~L} / \mathrm{min}$ was bubbled into a trap containing either chilled water or methanol. Airflow was continued for an additional 5 minutes after pressing to purge any residual VOC from the bag. The trapped samples were analyzed as described above.

\section{Results and Discussion}

Laboratory and field emissions from green aspen

Some of the compounds released from aspen flakes during drying at $160^{\circ} \mathrm{C}$ for 2 hours are listed in Table 1. Since the wood dries in about 20 minutes under these conditions, these values include emissions from both green and dry wood. This was done to ensure capture of compounds released from both early and late drying. Field VOC data collected at four 30-minute intervals from the core dryer at the Georgia-Pacific mill in Woodland, ME, are reported in Table 2. Comparison of the Method 25A and compound-specific results is qualitative, at best, for two reasons. First, the Method 25A response for methanol and formaldehyde is quite low. Second, the mill includes about $15 \%$ pine in its furnish (3) which would approximately double the Method 25A values on account of the terpenes present. If the Method 25A values are halved on this account (3), then the correspondence between the Method 25A and the speciated VOC values is quite good.

There were surprisingly large differences in the nature of the VOCs from laboratory and field-derived VOCs. Pentanal and hexanal, which constitute half of the total emissions in laboratory work (Table 1), were not found in the field $(\mathrm{mdl}=4 \mathrm{ppm})$. Aldehydes have frequently been measured in previous laboratory drying or pressing work. For example, Carlson et al. found hexanal to be the major VOC constituent during pressing of aspen strand (9), and Wang and Gardner (10) obtained similar results from pressing Southern pine. Conversely, ethanol, a major component of the field VOCs, was absent in the laboratory sample. Ethanol has frequently been found in unpublished fieldwork (11).

The laboratory results are consistent, at least to the extent that similar compounds have consistently been found across different furnishes and processes, and it is likely that differences between laboratory and field measurements originate from differences in drying conditions.

Large temperature and humidity gradients exist in the field, and it is very difficult to reproduce these in the laboratory. For example, aldehydes are relatively unstable, and it is possible that 
they could have degraded in the air stream. Differences may also be anticipated across samples taken from various commercial facilities, where dryer temperatures and profiles can vary appreciably.

In order to determine the effect of furnish storage time on emissions from aspen, flakes were stored cold, and VOCs periodically measured from drying over $1 \mathrm{hr}$. at $160^{\circ} \mathrm{C}$. The results, listed in Table 3, show that drying stored flakes leads to more formaldehyde, suggesting that formaldehyde is biologically or chemically generated during storage. The generation of formaldehyde during lignin biodegradation is well known (12). In contrast, emissions of the other VOCs decrease upon storage, with the decrease being most pronounced for pentanal and hexanal. Corresponding Method 25A emissions also show a decrease in VOCs upon storage.

\section{Emissions from green pine}

The surface temperature of pine flakes during $160^{\circ} \mathrm{C}$ drying is provided as a function of $\mathrm{MC}$ in Figure 1. As discussed above, the temperature levels off at about $90^{\circ} \mathrm{C}$ during the evaporative cooling period and then rises during the later falling rate period. Although terpenes are the principal constituents of emissions from pine, the compounds released from aspen should also be found in pine VOCs, if indeed they also derive from the breakdown of wood tissue.

While the rise in VOCs observed from drying aspen is sharp, that from pine is much more gradual (2), since the terpenes, the major component of pine VOCs, are not degradation products. However, the suite of compounds that arise from the breakdown of pine tissue should be strongly temperature-dependent, just as in the case of aspen. If so, then drying softwood to lower wood tissue temperatures would substantially reduce the amount of methanol and aldehydes released, although the decrease in total VOC emissions would be much more modest.

In order to establish that methanol and aldehydes emerge principally during late drying, pine flakes of varying final moisture were dried at different temperatures. The results shown in Figure 2 confirm that the bulk of the release occurs when the wood is almost dry and that overdrying should substantially increase these emissions. The clear link between formaldehyde and the other traces in Figure 2 suggest that they arise from the same process. However, since formaldehyde increases upon storage, there are probably two sources of formaldehyde: biological and thermal.

The VOC surge occurs slightly earlier $(10 \% \mathrm{MC})$ at $160^{\circ} \mathrm{C}$ as compared to about $5 \%$ at $130^{\circ} \mathrm{C}$, since the VOCs start being released at about $130^{\circ} \mathrm{C}$ as the flake warms to the oven set temperature of $160^{\circ} \mathrm{C}$. The effect is exaggerated at $200^{\circ} \mathrm{C}$, where the VOC rise starts even earlier, since the flakes start decomposing at temperatures well below $200^{\circ} \mathrm{C}$; i.e. the higher dryer temperature puts the surface tissue into the falling rate zone, although appreciable moisture still remains in the flakes. The position of the surge for methanol and formaldehyde tracks those for the higher aldehydes, but much more methanol and formaldehyde are evolved at the higher temperature. Clearly, the VOC species produced will depend upon the drying conditions, with higher temperatures favoring methanol/formaldehyde emissions. That all of the VOCs surge from the same $\mathrm{MC}$ value suggests a common source, almost certainly the thermal breakdown of wood tissue. The finding that the VOC mix changes with temperature indicates that the smaller compounds on the one hand, and the larger aldehydes on the other, arise from different pathways along the degradation of wood tissue. 
The Figure 2 result that methanol and the aldehydes are released late suggests that they could be drastically reduced if the temperature was reduced, and if drying was terminated just before the surge, i.e., a slightly wetter furnish was accepted. This practice would require a resin capable of handling the higher moisture, but this is already being done at the Georgia-Pacific Woodland facility (3) and it should be easily extended to softwood. The release of terpenes, the major constituent of softwood will be reduced minimally, but large reductions in HAPs could be taken at relatively low cost. However, HAPs reduction will be difficult at temperatures exceeding $160^{\circ} \mathrm{C}$, since the wood would still be appreciably wet when HAPs evolution begins, i.e. the surface will dry too rapidly.

The Figure 2 profiles differ sharply from those of the terpenes, where two signals are observed (13). The first is sharp and arises early and reflects material on the surface of the wood. The second is broader and starts when evaporative cooling tails off. Wood breakdown is not involved for terpene release, which is akin to a distillation process, in contrast to the Figure 2 components, which arise from tissue degradation.

\section{Emissions from dry pine and aspen}

Emissions collected from dry pine and aspen flakes heated at 130,160 , and $190^{\circ} \mathrm{C}$, respectively, for 30 minutes are illustrated in Figure 3 and demonstrate that the total water-soluble VOCs increase with increasing dryer temperature. The VOC profiles between the two species are remarkably similar, confirming that they arise from the thermal degradation of wood tissue. A similar correspondence between softwood and hardwood has been observed in the field in an extensive multi-facility study (14). Since the furnish dries in about 20 minutes at $160^{\circ} \mathrm{C}$, it is clear that overdrying will enhance methanol release. Means to minimize this, e.g., through green-screening (to remove the faster-drying fines), or drying to slightly higher moisture, should reduce methanol emissions.

\section{Emissions from pressing pine and aspen}

With the exception of pinene, the similarity in dryer emissions between softwood and hardwood extends to releases from pressing as shown in Table 4, indicating that they too arise from the thermal degradation of wood. Formaldehyde emissions from pressing either hardwood (9) or softwood (10) increase linearly with press time and exponentially with temperature, indicating that they arise from thermal degradation. Modifying pressing conditions to minimize the temperature rise or using higher MC furnish should lead to reduced emissions from the wood furnish.

\section{Control implications}

Although the VOC composition changes with both species and drying conditions, methanol and formaldehyde, the two major HAPs emitted from both hardwood and softwood, are always released in both laboratory and fieldwork under conditions where wood tissue thermally degrades. Since these HAPs constitute much of the total VOC package from hardwood, drying to higher MC and pressing higher-moisture flakes should reduce the quantity of HAPs emitted. The Georgia-Pacific Woodland, ME, mill has won regulatory approval to adopt this practice in lieu of end-of-pipe control devices. We have now shown that a similar strategy can also reduce 
HAPs from softwood, although the total VOC load (mainly terpenes) will remain relatively unaffected. The economic, energy, and environmental trade-off is under study.

\section{Acknowledgment}

This study was funded by the Electric Power Research Institute, Southern Company, and Georgia-Pacific Corporation.

\section{References}

1. Cronn, D.R., Truitt, S.G., Campbell, M.J. Atmos. Environ. 1983, 17(2), 201.

2. Banerjee, S., Su, W., Otwell, L. P., Hittmeier, M.E., Nichols, K.M. Environ. Sci. Technol. 1998, 32, 1303.

3. Su, W., Yan, H., Banerjee, S., Otwell, L.P., Hittmeier, M.E. Environ. Sci. Technol. 1999, 33, 1056.

4. Barry, A.O., Corneau, D. Holzforschung, 1999, 53, 441-446.

5. Code of Federal Register, 40 CFR Part 63, 71376 (1998)

6. NIOSH Manual of Analytical Methods, Fourth Edition, 1994.

7. Method 25A - Determination of Total Gaseous Organic Concentration Using a Flame Ionization Analyzer, 40CFR Part 60, pp 870-872, August 1, 1995.

8. Banerjee, S., Mahmood, T., Phelan, P.M., Foulke, R.W. Water Res. 1998, 32, 258.

9. Carlson, F.E., Philips, E.K., Tenhaeff, S.C., Detelefson, W.D. Forest Products J. 1995, 45(3) 71-77.

10. Wang, W., Gardner, D.J. Forest Products J. 1999, 49(3) 65-72.

11. Georgia-Pacific Corporation, unpublished results.

12. Kuwahara, M. in Lignin Biodegradation: Microbiology, Chemistry, and Potential Applications, Vol II Kirk, T.K., Higuchi, T., Chang, H., Eds., CRC Press Boca Raton, FL 1980.

13. Banerjee, S., Hutten, M., Su. W., Otwell, L.P., Newton, L. Environ. Sci. Technol. 1995, 29, 1135.

14. Word, D., presented at the American Forest and Paper Association Symposium on VOCs from Wood Drying, Raleigh, NC, February, 1999. 


\begin{tabular}{|l|c|c|}
\hline \multicolumn{3}{|c|}{ Table 1: VOC emissions from aspen } \\
\hline & avg. $(\boldsymbol{\mu g} / \mathbf{g})^{\mathbf{1}}$ & std dev $(\boldsymbol{\mu g} / \mathbf{g})$ \\
\hline methanol & 100 & 9 \\
\hline pentanal & 70 & 20 \\
\hline hexanal & 30 & 3 \\
\hline formaldehyde & 11.3 & 5 \\
\hline unknowns ${ }^{2}$ & 53 & \\
\hline \multicolumn{2}{|c|}{} \\
\hline${ }^{1} \mathrm{n}=5 ;{ }^{2}$ determined assuming a gc response factor of pentanal \\
\hline
\end{tabular}

\begin{tabular}{|c|c|c|c|c|c|}
\hline \multicolumn{6}{|c|}{ Table 2: VOC concentration (ppm) in the stack gases of the core dryer at Woodland } \\
\hline run & $\begin{array}{c}\text { formal- } \\
\text { dehyde }\end{array}$ & $\begin{array}{c}\text { metha- } \\
\text { nol }\end{array}$ & ethanol & $\begin{array}{c}\text { total trapped } \\
\text { VOCs }\end{array}$ & method 25A VOC \\
\hline 1 & 2.93 & 4.12 & 5.49 & 12.5 & 29.2 \\
\hline 2 & 4.62 & 5.53 & 6.41 & 16.6 & 23.9 \\
\hline 3 & 2.89 & 8.61 & 5.90 & 17.4 & 37.3 \\
\hline 4 & 4.20 & 12.1 & 9.22 & 25.5 & 50.8 \\
\hline avg (avg. dev.) & $3.7(0.8)$ & $8(3)$ & $7(2)$ & $18(5)$ & $35(6)$ \\
\hline
\end{tabular}

\begin{tabular}{|c|c|c|c|c|c|c|}
\hline $\begin{array}{l}\text { days of } \\
\text { storage }\end{array}$ & methanol & acetone & pentanal & hexanal & $\begin{array}{c}\text { formalde- } \\
\text { hyde }\end{array}$ & n \\
\hline \multicolumn{7}{|l|}{$160^{\circ} \mathrm{C}$} \\
\hline 10 & $126(7)$ & $25(5)$ & $42(9)$ & $120(10)$ & $11(2)$ & 4 \\
\hline 30 & $100(10)$ & $20(3)$ & $19(2)$ & $40(10)$ & $43(2)$ & 2 \\
\hline 55 & $100(20)$ & $15(2)$ & $11(2)$ & $26(7)$ & $35(1)$ & 2 \\
\hline \multicolumn{7}{|l|}{$130^{\circ} \mathrm{C}$} \\
\hline 10 & $59(3)$ & $19(3)$ & $2(0)$ & $27(4)$ & $1.0(0.3)$ & 2 \\
\hline 30 & $10(3)$ & $4(0)$ & $5(1)$ & $15(2)$ & $3.3(0.2)$ & 2 \\
\hline
\end{tabular}




\begin{tabular}{|c|c|c|c|c|c|c|c|}
\hline & acetone & $\begin{array}{c}\text { meth- } \\
\text { anol }\end{array}$ & $\begin{array}{l}\text { formal- } \\
\text { dehyde }\end{array}$ & pentanal & hexanal & pinene & total \\
\hline \multicolumn{8}{|c|}{ water trap ${ }^{2}$} \\
\hline pine & $3 \pm 1(5)$ & $7 \pm 6(4)$ & $1.1 \pm 0.5(4)$ & $1.0 \pm 0.3(3)$ & $4 \pm 2(3)$ & & $13 \pm 3(5)$ \\
\hline aspen & $1.2 \pm 0.7(8)$ & $4 \pm 2(8)$ & $0.5 \pm 0.4(7)$ & $1.1 \pm 0.8(8)$ & $6 \pm 5(7)$ & & $15 \pm 8(8)$ \\
\hline \multicolumn{8}{|c|}{ methanol trap ${ }^{3}$} \\
\hline pine & 3.0 & & & 3.0 & 14 & 35 & 55 \\
\hline aspen & 15.1 & & & 4.3 & 24 & & 34 \\
\hline
\end{tabular}

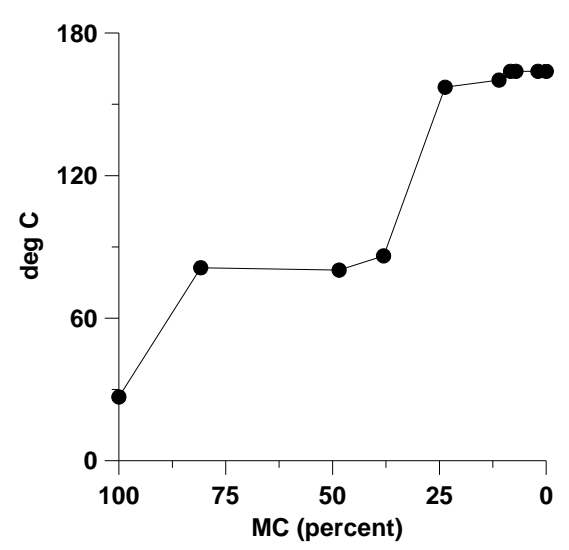

Figure 1: Surface temperature profile of pine flakes during drying at $160^{\circ} \mathrm{C}$. 

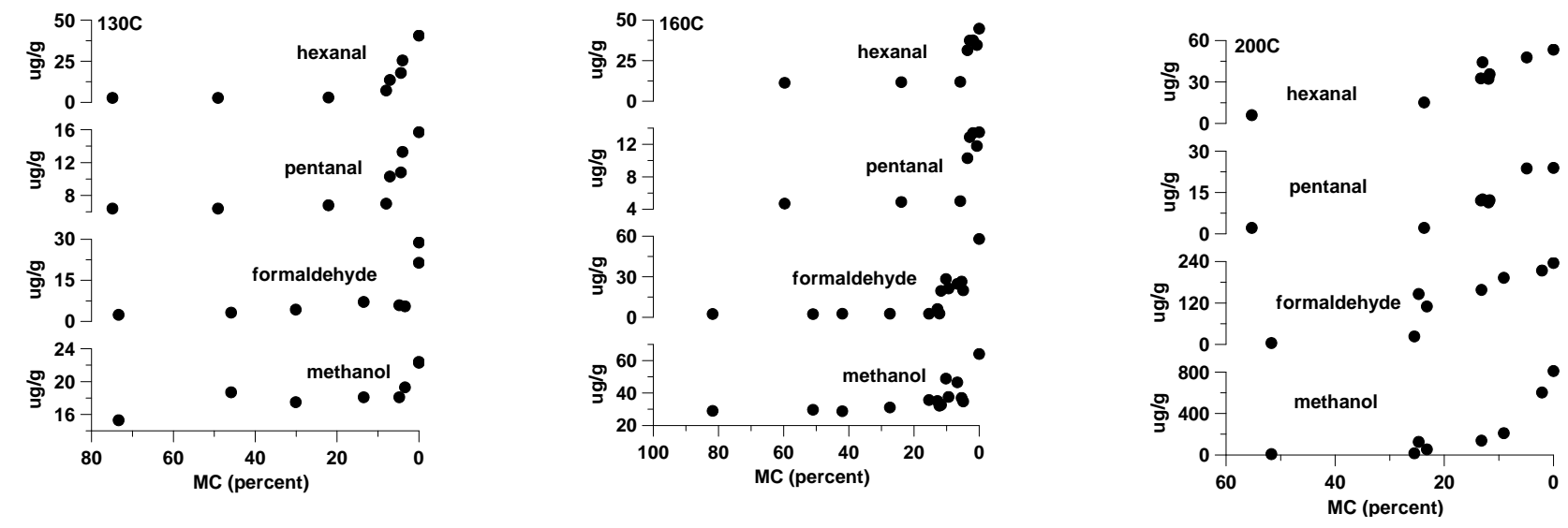

Figure 2: Profiles of selected constituents released from drying pine flakes at 130,160 , and $200^{\circ} \mathrm{C}$.
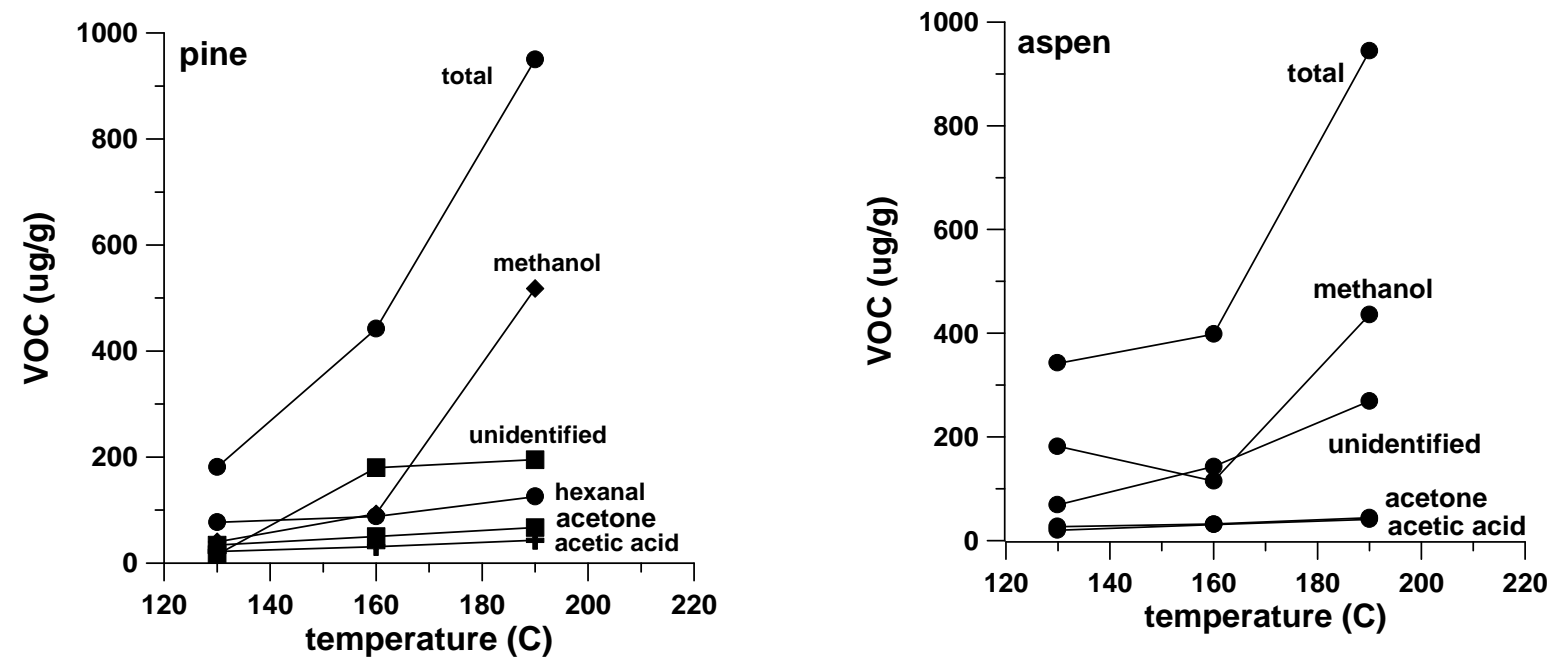

Figure 3: Water-soluble VOCs from dry pine and aspen. 


\title{
Seasonal Variation In Southern Pine Terpenes
}

\author{
T. E. Conners ${ }^{1}$, L.L. Ingram ${ }^{1}$, W. $\mathrm{Su}^{2}$, S. Banerjee ${ }^{2}$, A.T. Dalton ${ }^{1}$, M.C. Templeton ${ }^{1}$ and S.V. \\ Diehl $^{1}$
}

Forest Products J., 51(6), 89 (2001).

${ }^{1}$ Forest Products Laboratory

Mississippi State University

Box 9820

Mississippi State, MS 39762

${ }^{2}$ The Institute of Paper Science and Technology

$50010^{\text {th }}$ Street, NW

Atlanta, GA 30318

\begin{abstract}
Monoterpene and volatile organic compound (VOC) concentrations measured at some mills have large swings of a seemingly seasonal nature and a great amount of variability is evident. The question to be resolved is whether these differences are attributable to wood handling and mill operations or to biological factors associated with tree growth. Information in the available literature primarily describes monoterpene production and release associated with foliage, not wood. This paper describes the results of a study comparing the amounts of VOCs released from drying southern pine wood to the amount of monoterpenes collected from loblolly pine (Pinus taeda) increment cores. Handling and storage have been shown to potentially affect quantitative results, but it appears that more monoterpenes are produced in trees in response to higher temperatures and increased precipitation. At least for reasonably fresh material, measurements of monoterpenes and VOC concentrations at mills probably reflect climatically-affected patterns of tree development.
\end{abstract}

\section{Introduction}

In 1995 a southern pine oriented strand board (OSB) mill reported wide variability in Method 25A VOC emissions measured at flake drying operations in the field. Measurements could not be reproduced even when taken on the same day, and the mill was interested in alternative means of making measurements; consequently, samples of fresh flakes were sent to the Institute of Paper Science and Technology for analysis on a more-or-less monthly basis beginning in February 1995. These samples were wrapped, stored cold, and dried in a $130^{\circ} \mathrm{C}$ tube furnace equipped to monitor total hydrocarbon emissions (1). It was anticipated that there would be some 
variability among the monthly samples due to different proportions of heartwood and sapwood, and that additional variability might result from handling, storage conditions, or convenience sampling at the mill. Nonetheless, the results of laboratory analyses from the first two years' samples were surprising in that the VOC concentrations of individual samples varied by as much as $500 \%$ (from $300: \mathrm{g} / \mathrm{g}$ to $1500: \mathrm{g} / \mathrm{g}$ on a wet basis) (Figure 1).

Consistent with the mill's previous Method 25A measurements and, as expected, due to the samples' origins, significant variability was apparent even within single sampling dates. It appeared probable that more VOCs were collected during the warm months during this sampling period; it also appeared that there might be some interactive effect of ambient temperature and rainfall as wet weather often coincided with warm weather (Figure 2), but (at least in part because of the data variability) it was not clear whether this hypothesis was provable or even if these data were typical. The company requested further work, including measurements of monoterpenes from standing trees, to verify the scatter (and possible trends) in the flake VOC measurements and to determine, if possible, the reasons for the large variation in the measured VOC concentrations. This work is still in progress, but this report provides the information currently available.

\section{Literature Review}

As part of this investigation, the available literature was surveyed to determine if variability in total VOC (monoterpene) content had been studied before. No information was found that described a seasonal variation of monoterpenes in the trunks of standing trees, although one study reported differences in the turpentine content of southern pine chips going into a kraft paper mill over a two-year period (7). The analyzed chips had about $30 \%$ higher turpentine contents in cool months than in the summer months; this appears to contradict the initial analytical results of the OSB flakes, but the report provided no information about handling or sampling of the chips. An investigation of Pinus elliottii by Bin et al. (2) found that the amount of "turpentine" steam-distilled from the resin of tapped trees increased from July to November, and that the major constituents were $\alpha$-pinene and $\beta$-pinene. $\alpha$-Pinene constituted about two-thirds of this mixture, although the proportion of $\beta$-pinene was somewhat greater during the cooler months. A number of reports describe the seasonal changes in monoterpenes of needles, twigs or seedlings for various species, but most of these studies were conducted over periods of one year or less. For example, Lerdau and Dilts (5) found "seasonal declines" in monoterpene concentration but constant emissions from foliage; Lerdau et al. (6) later reported a strong effect of temperature and seasonality on emissions. Fulton et al. (3) reported that the volatile emissions from black spruce trees increased with temperature. He-Ping (4) reported that the relative contents of some volatile terpene compounds collected from the foliage of Pinus tabulaeformis varied between the summer and the winter months; for example, the $\alpha$-pinene and $\beta$-pinene concentrations both increased by about $25 \%$ during the summer months compared to the January samples. Others have also reported that the proportions of the various monoterpenes have seasonal changes (10). There are evidently important physiological and/or genetic aspects of terpene biosynthesis that affect tree-to-tree variations. Raffa (9) has also reported that the monoterpene concentration in grand fir (Abies grandis) increased nearly four-fold after insect attack. None of this information directly answered the immediate questions, but the indications of possible seasonal effects on terpene expression were intriguing. 


\section{Experimental}

An experiment was planned that would enable comparisons between the VOC emissions from fresh southern pine OSB flakes and the monoterpene contents of samples obtained from standing southern pine trees. In a continuation of the initial study, samples of southern pine flakes were requested on a periodic basis from the North Carolina OSB mill for laboratory VOC analysis and plans were made to monitor the monoterpene concentrations in a longitudinal study using twelve straight, well-formed loblolly pine (Pinus taeda) trees (each approximately $39 \mathrm{~cm}$ (15 inches) in diameter and forty years old) in the Mississippi State University's John W. Starr Memorial Forest. These trees were naturally reseeded - not from a plantation - and all of the trees should have a somewhat similar genetic provenance because they were located in the same area. From March to September 1997, one $0.5 \mathrm{~cm}$ (0.2 inch) diameter increment core was taken from each tree per month for analysis of the monoterpene and resin acid content. The first core from each tree was taken at breast height, and successive cores were offset by several inches both horizontally and vertically/upwards (Figure 3). To prevent infection, each hole was plugged with a maple dowel immediately after the core was taken. Each core was divided into three portions prior to analysis (inner third, center third, and outer third) to enable the study of intra-tree monoterpene distributions at a later date. The specimens were stored in methylene chloride and sonicated, and the extract was analyzed with a gas chromatograph to determine the amount of monoterpenes present; appropriate internal standards were used, but no claims are made that the data are quantitatively accurate. The increment core segments were dried in an oven overnight at $103^{\circ} \mathrm{C}$ to obtain their dry weight, and a weighted average concentration for the entire core was calculated based upon the differently sized areas of the tree cross-section represented by each one-third of the increment core.

In September of 1997 the sample trees (although clearly marked) were cut by an overzealous logging equipment demonstrator, and after a one-month hiatus the experiment was continued with another twelve trees in a nearby location. These trees are of similar age and size to the original sample trees. Like the original sample, the second group was naturally reseeded and was not part of a plantation planting. One of the twelve trees was cut and dissected during the month of December 1998, to determine whether the repeated sampling and plugging caused injury-induced resin to bleed internally and bias the data, but no evidence was seen to indicate that this was anything but an occasional problem.

Figure 4 shows the monoterpene concentration data collected and analyzed through December 1998; a locally-weighted (loess) regression line $(\operatorname{span}=0.5)$ has been drawn through the data to illustrate the overall trend in the face of such evident variability. Figure 4 shows that there are slight differences from one year to the next (no doubt partly caused by sampling different trees), but most of the change in concentration appears to be due to season or some associated climatological component. During this sampling period the loblolly pine trees had a greater monoterpene content during the cooler and wetter months of the year, but there was uncertainty whether this was a typical response as Mississippi weather was slightly cooler and significantly wetter than usual during this experiment due to the prevailing El Niño weather pattern. There is a wide range in the monoterpene values determined; considering all the data, there is about a $700 \%$ difference between the highest and the lowest analyzed values caused by both variability within the 12-tree sample and variability due to seasonal influences. 
The Mississippi data (analyzed on an oven-dry wood basis) were compared with the Institute of Paper Science and Technology data for the North Carolina OSB flakes (analyzed on a green weight basis). Figure 5 shows two loess regression lines $(\operatorname{span}=0.5)$ based on averaged data for each sampling date; considering the differences in both analytical techniques and in the geographical origins of the specimens, the Figure 5 curves are remarkably similar. As both North Carolina and Mississippi experience similar weather, these data would appear to indicate that the analyses of the OSB flakes were either unaffected by sampling, handling and storage, or that these influences were insufficient to mask the trends of monoterpene expression in standing trees.

In contrast to the monoterpene variations seen during the joint North Carolina - Mississippi sampling period (March 1997 through December 1998), Figure 1 showed that monoterpenes apparently peaked in North Carolina during the warmer months of 1995 and 1996. To resolve this apparent incongruity, all four years' data from the North Carolina portion of the study were plotted (Figure 6) and compared to seasonal data obtained from the Climvis data set from the National Oceanic and Atmospheric Administration (NOAA) (8) (Figures 7 - 8). Between February 1995 and April 1999 the North Carolina data showed four peaks, and although the first two were similar, the third was lower and seemed to peak at a different time of the year (cool months instead of warm months) (Figure 7). During the period from March 1997 through July 1998 the weather in the southeastern United States was affected by an El Niño weather pattern (slightly cooler average temperatures with $20 \mathrm{~cm}$ or more precipitation than usual compared to "normal" climate conditions for the same time period), so the precipitation data were also compared to the VOC data (Figure 8). Figure 9 shows the VOC trend together with the data for temperature and precipitation.

It appears that the VOCs from the OSB flakes were maximized during periods which had both warm temperatures and high rainfall. VOCs seemed to be at their minimal levels during periods that had both low temperatures and low rainfalls, and VOCs arose to intermediate levels during the cool months of 1997-1998 when rainfall significantly exceeded normal levels. It was also interesting to note that the VOCs apparently rose in early 1996 in response to temperature as the rainfall lagged temperature somewhat that year. A rigorous statistical analysis of these data is just beginning, but it seems likely that VOC levels in southern pine trees are positively affected by both temperature and rainfall and that higher levels of both are required for the maximum monoterpenes to be expressed in standing trees. This analysis is consistent with the observations taken in Mississippi for the more limited timeframe which included the El Niño season.

The potential for handling and storage conditions to affect VOC measurements was addressed in a series of controlled experiments. Southern pine chips from freshly-cut 16- to 18year-old trees were taken directly from a paper mill chipper and samples of these chips were analyzed immediately (using five replications) for both $\alpha$-pinene and $\beta$-pinene (which together comprise most of the monoterpenes in loblolly pine). Additional samples, sterilized using sodium azide and maintained at room temperature, were measured every two or three days for two weeks. Approximately one-third of the $\alpha$-pinene was lost during the first week, after which no further losses were noted. $\beta$-pinene concentrations did not appear to be affected. Based on these results it is concluded that the handling and storage history of the flakes sent from the mill might 
affect the monoterpene concentrations of some samples and that this may have affected the variability inherent in the data presented here.

\section{Significance of Findings}

There was a great deal of variability from sample to sample during this analysis period, and this variability may be affected by handling or sampling considerations. In the trees sampled, however, the typical monoterpene concentrations varied by as much as 300 to $500 \%$ during the course of a year (depending on whether averaged data or data trends are chosen for comparisons). Between the lowest and the highest monoterpene concentrations recorded to date in the longitudinal study of standing trees there is a difference of more than $700 \%$ over time, and there is no reason to believe that the variability might be less for trees sampled from other locations.

The Mississippi and North Carolina data patterns are similar, suggesting that the data presented here are indicative of real trends and that they are not artifacts of analytical techniques. Seasonal influences appear to affect the monoterpene concentration in the stemwood of these loblolly pines, and it seems likely that there is an interactive effect of temperature and rainfall. A more rigorous statistical study of the effects of temperature and precipitation on monoterpenes/VOCs is underway. Overall, it seems likely that a significant part of the variability in OSB flake dryer emissions and kraft mill terpene recoveries can be traced to climatically-affected physiological effects, and the rest can be attributed to handling and other factors.

\section{Acknowledgements}

We thank the US Department of Energy for funding most of the study under contract DE-FCO796IDI3439.

\section{Literature Cited}

1. Banerjee, S., W. Su, L.P. Otwell, M.E. Hittmeir, and K.M. Nichols. 1998. Wet Line Extension Reduces VOCs from Softwood Drying. Environmental Science and Technology 32:1303-1307.

2. Bin, X., Z. Qihua, L. Zhongxun, Z. Guangyao. 1992. Studies on the yield and chemical compositions of oleoresin from Pinus elliottii Engelm. in different tapping seasons. Linchan Huaxue Yu Gongye (Chemistry and Industry of Forest Products) 12(1):75-82. (In Chinese).

3. Fulton, D., T. Gillespie, J. Fuentes, and D. Wang. 1998. Volatile organic compound emissions from young black spruce trees. Agricultural and Forest Meteorology 90(3):247-255.

4. He-Ping, L., and Z. Yi-Zao. 1995. The seasonal variation of relative contents of foliar terpenes in Pinus tabulaeformis Carr. Journal of Plant Resources and Environment 4(3):45-48. (In Chinese).

5. Lerdau, M.T. and S. Dilts. 1992. Seasonal changes in plant function and monoterpene emission. Bulletin of the Ecological Society of America 73(2)(Supplement):247.

6. Lerdau, M., M. Litvak and R. Monson. 1995. Controls over hydrocarbon emissions from boreal forest conifers. Bulletin of the Ecological Society of America 76(2)(Supplement):153. 
7. McSweeney, E. 1989. Sulfate Naval Stores. In: Naval Stores: Production, Chemistry, Utilization. Zinkel, D. and J. Russel, eds., pp. 176-199.

8. National Oceanic and Atmospheric Administration (NOAA). 1999. Climvis Data Set available on the internet at http://www.ncdc.noaa.gov/.

9. Raffa, K. In Phytochemical Induction by Herbivores (Tallamy, D. and M. Raupp, eds.), Wiley and Sons, New York, 1991, pp. 245-276. Original not seen, cited in: Lerdau, M. M. Litvak and R. Monson. 1994. Trends in Ecology and Evolution 9(2):58-61.

10. Zafra, M. and E. Garcia-Peregrin. 1976. Seasonal variations in the composition of Pinus halepensis and Pinus sylvestris twigs and needles essential oil. J. Agric. Sci., Camb. 86:1-6.

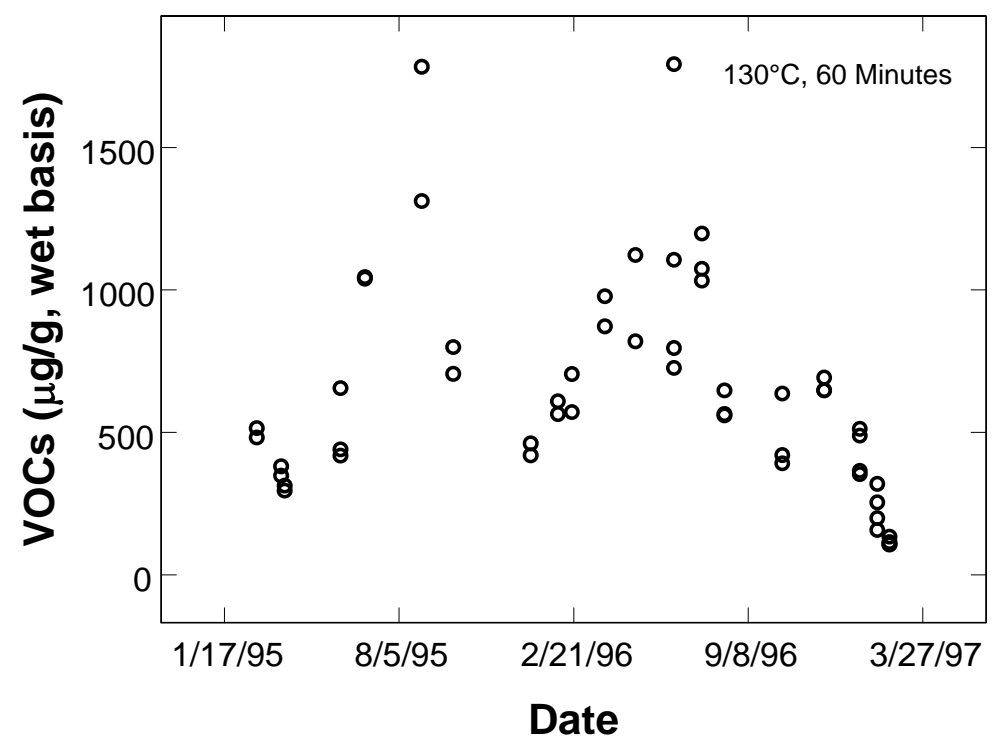

Figure 1: Results of laboratory analyses of southern pine flakes from a North Carolina OSB mill, 2/95-2/97. 


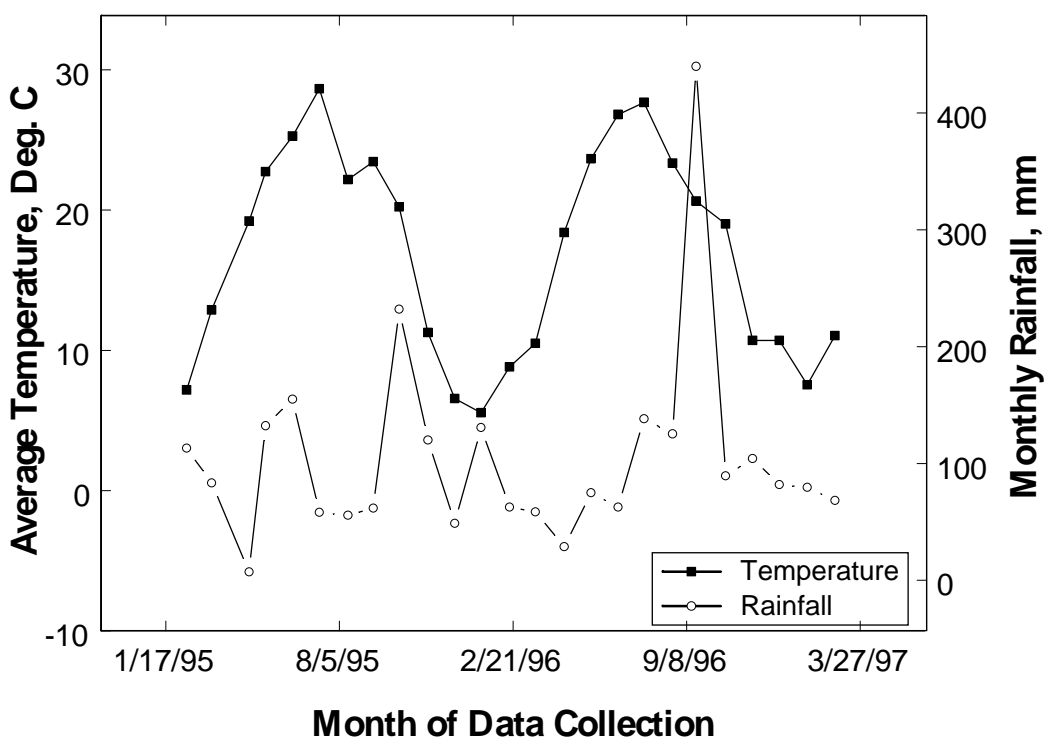

Figure 2: Rainfall and temperature data corresponding to North Carolina OSB mill location.

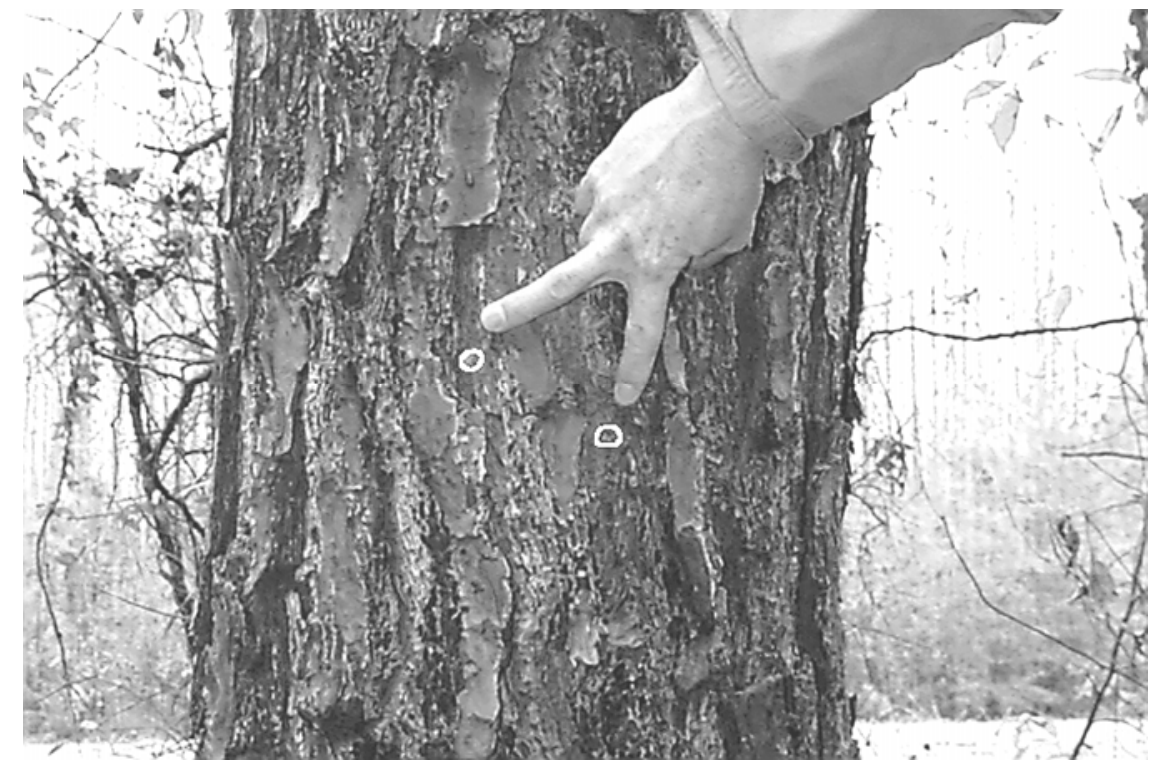

Figure 3: One of the sampled trees with two increment-cored locations marked. 


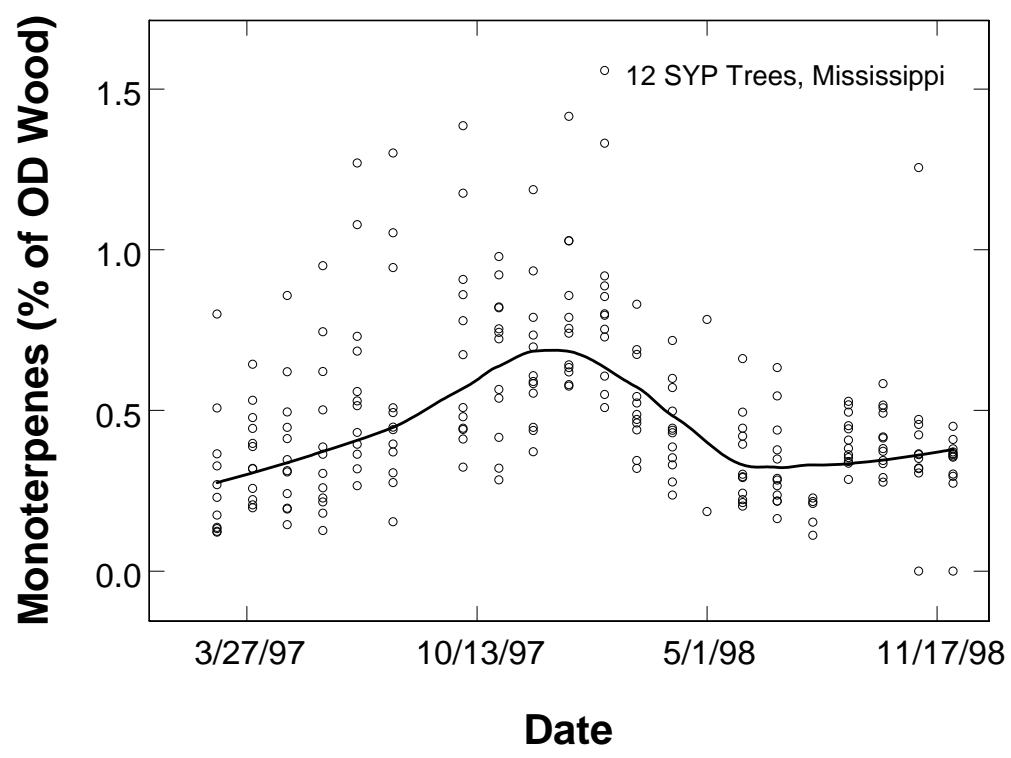

Figure 4: Total monoterpenes as a percent of ovendry (OD) wood from the longitudinal study of 12 loblolly pine trees in Starkville, Mississippi (loess regression line shown overlaid on data, degree $=2$, span $=0.5$ ).

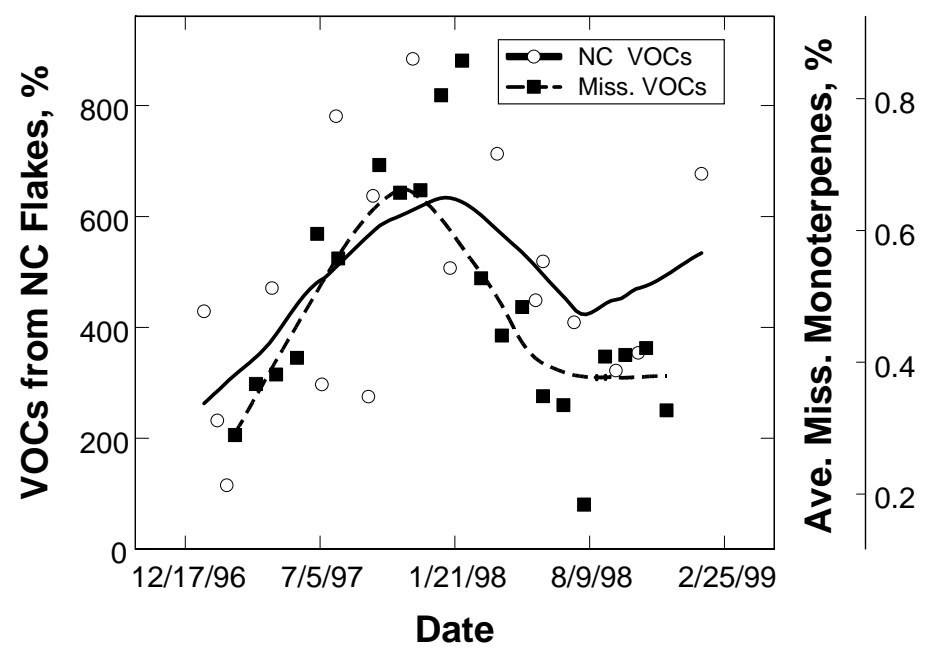

Figure 5: Comparison of the amounts of monoterpenes from Mississippi tree analyses with VOCs from North Carolina OSB flakes. 


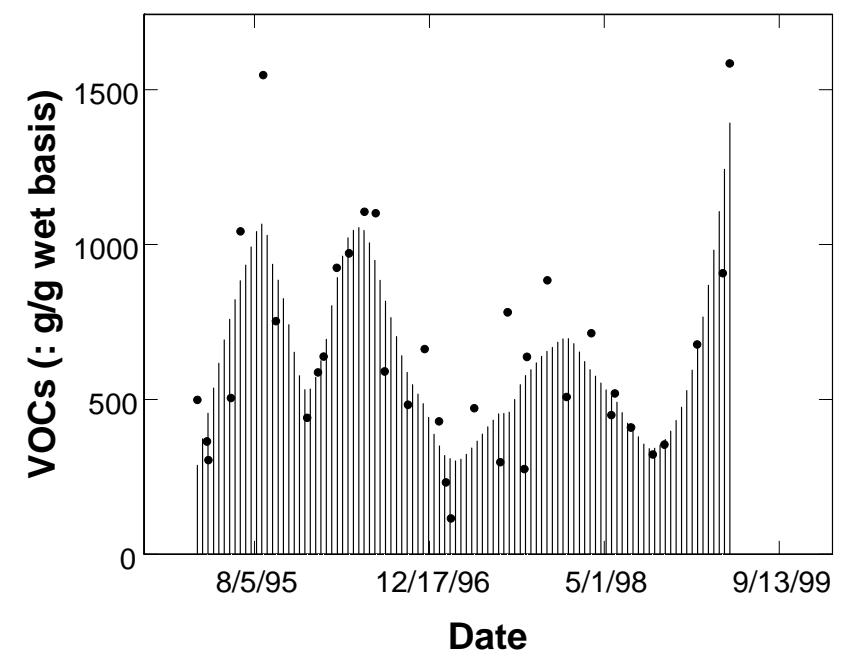

Figure 6: North Carolina data for VOCs from February 1995 through April 1999. Loess regression shown for data.

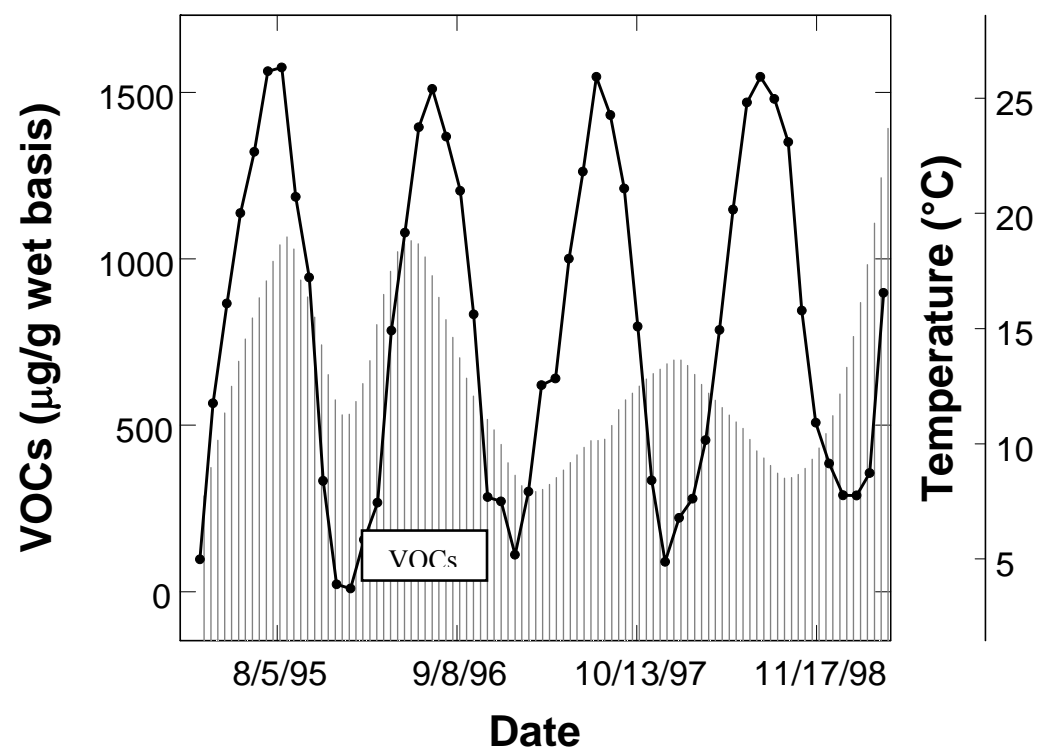

Figure 7: North Carolina VOC data and temperature data from Raleigh, NC. 


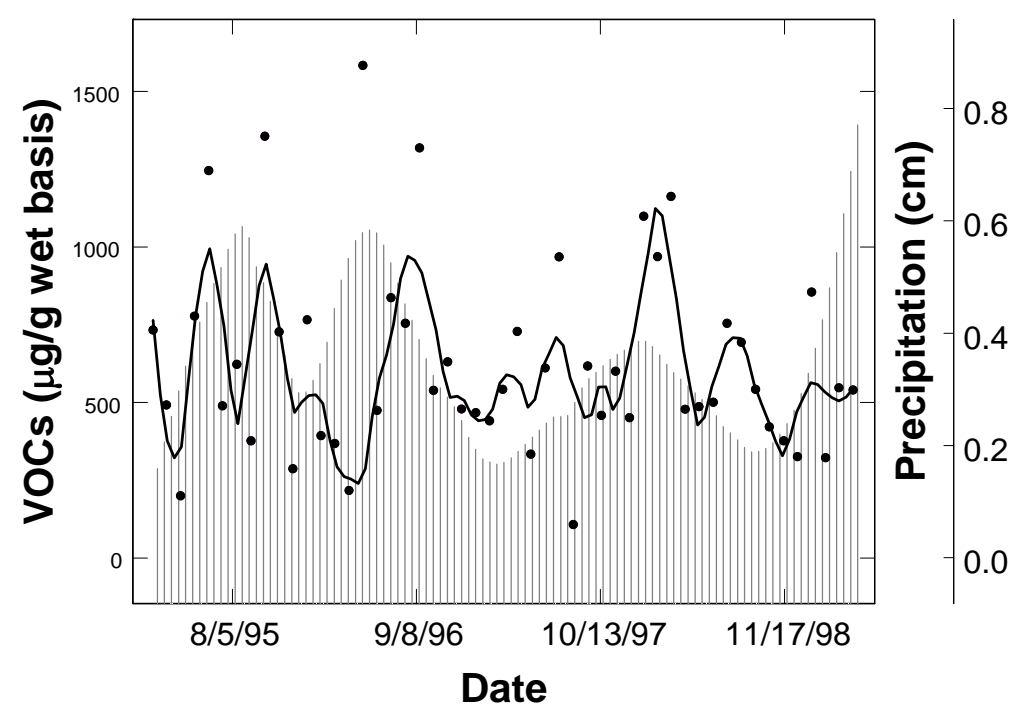

Figure 8: VOCs and precipitation data with trend line for North Carolina during sampling period $1995-1999$.

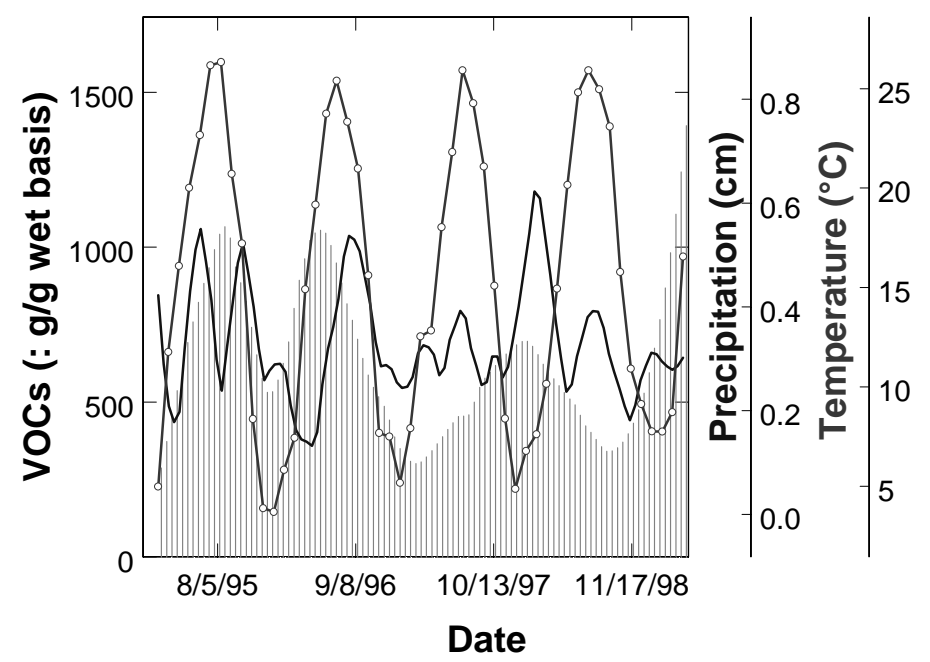

Figure 9: VOCs, precipitation and temperature in North Carolina during sampling period 19951999. 


\title{
Mechanisms of Terpene Release During Sawdust and Flake Drying
}

\author{
Holzforschung, 55, 413 (2001)
}

Sujit Banerjee

Institute of Paper Science and Technology, Atlanta, GA, USA

\section{Summary}

The water and $\alpha$-pinene released during sawdust and flake drying were simultaneously measured. For sawdust, the drying profiles for water and pinene are very different at oven temperatures of $105^{\circ} \mathrm{C}$, but are similar at $200^{\circ} \mathrm{C}$. There is an initial burst of pinene very early in the process, which is mainly attributed to the loss of pinene dissolved in surface water. Later, the pinene and water are released in a near-constant ratio, which is ascribed to water mobilizing pinene from the interior of the wood matrix to the wet line. The surfactants present in wood are believed to solubilize pinene into water. Finally, pinene is lost through evaporation when the wood is almost dry. Hence, at least three mechanisms are operative for the movement and release of $\alpha$-pinene and other terpenes from wood.

\section{Keywords}

Pinene VOC Softwood Pressing Drying Solubility Surfactants

\section{Introduction}

Volatile organic compounds (VOCs) released during softwood drying and pressing fall under environmental regulation, and there is much recent interest in defining the nature and mechanism of these emissions (Baumann et al. 1999; Cronn et al. 1983; Wang and Gardner 1999). VOCs from softwood drying are principally terpenes, of which $\alpha$-pinene is the major constituent. Methanol, formaldehyde, and other products of wood tissue decomposition are also present (Barry and Corneau 1999; Su et al. 1999). VOCs from hardwood consist of only these decomposition products. Two VOC signals emerge during softwood drying. There is a sharp initial spike, followed later by a second broad signal that begins when the wood is almost dry (Banerjee et al. 1995). The intensity of the second signal increases with increasing dryer temperature; it rises sharply above $165^{\circ} \mathrm{C}$, the boiling point of $\alpha$-pinene, indicating that it originates from simple evaporation of terpenes (Banerjee et al. 1998b). This paper evaluates the various mechanisms through which terpenes are released from softwood sawdust and flakes during drying, through study of $\alpha$-pinene as a model compound.

\section{Materials and Methods}

Sawdust obtained from the Adel, GA, mill (owned at the time by Weyerhaeuser Co.) was sieved through a 1-mm screen. Flakes were obtained from the Georgia-Pacific OSB mill in Dudley, NC. The material was dried in a 3.8-cm diameter ceramic tube furnace whose midsection was electrically heated (Banerjee et al. 1998b). The furnish $(<8 \mathrm{~g})$ was placed in a ceramic boat 
in the heated zone. Air was metered to the tube inlet at $0.25 \mathrm{lpm}$, and the emissions collected in a trap containing $2 \mathrm{~g}$ of Tenax-GR. To establish recoveries, $\alpha$-pinene $(2 \mu \mathrm{l})$ was evaporated in a $130^{\circ} \mathrm{C}$ furnace for 3 minutes under an airflow of $0.25 \mathrm{lpm}$, and the emissions trapped. The trap was then desorbed with about 3-4 ml of methanol, which was analyzed by gc/fid on an HP5 column. A recovery of $80 \pm 10 \%(\mathrm{n}=14)$ was obtained. Corresponding experiments where $0.5-1 \mathrm{~g}$ of deionized water were evaporated and trapped gave a recovery of $80 \pm 16 \%$, as measured by the weight gained in the trap. The traps were changed every three minutes when emissions from wood were collected. $\alpha$-Pinene constituted 65 and $40 \%$ of all the gc signals observed during drying at 105 and $200^{\circ} \mathrm{C}$, respectively. All experiments were duplicated. Typical results are illustrated in Figs. 1-4, with $\alpha$-pinene and water emissions being expressed as ppb and ppm, respectively, per green-basis weight of wood. The dried sawdust was Soxhlet-extracted with methanol, which was analyzed by gc.

For the pressing experiments, green softwood flakes (4 pieces, 8-10 g) were pressed between blotters in an electrohydraulic press (Banerjee et al. 1998a) at a peak pressure of 2,000 psi delivered in a $40 \mathrm{~ms}$ pulse. Water and organics were expressed into the blotters, which were sonicated in methanol, and analyzed by gc.

\section{Results and Discussion}

Drying curves for $\alpha$-pinene and water at various temperatures are illustrated in Figures 14. First, consider the $200^{\circ} \mathrm{C}$ profile in Figure 4 where the pinene and water signals closely track each other. Both components are removed through heat, and if they had behaved independently of each other, the profile for pinene should have lagged behind that of water on account of its higher boiling point. The similar profiles of the two components require a common mechanism to be responsible for their removal. Most likely, water transports the pinene through the wood matrix to the wet line.

One possibility is that pinene dissolves in water and then moves with it. In order to determine whether the water in wood is saturated with $\alpha$-pinene, water was pressed out of green wood and its $\alpha$-pinene content measured. A value of $15 \mathrm{ppm}$ was obtained, which is higher than the reported water solubility of $5 \mathrm{ppm}$ at $25^{\circ} \mathrm{C}$ (Fichan et al. 1999). The higher value in wood moisture is probably due to the presence of surfactants such as oleic acid, which would increase solubility. The solubility of $\alpha$-pinene at higher temperatures is unknown, but a value of $25 \mathrm{ppm}$ at $95^{\circ} \mathrm{C}$ was estimated through the UNIFAC method (Banerjee 1996). Pinene:water ratios (taken from values in Figures 1-4) are plotted in Figure 5. The ratio in the central region (where the temperature remains steady at about $95^{\circ} \mathrm{C}$ because of evaporative cooling) is fairly constant at about $1,000 \mathrm{ppm}$, which is much higher than the estimated solubility. However, as discussed above, the surfactants in wood will increase pinene solubility, and more surfactant will dissolve at the higher temperature. Surfactants are known to be able to induce order-of-magnitude increases in the water solubility of hydrophobic organics (Edwards et al. 1991; Kile and Chiou 1989; Liu and Chang 1997). At $25-50 \mathrm{~kg} /$ tonne, there is certainly a sufficient quantity of resin and fatty acids in wood to induce solubilization (Smook 1989), although only a small fraction of this will dissolve. Hence, the simplest mechanism that accommodates the similar pinene and water profiles in Figure 4 is that pinene is solubilized into water by the surfactants present, and is then moved to the wet line. It should be noted that the pinene must be actually solubilized and not just moved as droplets. If droplets were moved to the wet line and then vaporized, they 
would give rise to bursts of VOC. This is not the case; hydrocarbon analyzers used to continuously monitor VOCs display smooth VOC signals (Banerjee et al. 1995).

Corresponding profiles for flakes are illustrated in Figures 6-8; the pinene and water signals match well. A plot reported earlier for flakes (with total VOCs measured instead of just $\alpha$ pinene) is reproduced in Figure 9, and the VOC:water ratio in the central region is similar to the value observed in Figure 5. This confirms the validity of using $\alpha$-pinene as a model compound for softwood VOCs. Hence, the pinene:water ratio in this region of the drying curve is relatively insensitive to both the type of furnish and the dryer temperature, which would occur if the water in wood was pinene-saturated. Differences in dryer temperature do not affect solubility, since the wood tissue temperature remains at just below the boiling point of water on account of evaporative cooling, regardless of the dryer set temperature (Banerjee et al. 1998b).

The position of the early pinene peak is temperature-independent and remains constant at 3 minutes, which suggests that it originates from the surface. If this peak originated from simple evaporation of pinene deposited on the surface from the ruptured resin canals, its position and intensity should have been temperature-dependent. Also, although the boiling point of $\alpha$-pinene is higher than that of water, the pinene peak occurs earlier than that of water at the lower temperatures. Consider the effect of heating a piece of green wood in air. Since the Henry's Law coefficient (the air:water distribution) of $\alpha$-pinene is high at $14,300 \mathrm{~Pa} \mathrm{~m}^{3} / \mathrm{mol}$ (Fichan et al. 1999), the compound will tend to transfer from surface water to air. A standard two-resistance air:water model shows that the half-life of a compound with a Henry's Law coefficient of $>250$ $\mathrm{Pa} \mathrm{m} / \mathrm{mol}$ in a $1 \mathrm{~m}^{2}$ water film is $0.69 \mathrm{~L} / \mathrm{K}_{\mathrm{w}}$, where $\mathrm{L}$ is the film thickness of water in meters, and $\mathrm{K}_{\mathrm{w}}$, the water mass transfer coefficient, is $1 \times 10^{-5} \mathrm{~m} / \mathrm{s}$ at $25^{\circ} \mathrm{C}$ (Mackay 1985). This leads to a half-life of 100 seconds from a depth of $1 \mathrm{~mm}$, and much less at higher temperatures. Although the depth of the surface water film in wood is unknown, it is clear that $\alpha$-pinene can be rapidly lost from surficial water even when the wood is relatively cool. Hence, the transfer of dissolved pinene to air must be a major component of the initial signal. The initial dip in Figure 5 , which reflects the proportionately higher loss of pinene over water from sawdust is absent in Figure 9, which applies to flakes. This occurs because there is less surface water in flakes on account of their lower surface area.

The differences between the water and pinene signals from sawdust at 105 and $200^{\circ} \mathrm{C}$ can now be reconciled through the following argument. At $105^{\circ} \mathrm{C}$, the evaporation of water is initially slow, and dissolved pinene is lost from the surface water with a proportionately small loss of water. At the higher oven temperature, the wood heats up faster, the interior water with its dissolved pinene load moves to the surface more quickly, and both constituents are released together.

Finally, pinene can be lost through simple evaporation late in the drying process. It has been shown previously (Banerjee et al. 1998b) that the loss of VOCs from dry wood is vapor pressure driven. For example, the VOC-dryer temperature curve breaks upwards at about $160^{\circ} \mathrm{C}$, the boiling point of $\alpha$-pinene. The increase in VOC emissions during late drying in Figures 5 and 9 reflects increasing pinene evaporation as the wood temperature climbs after the evaporative cooling effect of water is lost. 
It is apparent from Figures 1-4 that the amount of $\alpha$-pinene released increases with increasing temperature. In an attempt to establish a mass balance, the dried wood was solventextracted to determine the residual $\alpha$-pinene. The results, shown in Table 1, indicate that the total pinene (released during drying and remaining in the dried wood) apparently increases with increasing temperature. The reasons are not known. One possibility is that there are occluded regions in wood that are difficult for the solvent to access, but from which pinene can be removed through heat.

The hypothesis that water dissolves pinene and carries it out at a concentration of about $1,000 \mathrm{ppm}(0.1 \%)$ was verified by applying it to other furnishes. Lumber is usually dried to a moisture content of about $15 \%$, and the VOCs released during late drying of particle and flakes should be absent for lumber. If the $0.1 \%$ value is applied, then pinene emissions from lumber should be about $1 \mathrm{~kg} / \mathrm{dry}$ tonne. This is in the range of reported values.

\section{Conclusions}

In summary, there seems to be (at least) three mechanisms for the movement and release of $\alpha$-pinene and other terpenes from wood. A burst occurs very early in the process, and is attributed to the loss of pinene dissolved in surface water. Pinene and water then tend to be released in a near-constant ratio, and this is attributed to water mobilizing pinene from the interior of the wood matrix to the surface. It is believed that the surfactants present in wood solubilize pinene into water. Finally, when the wood is nearly dry, pinene is lost through evaporation. These mechanisms can be used to predict VOC emissions under different drying conditions, and to identify strategies that favor isolation of low-volume VOC-rich streams that lend themselves to incineration.

\section{Acknowledgements}

This study was funded by the Department of Energy through contract DE-FCO796IDI3439, Electric Power Research Institute, and Weyerhaeuser Corporation. The experimental work was done by Wei Su.

\section{References}

Banerjee, S. 1996. Estimating water solubilities of organics as a function of temperature. Water Res. 30, 2222-2225.

Banerjee, S., M. Hutten, W. Su, L. Otwell and L. Newton. 1995. Release of water and volatile organics from wood drying. Environ. Sci. Technol. 29, 1135-1136.

Banerjee, S., T. Mahmood, P.M. Phelan and R.W. Foulke. 1998a. Impulse drying sludge. Water Res. 32, 258-260.

Banerjee, S., W. Su, M.P. Wild, L.P. Otwell, M.E. Hittmeier and K.M. Nichols. 1998b. Wet line extension reduces VOCs from softwood drying. Environ. Sci. Technol. 32, 1303-1307.

Barry A.O. and D. Corneau. 1999. Volatile organic chemicals emissions of OSB as a function of processing parameters. Holzforschung. 53, 641-646.

Baumann, M.G.D., A.A. Batterman and G-Z Zhang. 1999. Terpene emissions from particleboard and medium-density fiberboard products. Forest Products J. 49 (1), 49-56.

Cronn, D.R., S.G. Truitt and M.J. Campbell. 1983. Chemical characterization of plywood veneer drying emissions. Atmos. Environ. 17, 201-211. 
Edwards, D.A., R.G. Luthy and Z. Liu. 1991. Solubilization of polycyclic aromatic hydrocarbons in micellar nonionic surfactant solutions. Environ. Sci. Technol. 25, 127-133.

Fichan I., C. Larroche and J.B. Gros. 1999. Water solubility, vapor pressure and activity coefficients of terpenes and terpenoids. J. Chem. Eng. Data 44, 56-62.

Kile, D.E. and C.T. Chiou. 1989. Water solubility enhancement of DDT and trichloroethylene by some surfactants below and above the critical micelle concentration. Environ. Sci. Technol. 23, 832-838.

Liu, J.C. and P.S. Chang. 1997. Solubility and adsorption behaviors of chlorophenols in the presence of surfactant. Wat. Sci. Tech. 35 (7), 121-130.

Mackay, D. 1985. Air/water exchange coefficients in environmental exposure from chemicals. Volume 1. Eds. W.B. Neely and G.E. Blau, CRC Press, Boca Raton, FL.

Smook, G.A. 1989. Handbook for Pulp and Paper Technologists. TAPPI/CPPA.

Su, W., H. Yan, S. Banerjee, L.P. Otwell and M.E. Hittmeier. 1999. Field-proven strategies for reducing VOCs from hardwood drying. Environ. Sci. Technol. 33, 1056-1059.

Wang, W. and D.J. Gardner. 1999. Investigation of volatile organic compound press emissions during particleboard production. Part I. UF-bonded Southern pine. Forest Products J. 49, (3), 65-72.

Table 1. $\alpha$-Pinene released during drying and retained in sawdust.

\begin{tabular}{cccc}
\hline $\begin{array}{c}\text { temperature } \\
\left({ }^{\circ} \mathrm{C}\right)\end{array}$ & $\begin{array}{c}\text { released during } \\
\text { drying }(\mu \mathrm{g} / \mathrm{g})^{1}\end{array}$ & $\begin{array}{c}\text { residual in } \\
\text { wood }(\mu \mathrm{g} / \mathrm{g})^{1}\end{array}$ & total $(\mu \mathrm{g} / \mathrm{g})^{1}$ \\
\hline green furnish & & $250 \pm 50$ & 250 \\
105 & $248 \pm 1$ & $102 \pm 0$ & 350 \\
130 & $373 \pm 2$ & $27 \pm 2$ & 400 \\
160 & $350 \pm 10$ & $6 \pm 0$ & 356 \\
200 & $480 \pm 60$ & $3 \pm 0$ & 483 \\
\hline
\end{tabular}

${ }^{1}$ average of 2 values, green basis 


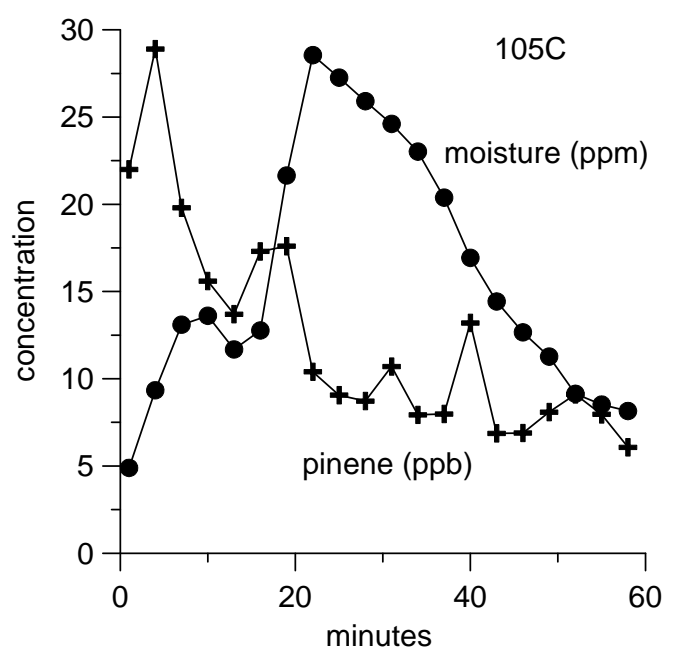

Fig. 1. Emissions from sawdust at $105^{\circ} \mathrm{C}$.

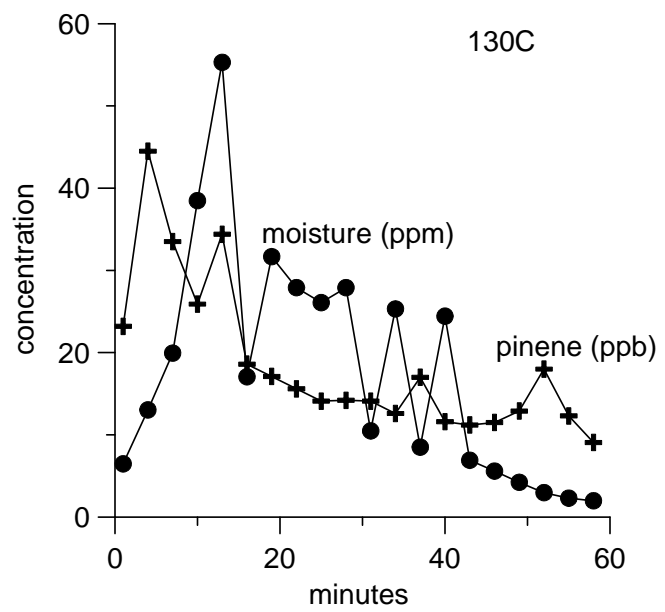

Fig. 2. Emissions from sawdust at $130^{\circ} \mathrm{C}$. 


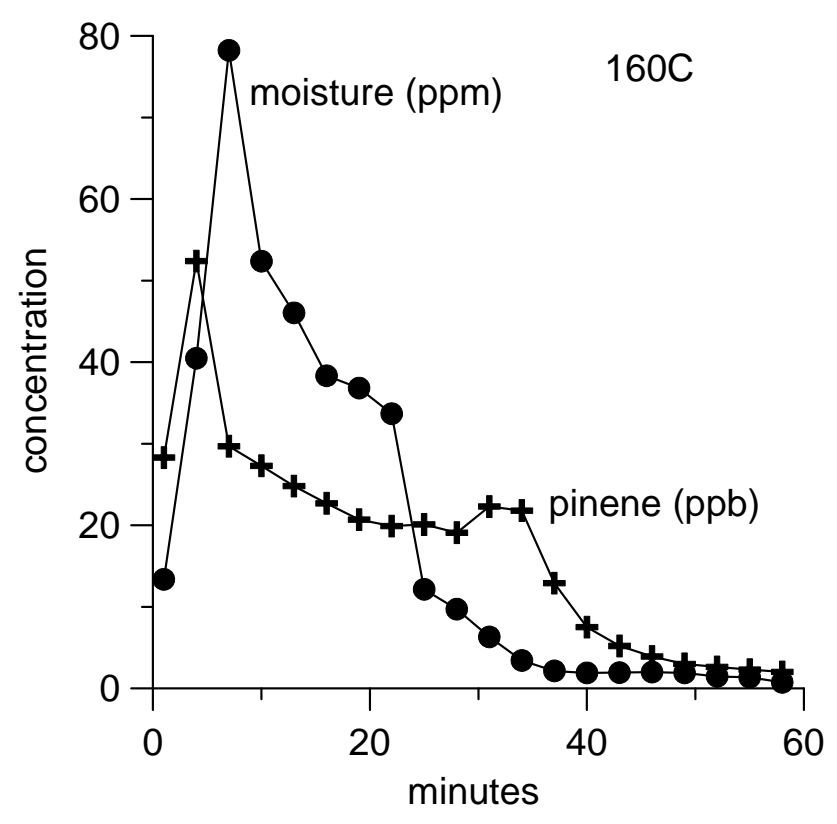

Fig. 3. Emissions from sawdust at $160^{\circ} \mathrm{C}$.

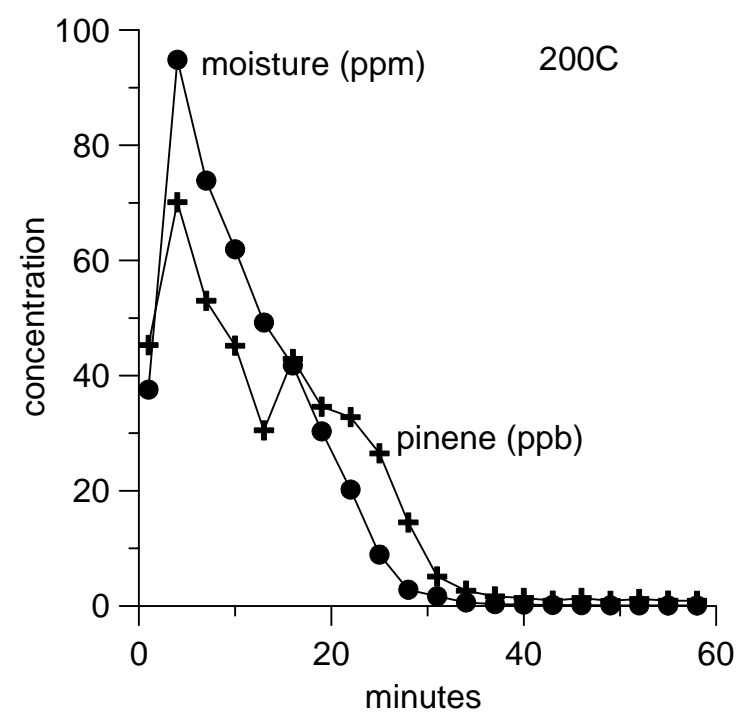

Fig. 4. Emissions from sawdust at $200^{\circ} \mathrm{C}$. 


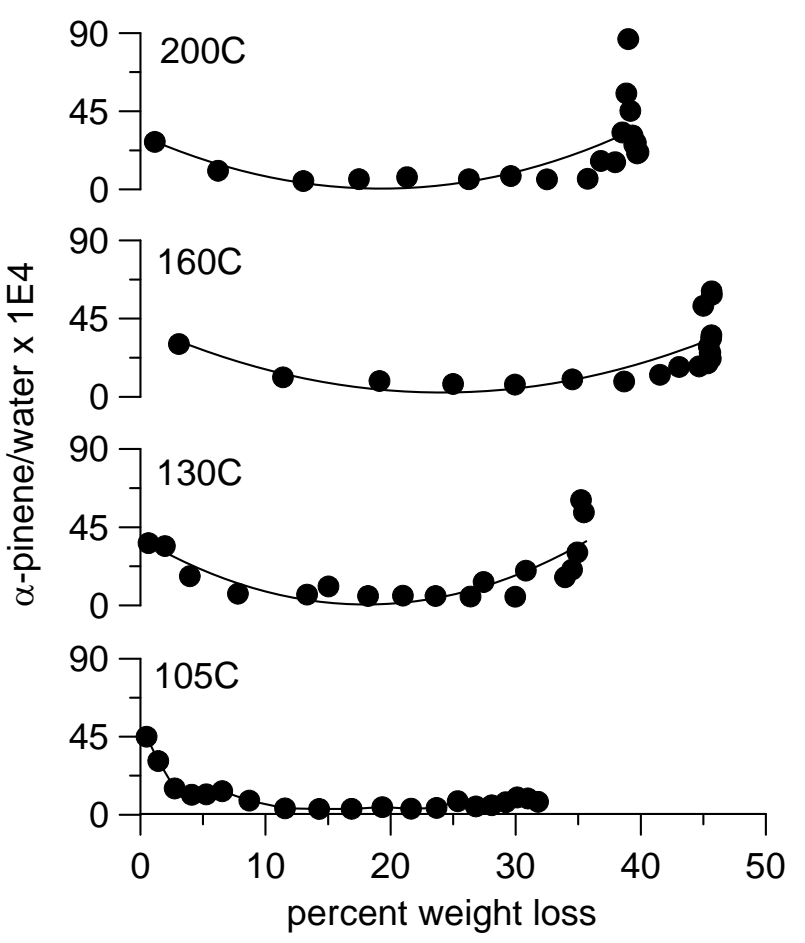

Fig. 5. VOC/water ratios for sawdust.

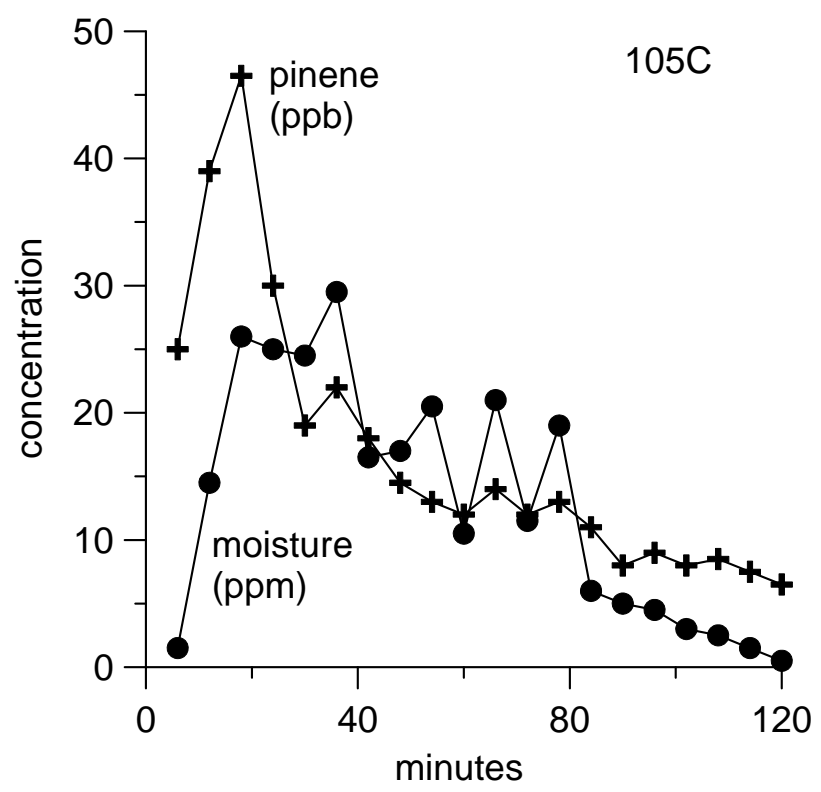

Fig. 6. Emissions from flakes at $105^{\circ} \mathrm{C}$. 


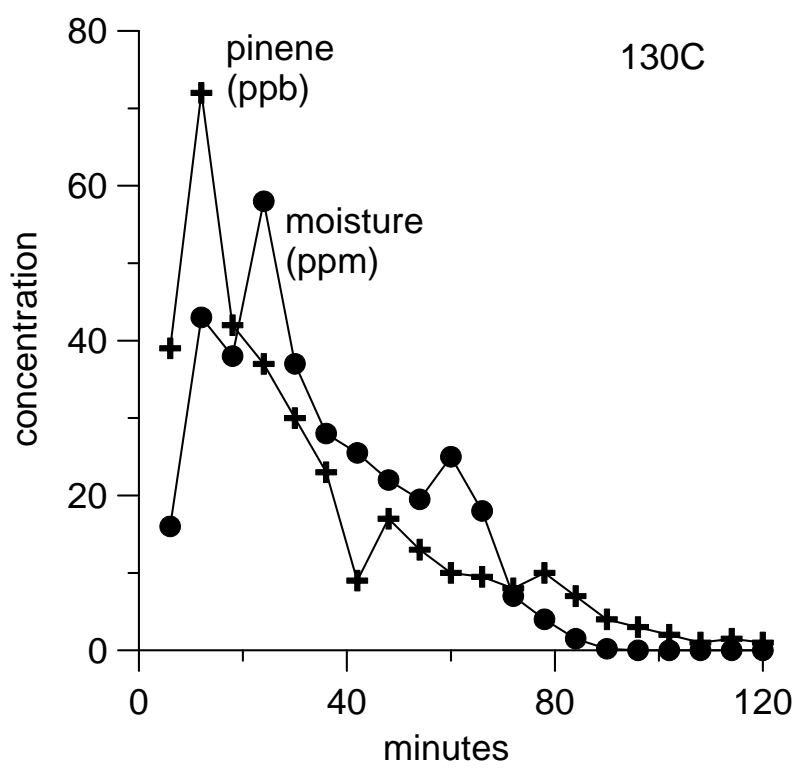

Fig. 7. Emissions from flakes at $130^{\circ} \mathrm{C}$.

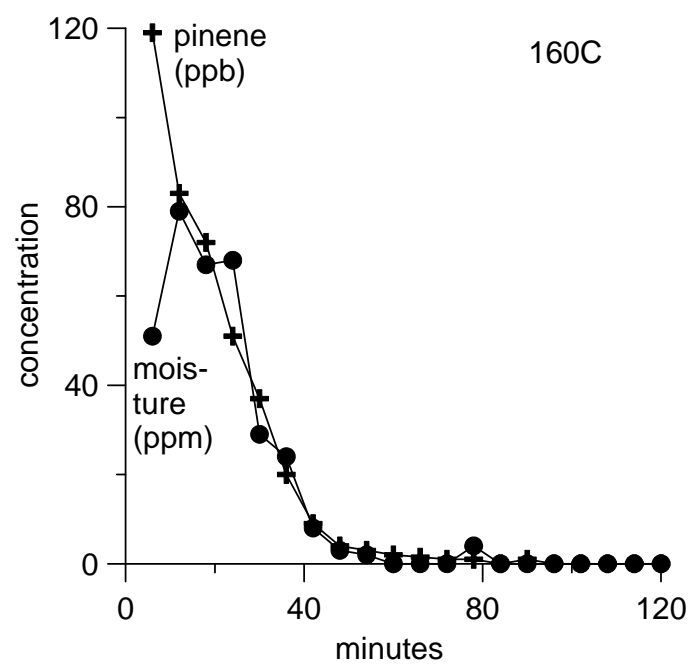

Fig. 8. Emissions from flakes at $160^{\circ} \mathrm{C}$. 


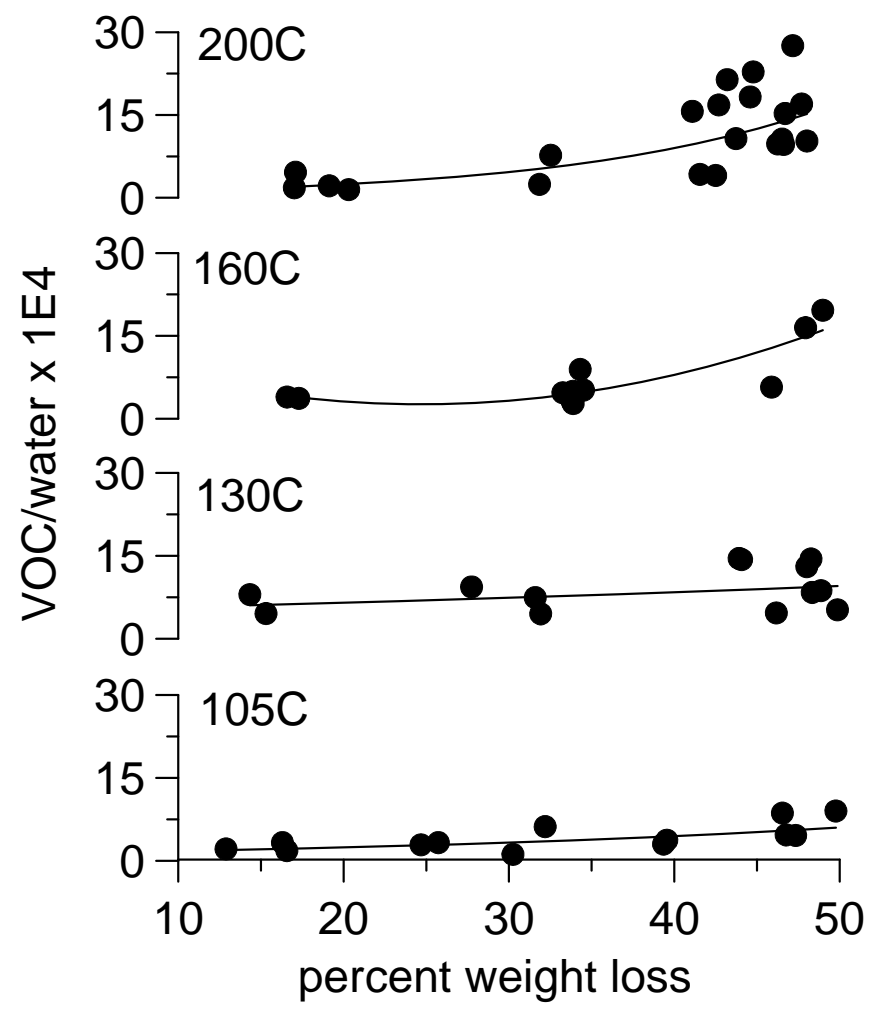

Fig. 9. VOC/water ratios for flakes (Banerjee et al. 1998). 


\title{
Flake Drying Temperature Affects Mat Properties During Pressing
}

\author{
Holzforschung, 56, 558 (2002).
}

\author{
Christopher J. Martino ${ }^{1}$, Suresh Shrauti ${ }^{1}$, Sujit Banerjee ${ }^{1,3}$, Lawrence P. Otwell ${ }^{2}$, Eddie W. Price ${ }^{2}$ \\ ${ }^{1}$ Institute of Paper Science and Technology, Atlanta, GA, USA \\ ${ }^{2}$ Georgia-Pacific Corporation, Atlanta, GA, USA
}

\begin{abstract}
Summary
The contact angle of water on wood rises sharply as the wood approaches dryness. The general shape of the rise can be reproduced through thermodynamic calculations that consider the presence of extractives on the surface. SEM work confirms that extractives move progressively to the surface with increasing drying temperature. Other factors such as pore closure also contribute to surface hydrophobicity. The temperature profile within a stack of flakes during accelerated pressing shows a break at $100^{\circ} \mathrm{C}$ when flakes dried at high temperature are processed. Moisture is known to be driven from the outer layers of the stack to the core during early pressing. If the flake surface is hydrophobic then this moisture would film on the surface rather than penetrate into the flake. Subsequent evaporation of the moisture would lead to high pressure. Hence, flakes dried at high temperature should be more prone to delamination. Hightemperature drying also promotes VOC emissions and there should be operational and environmental benefits to drying at lower temperature.
\end{abstract}

Keywords: Contact angle, Pressing, Extractives, Delamination, Mechanism

\section{Introduction}

Numerous studies have established that the surface of wood is inactivated when overdried. Christiansen $(1990,1991)$ studied the effect of overdrying on the glue bond. The movement of extractives to the surface, reorientation of molecules on the wood surface, and irreversible closure of large micropores in cell walls were identified as contributing factors. For Southern pine, the movement of extractives during drying was believed to lead to poor wettability. Hemingway (1969) demonstrated the reduction in surface wettability of yellow birchwood after heating, and Yazaki et al. (1994) showed that the uneven extractives distribution in blackbutt veneers made high quality bonding difficult to achieve with phenolic adhesives. Jordan and Wellons (1977) showed that commercial drying of veneer damaged the surface, and that extractive content and type had a major effect on wettability. These studies provide ample evidence that drying temperature inactivates the wood surface. In this paper we demonstrate that surface properties also influence the pressure developed in the core during pressing.

\section{Materials and Methods}

Green veneer (pine) was obtained from the Georgia-Pacific mill in Madison, GA. Specimens $(25.4 \times 25.4 \times 3.2 \mathrm{~mm})$ were first dried to moisture contents (MC) of less than $25 \%$. Contact angles were measured on the tight side of the veneer after allowing the specimen to cool. The specimen was then returned to the oven, and the procedure repeated at different MCs. Pine flakes were obtained from the Georgia-Pacific facility at Dudley, NC, and were moistureequilibrated in plastic bags before use. The mill uses a high-temperature rotary dryer, to dry the 
furnish to 5\% MC. Two presses were used. Small-scale work was done in an electrohydraulic press (Banerjee et al. 1998a) with platens of 14-cm diameter. The temperature of a stack of flakes (without added resin) was measured during pressing. The stack was placed inside a stainless steel bag fitted with inlet and outlet tubes. The top of the bag contacted a $200^{\circ} \mathrm{C}$ platen and the bottom was insulated with a dry felt. The temperature at the bottom would correspond to that at the center of a mat if both platens of the press were heated. The press closed in about 1 second at an applied pressure of $18 \mathrm{~atm}$. The thermocouple was positioned in the mat at a distance of $2.2 \mathrm{~mm}$ (after pressing) from the top platen.

Larger-scale pressing was done at the Georgia-Pacific laboratory in Decatur, GA where $1.14 \mathrm{~kg}$ (dry basis) of wood was pressed at the temperature and pressure listed above to create $929-\mathrm{cm}^{2} \times 1.9-\mathrm{cm}$ boards.

Contact angle was measured with a First Ten Angstroms FTA 200 instrument. A piece of veneer was placed under a syringe that delivered a water drop of controlled volume. A computer-controlled camera captured images of the drop at predetermined time intervals; image analysis software was then used to determine the contact angle, volume, base-width, and height of the water drop as a function of time. The rate of water penetration was measured by noting the decrease in droplet volume over one second.

\section{Results and Discussions}

The contact angles of a water drop on veneer dried in the laboratory at 105, 150, and $175^{\circ} \mathrm{C}$ are shown in Figures 1-3, respectively. Drying to less than about 4\% MC causes the contact angle to increase sharply. The rates of water penetration into veneer are listed in Table 1 and decrease with decreasing MC; bone-dry wood is almost impenetrable in the time frame of the measurement. The two sets of experiments show that surface hydrophobicity increases rapidly as the wood approaches dryness.

In order to relate these results to mill-dried specimens, contact angles of two commercially dried pieces of veneer were measured at ten different locations on the surfaces. Surprisingly, a value of $93^{\circ}$ was obtained for both pieces $\left(\sigma=4^{\circ}, 6^{\circ}\right)$, which corresponds to an $\mathrm{MC}$ of $<1 \%$ on the basis of Figures $1-3$. This leads to an anomaly since the wood was at $4 \% \mathrm{MC}$, which corresponds to a lower contact angle on the basis of Figures 1-3. It is possible that the disparity arises from differences in airflow and temperature between laboratory and field drying. The inlet temperature of the jet dryer in the mill was $200^{\circ} \mathrm{C}$, and it is likely that surface dry-out occurred; i.e., the moisture was preferentially located in the interior of the sample, leaving the surface relatively dry. This type of behavior has been implicated before in high-temperature drying of flakes or particle (Banerjee et al. 1998b).

According to Hse (1972), a high contact angle (low moisture) is favorable in that it leads to good resin spread during pressing. On the other hand, drying to a higher moisture (MC $>5 \%$ ) is desirable from an environmental perspective since methanol and formaldehyde emissions rise sharply at lower MC (Otwell et al. 2000; Su et al. 1999). These compounds arise from the degradation of wood tissue, and at an $\mathrm{MC}$ of less than 5\% evaporative cooling can no longer prevent the tissue temperature from rising to the point where degradation begins. It follows that a product with an overall MC of just over 5\% and a dry surface layer would be attractive for both op- 
erational and environmental reasons. The field-dried veneer is not far from this situation. Raising the moisture content by a percentage point or so should provide environmental benefit as well while leaving glue spread relatively unaffected.

SEM images of flake surfaces dried at $105^{\circ} \mathrm{C}$ in the laboratory and processed commercially in a high-temperature triple pass rotary dryer are compared in Figure 4. The loss of detail in the field-dried flake is clearly evident and suggests that the surface was glazed to a greater degree, possibly with extractives and/or thermal breakdown products of the surface tissue. Clearly, heat reduces the surface porosity. This is consistent with the literature discussed earlier and with a report that drying temperature influences the surface properties of flakes (Plagemann et al. 1984). These micrographs are only a few of many taken, all of which showed a similar glaze for the field-dried flakes.

The contribution of extractives to surface hydrophobicity can be evaluated theoretically by computing the contact angle of water on a wood surface containing varying amounts of extractive. The algorithm (Banerjee and Etzler 1995) is based on the UNIFAC equation, an established chemical engineering method of estimating thermodynamic properties of mixtures (Poling et al. 2000). Contact angles of a wide range of polar and nonpolar liquids (including water) on polymer surfaces were calculated to within an average of $7^{\circ}$ of measured values (Banerjee and Etzler 1995). For the present application, the solid surface was taken to be a mixture of glucose and oleic acid. The glucose represents cellulose, and oleic acid is a model for extractives. Increasing the oleic acid content on the surface increases the contact angle as shown in Figure 5. The estimated value of $56^{\circ}$ for water on a pure cellulose surface corresponds quite well to the plateau values of about $60^{\circ}$ in Figure 1. The angle rises to $73^{\circ}$ as the presence of oleic acid increases on the surface. The Figure 5 curve is of the same overall shape as those in Figure 1, which we interpret as support for the role of extractives in influencing surface properties. However, the sharp rise in contact angle at low moistures seen in Figure 1 is absent in Figure 5, possibly because the Figure 1 rise reflects physical effects such as pore closure.

The above discussion indicates that drying at high temperature may increase surface hydrophobicity. To determine how this affects behavior during pressing, a stack of flakes was prepared by cutting a large flake into several pieces. An insulated thermocouple was attached to the top of the stack, which was placed on a $200^{\circ} \mathrm{C}$ hot plate. A 2-kg weight was applied to the stack, and the temperature was measured continuously. Temperature profiles of stacks of flakes at $5 \%$ $\mathrm{MC}$ dried in the laboratory $\left(\right.$ at $105^{\circ} \mathrm{C}$ ) and in the field are compared in Figure 6 . Note the slight break at about $100^{\circ} \mathrm{C}$ that occurs (reproducibly) only for the field-dried furnish. Since both sets of flakes were at the same MC, the difference likely originates from the manner in which the flakes were dried.

Next, temperature profiles within stacks of flakes were measured in the small press. Figure 7 illustrates a typical result for the temperature profiles for the pressing of both field- and laboratory-dried flakes. The temperatures rises smoothly for the low-moisture $(2.8 \% \mathrm{MC})$ laboratory-dried flakes, but a break is observed at about $100^{\circ} \mathrm{C}$ for the higher-moisture $(12.4 \% \mathrm{MC})$ laboratory-dried material and for the field-dried flakes, which were at 5\% MC. The press closing period was much shorter than that of a commercial press. This was done to force extreme conditions. Press blows are infrequent, and it would be difficult to identify the factors that lead to 
press blows through a study conducted under typical operating conditions. The faster close leads to more rapid heat transfer and identifies situations that would be smoothed over and be more difficult to recognize in a more gradual operation. Indeed, the results from our larger press show no evidence of a break. The temperature profile of the core of a $1.65-\mathrm{cm}$ board during the pressing of field-dried flakes in the larger press is illustrated in Figure 8. The heating rate of this stack is much lower than that of the smaller one because of the thicker board used. For example, the core of a stack of flakes in the small press reached $120^{\circ} \mathrm{C}$ in 2 minutes; the larger unit required a much longer period. No temperature break is observed in Figure 8, probably because of differences in heat transfer properties as discussed above.

Numerous studies have detailed the temperature profile within a stack of flakes or a bed of particle during pressing. Heat transfer from the surface to the core is mainly convective through the movement of steam. As a result, the moisture near the face decreases at the onset of pressing, while that at the core rises (Bolton et al., 1989). The temperature rise within the core and the internal pressure increases with increasing mat MC or platen temperature (Kamke and Casey 1988; Song and Ellis 1997).

The break in Figure 7 must represent evaporative cooling, which suggests that the water is unable to move easily towards the surface and evaporates in the vicinity of the thermocouple. The resulting build-up of pressure in the interior of the mat could lead to blows if the steam did not escape during pressing. Several mechanisms may be advanced to account for the break; perhaps the simplest involves moisture absorption by the flakes in the core. When the steam from the outer layers of the board moves to and condenses in the core, the water would be absorbed by the flakes if the flakes were sufficiently porous. However, the surface of the field-dried flakes is hydrophobic, as discussed above, and the condensed water would tend to form a film at the surface. When this moisture eventually evaporated it would give rise to local high pressure. The pressure increase for the laboratory-dried material would be lower, since its surface would be less hydrophobic and the moisture would have penetrated the furnish to a greater degree and be distributed over a larger volume. This suggests that the tendency towards delamination should increase with increasing dryer temperature.

In summary, both theoretical and experimental work suggests that the surface hydrophobicity of wood increases with increasing coverage of extractives. High-temperature drying promotes the exudation of extractives, which would inhibit water penetration into the furnish. Hence, much of the moisture driven from the outer layers of the mat dried at high temperature would be deposited on the surfaces of the wood in the core. This could lead to local overpressure when the water finally evaporated. In previous work we have shown that VOC emissions are lower when wood is dried at lower temperature. The present work demonstrates that lowtemperature drying may also lead to operational benefit and establishes a link between drying practice and pressing performance.

\section{Acknowledgements}

This work was funded by the Electric Power Research Institute, Georgia-Pacific Corporation, International Paper, Ottertail Power, and the US Department of Energy. 


\section{References}

Banerjee, S. and F.M. Etzler. 1995. An algorithm for estimating contact angles. Langmuir 11, 4141-4142.

Banerjee, S., T. Mahmood, P.M. Phelan and R.W. Foulke. 1998a. Impulse drying sludge. Water Res. 32, 258-260.

Banerjee, S., W. Su, M.P. Wild, L.P. Otwell, M.E. Hittmeier and K.M. Nichols. 1998b. Wet line extension reduces VOCs from softwood drying. Environ. Sci. Technol. 32, 1303-1307.

Bolton, A. J., P. E. Humphrey and P. K. Kavvouras. 1989. The hot pressing of dry-formed wood-based composites. Part IV. Predicted variation of mat moisture content with time. Holzforshung 43, 345-349.

Christiansen, A. W. 1990. How overdrying wood reduces its bonding to phenol-formaldehyde adhesives: a critical review of the literature. Part I. Physical responses. Wood Fiber Sci. 22(4), 441-459.

Christiansen, A. W. 1991. How overdrying wood reduces its bonding to phenol-formaldehyde adhesives: a critical review of the literature. Part II. Chemical reactions. Wood Fiber Sci. 23(1), 69-84.

Hemingway, R. W. 1969. Thermal Instability of Fats Relative to Surface Wettability of Yellow Birchwood (Betula lutea). Tappi J. 52(11), 2149-2155.

Hse, C. Y. 1972. Wettability of southern pine veneer by phenol formaldehyde wood adhesives. Forest Products J. 22(1), 51-56.

Jordan, D. L. and J. D. Wellons. 1977. Wettability of dipterocarp veneers. Wood Science 10(1), 22-27.

Kamke, F. A. and L. J. Casey. 1988. Fundamentals of flakeboard manufacture: internal-mat conditions. Forest Prod. J. 38(6), 38-44.

Otwell, L.P., M.E. Hittmeier, U. Hooda, H. Yan, W. Su and S. Banerjee. 2000. HAPs release from wood drying. Environ. Sci. Technol. 34, 2280-2283.

Plagemann, W.L., E.W. Price and W.E. Johns. 1984. The response of hardwood flakes and flakeboard to high temperature drying. J. Adhesion 16, 311-338.

Poling, B.E., J.M. Prausnitz and J.P.O'Connell. 2000. Properties of Liquids and Gases, $5^{\text {th }}$ Edition. McGraw-Hill.

Song, D. and S. Ellis. 1997. Localized properties in flakeboard: a simulation using stacked flakes. Wood Fiber Sci. 29, 353-363.

Su, W., H. Yan, S. Banerjee, L.P. Otwell and M.E. Hittmeier. 1999. Field-proven strategies for reducing VOCs from hardwood drying. Environ. Sci. Technol. 33, 1056-1059.

Yazaki, Y., P. J. Collins and B. McCombe. 1994. Variations in hot water extractives content and density of commercial wood veneers from Blackbutt (Eucalyptus pilularis). Holzforschung 48 (suppl.), 107-111. 


\begin{tabular}{|c|c|}
\hline MC (\%) & rate $(\mathrm{L} / \mathrm{s})$ \\
\hline \multicolumn{2}{|l|}{$105^{\circ} \mathrm{C}$} \\
\hline 10.1 & 6.0 \\
\hline 6.2 & 2.1 \\
\hline 3.9 & 2.4 \\
\hline \multicolumn{2}{|l|}{$150^{\circ} \mathrm{C}$} \\
\hline 1.6 & 3.5 \\
\hline 0.8 & 1.3 \\
\hline 0.0 & 0.2 \\
\hline \multicolumn{2}{|l|}{$175^{\circ} \mathrm{C}$} \\
\hline 3.1 & 2.8 \\
\hline 0.8 & 0.5 \\
\hline 0.0 & 0.0 \\
\hline
\end{tabular}

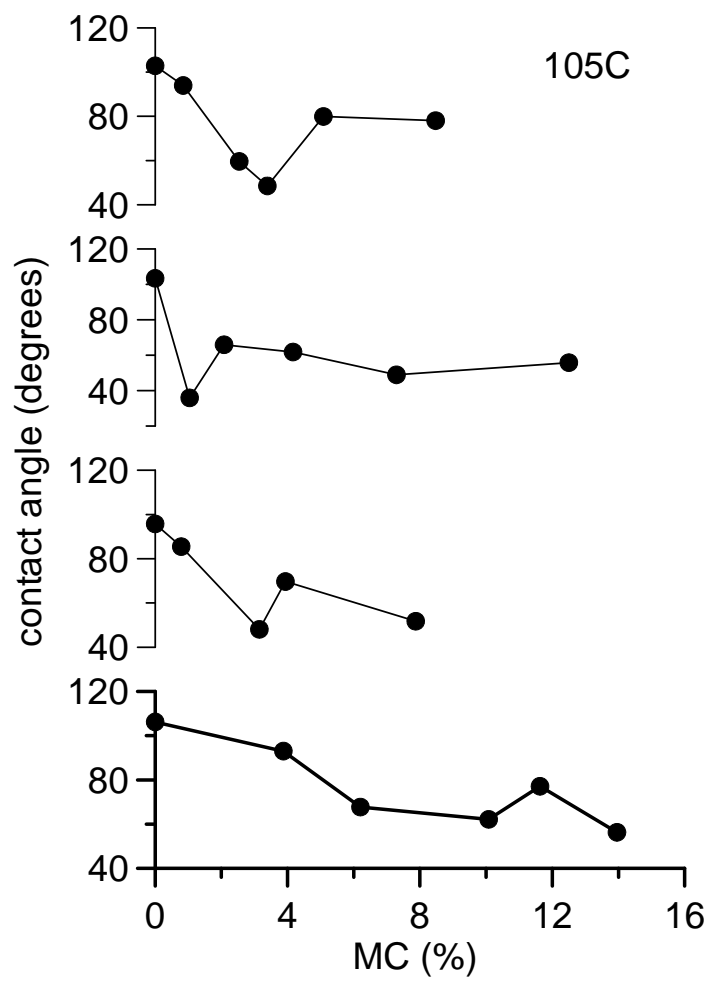

Fig. 1. Contact angles of water on wood dried at $105^{\circ} \mathrm{C}$. 


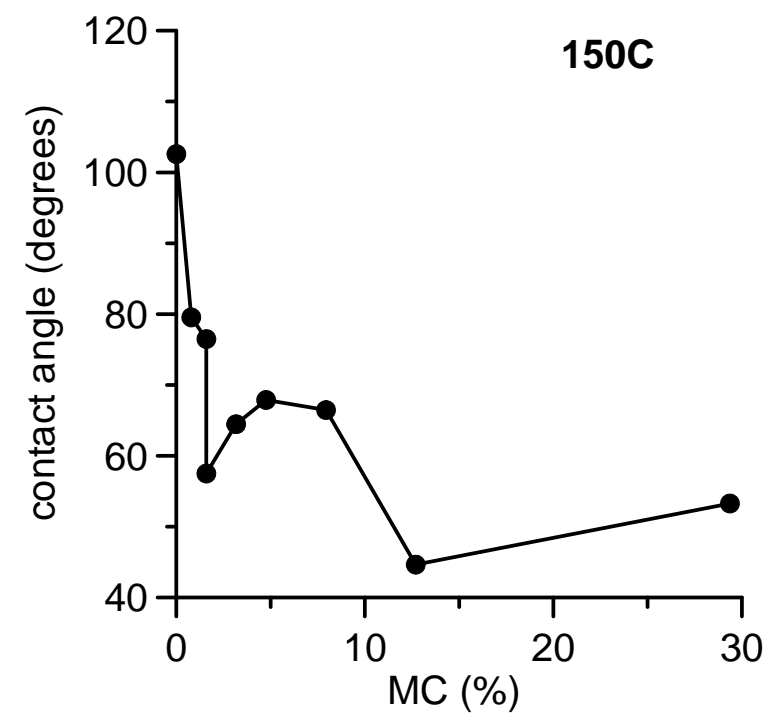

Fig. 2. Contact angles of water on wood dried at $150^{\circ} \mathrm{C}$.

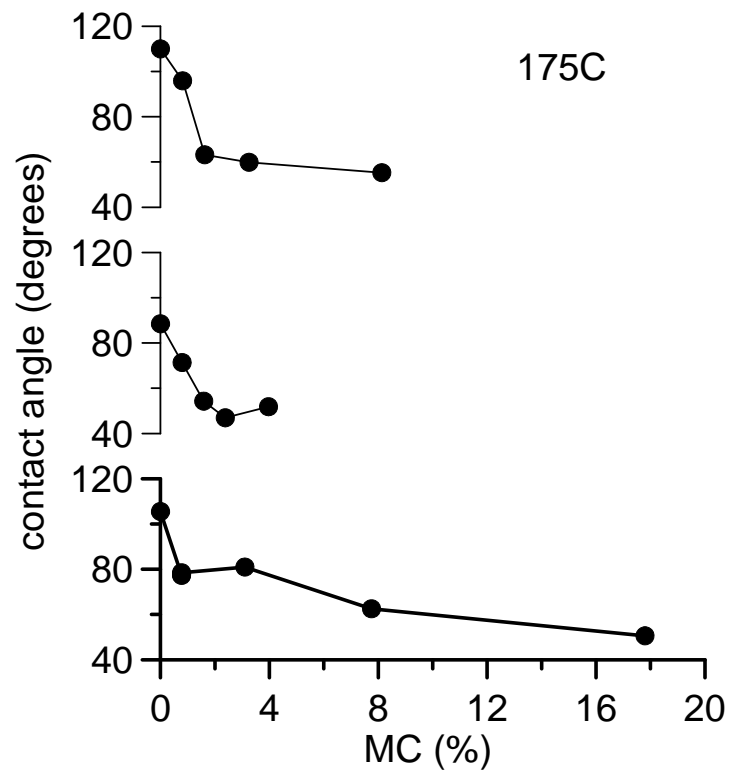

Fig. 3. Contact angles of water on wood dried at $175^{\circ} \mathrm{C}$. 

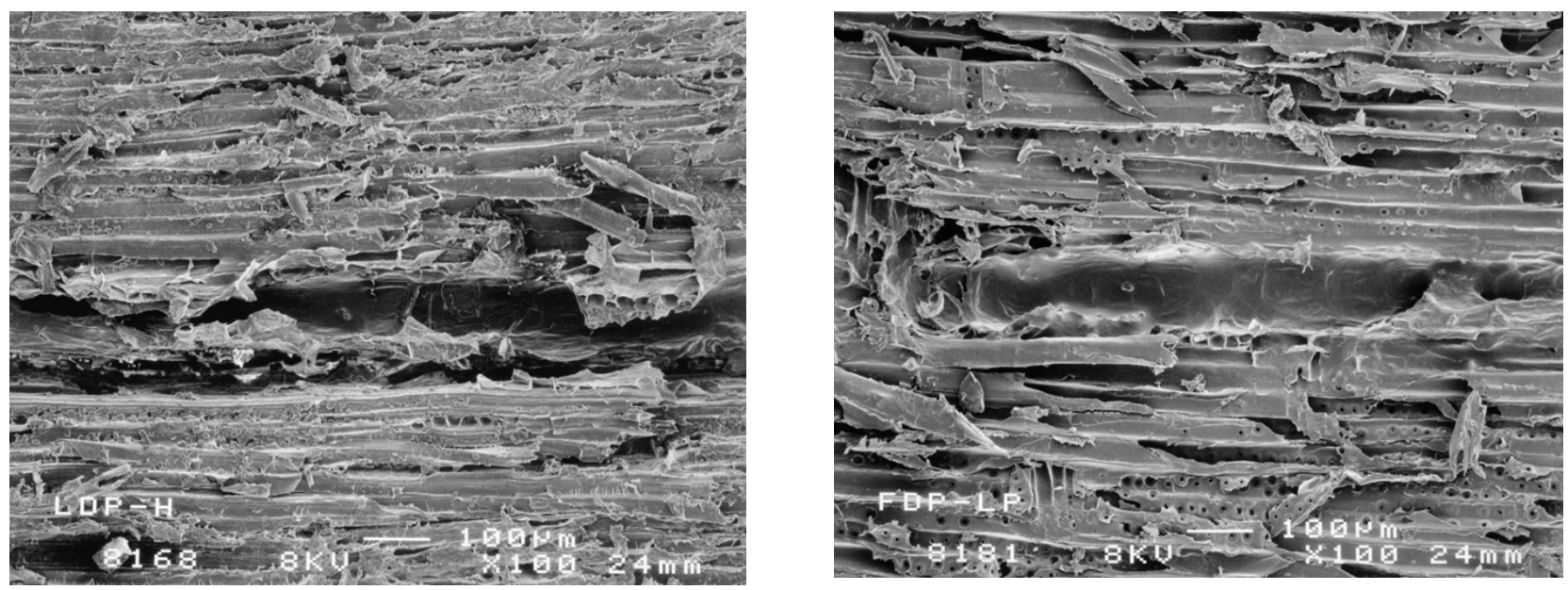

Fig. 4. SEM images of flake surfaces dried at $105^{\circ} \mathrm{C}$ (left) and in the field (right).

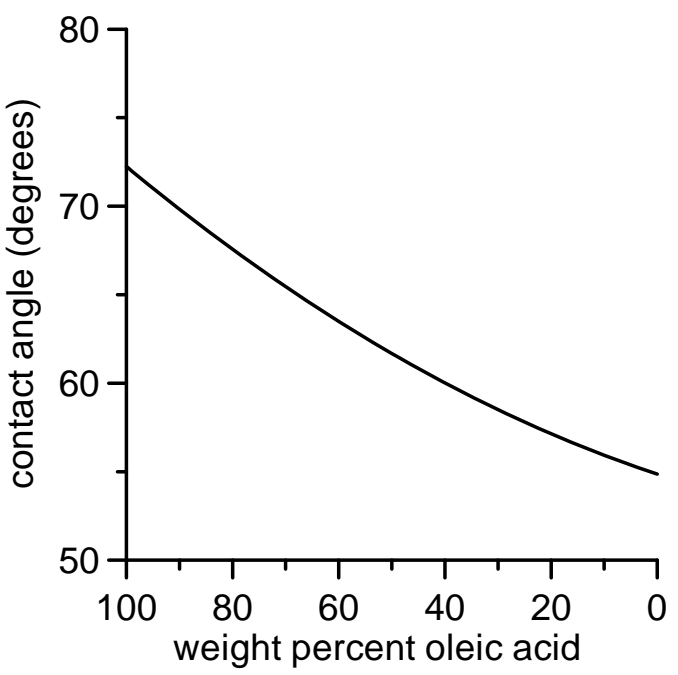

Fig. 5. Dependence of the contact angle of water on a surface constructed from glucose and oleic acid. 


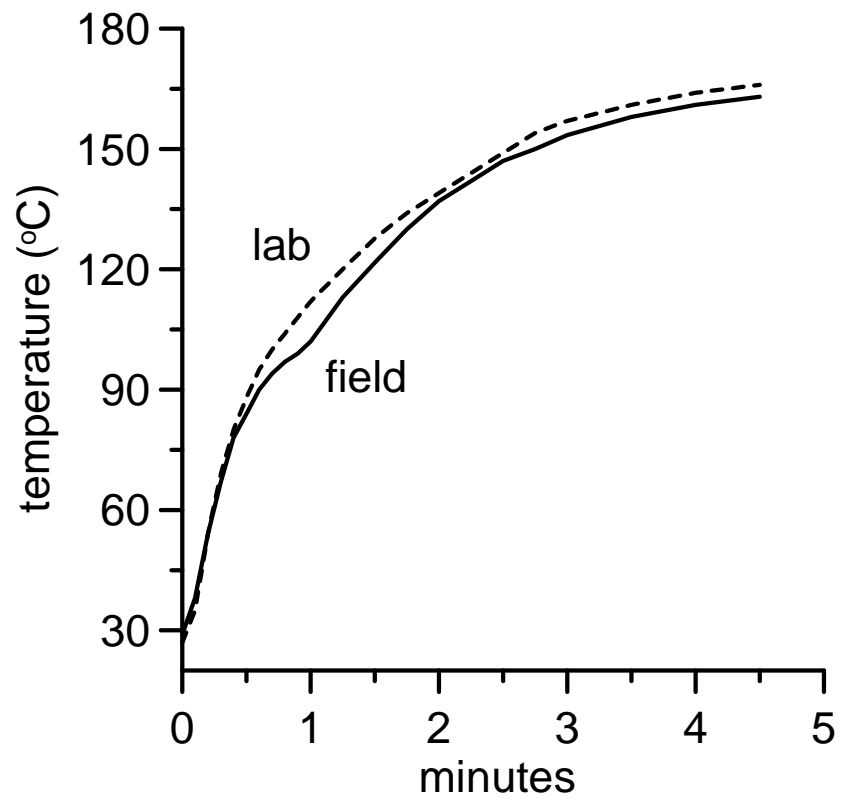

Fig. 6. Temperature profile for a $2.5-\mathrm{mm}$ stack of 3 flakes.

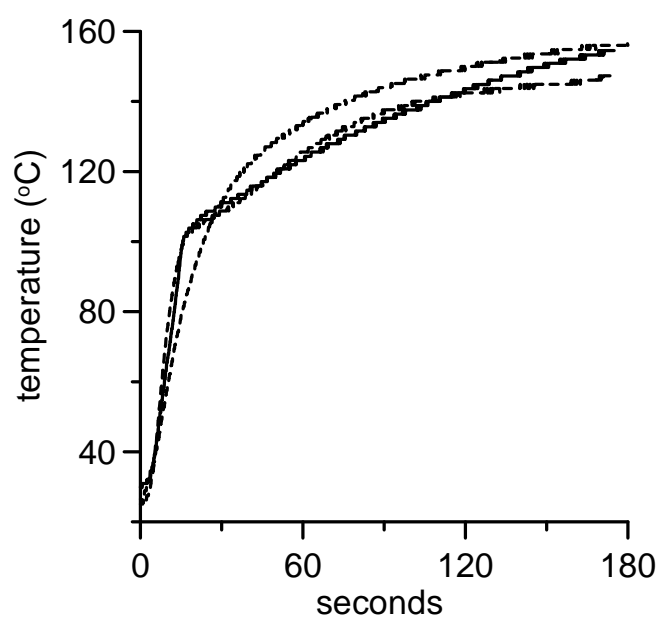

Fig. 7. Temperature profiles from pine flakes. Field-dried: solid line. Labdried to $2.8 \% \mathrm{MC}$ (upper dashed curve) and $12.4 \% \mathrm{MC}$ (lower dashed curve). 


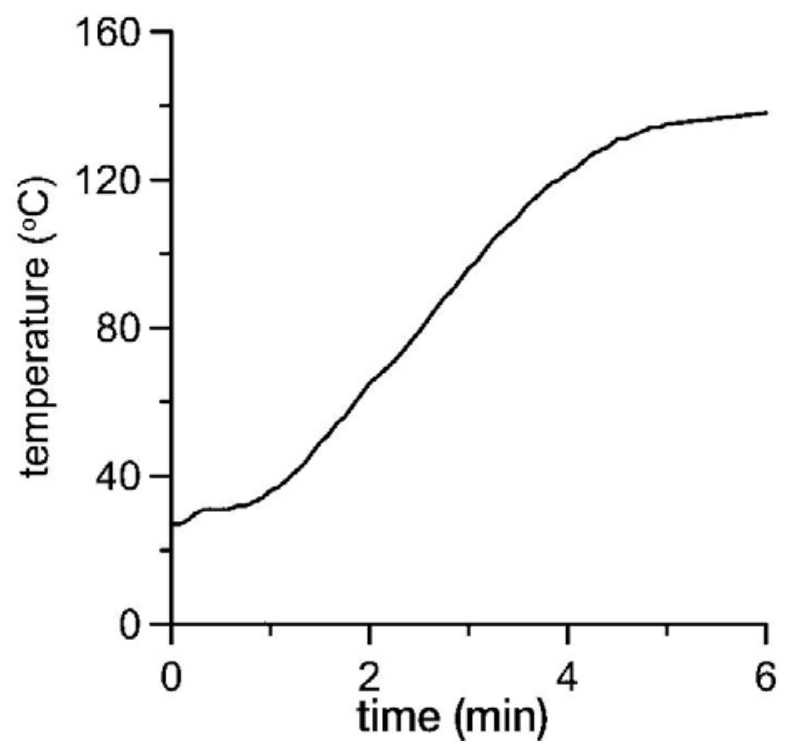

Fig. 8. Board core temperature during pressing. 


\title{
Mechanism of VOC Release from High-Temperature Southern Pine Lumber Drying
}

\author{
Wood Fiber Sci., 34, 666 (2002)
}

Terrance E. Conners, Extension Specialist in Forest Products, Department of Forestry, T.P. Cooper Building, University of Kentucky, Lexington, KY 40546.

Hui Yan, Assistant Scientist, and Sujit Banerjee, Professor, Institute of Paper Science and Technology, 500 Tenth St NW, Atlanta, GA 30318.

\begin{abstract}
Hydrocarbon (Method 25A) emissions from drying southern pine lumber have been measured in full-scale experiments. The mechanism proposed comprises three components: release of turpentine dissolved in the surface layer of water on the wood, water-mediated transport of turpentine from the interior of the wood to the surface, and evaporation of turpentine during the falling rate period. The result allows the total Method 25A release to be estimated without knowledge of the airflow through the kiln. Full-scale Method 25A emissions from lumber can be predicted from laboratory work on sawdust, indicating that the mechanism is independent of the type of furnish.
\end{abstract}

Keywords: VOCs, kiln drying, turpentine, pinene, Method 25A emissions

\section{Introduction}

The measurement and control of VOC emissions are of current interest since regulatory compliance is expensive. To date, the source of VOCs and the factors that govern their release have been addressed empirically, e.g. through study of the relationship between VOCs and operational parameters such as temperature and wood geometry (Shmulsky 2000 a,b,c; Shmulsky and Ingram 2000). Also, seasonal factors significantly affect the amounts of monoterpenes (the predominant VOC component) present in living southern pine trees (Conners et al. 2001).

Banerjee (2001) has shown that the concentration vs. time profile for VOC release from softwood flakes or particle has three regions. There is an initial burst very early in the drying process. The VOCs then emerge in a near-constant amount until the wood is almost dry, at which point the emissions increase. The location of the first peak is independent of dryer temperature, suggesting that it originates from surface material while the wood warms up. Pinene and water are then released in a near-constant ratio, which is ascribed to water mobilizing pinene from the interior of the wood matrix to the wet line. The surfactants present in wood are believed to solubilize pinene into water. Finally, pinene is lost through evaporation when the wood is almost dry. In this paper we demonstrate that this mechanism of VOC release applies to the commercial drying of lumber, and that emissions from lumber kilns can be estimated without knowledge of the airflow through the kiln.

\section{Experimental}

Southern pine lumber was dried in a relatively new commercial southern pine dry kiln in the Southeastern US. The wood was dried to a target MC of $14-14.5 \%$ through indirect heating 
with steam coils; the loads were mixed charges of $2 \times 10$ 's and $2 \times 12$ 's, with a volume of about 105,000 b.f. The dry bulb temperature was ramped up to $100^{\circ} \mathrm{C}$ in three hours and then gradually increased, reaching $115^{\circ} \mathrm{C}$ by the end of the run (about 17.5 hours). The vents were kept closed for the first four hours (i.e., the warm-up period plus one additional hour), and then the exhaust vents were opened fully for the duration of the run. The intake vents were kept closed throughout; hence the data collected generally represent actual changes in the kiln atmosphere resulting from lumber drying with minimal influence of external air infiltration.

Hydrocarbons emissions were measured during July and November 2000 with a JUM Model VE7 analyzer using Method 25A (Anonymous 1995) and are reported on an as-propane basis. The emissions were measured after diluting the kiln air sample with an equal amount of hydrocarbon-free air to minimize instrument problems caused by the high sample humidity. The sample to be analyzed was prepared by balancing (and then combining) the flows from the two separate gas input streams: (1) from the kiln atmosphere and (2) from the air tank. Air samples from within the kiln were also collected hourly in chilled methanol impingers, and the trapped $\alpha$ pinene was determined by gas chromatography. The condensed water was weighed to calculate the water:analyte ratio.

A trailer was sited adjacent to the kiln to house instrumentation, and sampling probes were inserted at breast height through two gasketed holes in the kiln wall to determine whether the air flow and/or sampling location might affect the measurements. One was placed close to the kiln entrance; the second was positioned at the middle of the kiln. Each probe was a 70-cm long piece of $0.6 \mathrm{~cm}$ copper tubing (preheated to over $200^{\circ} \mathrm{C}$ ) tipped with a fine mesh filter. Method 25A measurements were made continually at both locations; kiln air was sampled through heated lines to avoid condensation problems. The values from the two probes were almost identical, confirming that the kiln volume was well-mixed.

\section{Results and Discussion}

Emissions were measured during commercial dry kiln runs in July and November 2000, and representative profiles are illustrated in Figure 1. All runs were replicated, and the replicates within each sampling event agree very well. The November emissions are somewhat higher than those in July, possibly because of seasonal factors (Conners et al. 2001). Profiles of $\alpha$-pinene and water are illustrated in Figure 2; there is a remarkable mirror-image relationship. The high initial $\alpha$-pinene signal in Figure 1 is believed to reflect loss of surficial material, as discussed earlier for particle and flakes. $\alpha$-Pinene is then lost along with water at an approximately constant ratio from 5-13 hours. Finally, local overdrying occurs during the falling rate period and the VOCs rise as the water emissions taper off. Note that the pinene:water ratio (in Figure 2) after the vents are opened after four hours is approximately $0.1 \%$. This is the same value obtained earlier for laboratory measurements on particle (Banerjee 2001), and suggests that the same mechanism applies to both lumber and particles.

If the pinene released is $0.1 \%$-of the water lost from drying lumber, then $2.1 \mathrm{lbs} / \mathrm{Mbf}$ of $\alpha$-pinene would be released when lumber was dried from a moisture content of 100 to $15 \%$,. The final uptick in Figure 1 that reflects overdrying must now be added, and this increases emissions by about $35 \%$. $\alpha$-Pinene represents about two-thirds of the total turpentine emissions from 
southern pine, and therefore a value of $4.4 \mathrm{lbs} / \mathrm{Mbf}$ is calculated for Method 25A emissions after the vents were opened.

Emissions for the first four hours when the vents were closed can be estimated through the following analysis. The emissions will principally occur through leaks as the air within the kiln expands from an ambient temperature to $100^{\circ} \mathrm{C}$. The VOC concentration in the commercial kiln averages about 2,000 ppm during the first four hours, and the kiln volume less the volume of the wood is approximately 52,000 cu ft. Heating this volume from ambient temperature (say $30^{\circ} \mathrm{C}$ ) to $100^{\circ} \mathrm{C}$ expands it by $23 \%$. The amount of VOC contained in this volume is 0.5 $\mathrm{lbs} / \mathrm{MBf}$. If this is added to the emissions estimated for the remainder of the kiln cycle, then an overall value of $4.9 \mathrm{lbs} / \mathrm{MbF}$ or $3.9 \mathrm{lbs} /$ dry ton results, which compares well with results from a recent multi-facility study on lumber drying (Otwell, 2001). Importantly, the calculation does not consider airflow at all. Airflow is notoriously difficult to measure in the field since the vents open and close periodically and the volume of air released varies continuously.

Except for the initial spike, the emissions are normalized with respect to the water lost. Hence, the contribution of leaks is relatively unimportant, since the calculation does not consider how the emissions leave the kiln, only that it does so. Key features of the approach are that the VOCs and the water in the headspace are uniformly distributed, and that pinene is released as a constant fraction of water for most of the drying cycle. There are two major sources of variability. The $0.6 \mathrm{lbs} / \mathrm{Mbf}$ value for the initial closed-vent period is load-specific. It, and the $35 \%$ adjustment for the final uptick will depend on factors such the kiln layout, drying conditions and final moisture content. It is important to remember that the basis of the calculation, the $\alpha$ pinene:water ratio of $0.1 \%$ was derived from laboratory work with sawdust and can also be applied to emissions from drying OSB furnish (Banerjee 2001). Hence, the mechanism of VOC emissions from wood seems to be similar across furnish types.

\section{Conclusions}

A mechanism for VOC emissions developed from laboratory work on particle and flake was successfully applied to full-scale emissions from drying softwood lumber. There is an initial VOC surge as the wood heats up and surficial terpenes are released. The VOCs then leave as a constant fraction of the water lost until the falling rate period is reached, Portions of the wood then over dry and release additional VOC. Emissions estimated from these mechanistic considerations agree well with full-scale field data. This allows us to estimate VOC releases without measuring airflow, which is very difficult to measure in the field.

\section{Acknowledgements}

This study was funded by the Department of Energy through contract DE-FCO796IDI3439. This is manuscript number 01-09-130 and is approved for publication by the Director of the Agricultural Experiment Station at the University of Kentucky. 


\section{References}

Anonymous. Method 25A - Determination of Total Gaseous Organic Concentration using a Flame Ionization Analyzer, 40CFR Part 60, 870-872, August 1, 1995.

Banerjee, S. 2001. Mechanisms of terpene release during sawdust and flake drying. Holzforschung 55(4):413-416.

Conners, T.E., L.L. Ingram, W. Su, S. Banerjee, A.T. Dalton, M.C. Templeton, and S.V. Diehl. 2001. Seasonal variation in southern pine terpenes. Forest Products J. 51(6):89-94.

Otwell, L.P. 2001. Georgia-Pacific Corporation, personal communication.

Shmulsky, R. 2000a. Influence of lumber dimension on VOC emissions from kiln-drying loblolly pine lumber. Forest Products Journal 50(3):63-66.

Shmulsky, R. 2000b. Influence of drying schedule on VOC emissions from kiln-drying loblolly pine lumber. Forest Products Journal 50(4):45-48.

Shmulsky, R. 2000c. End grain influence on VOC emissions from kiln-drying loblolly pine. Forest Products Journal 50(5):21-23.

Shmulsky, R., and L.L. Ingram Jr. 2000. Empirical prediction of VOC emissions from drying southern yellow pine lumber. Forest Products Journal 50(6):61-63. 


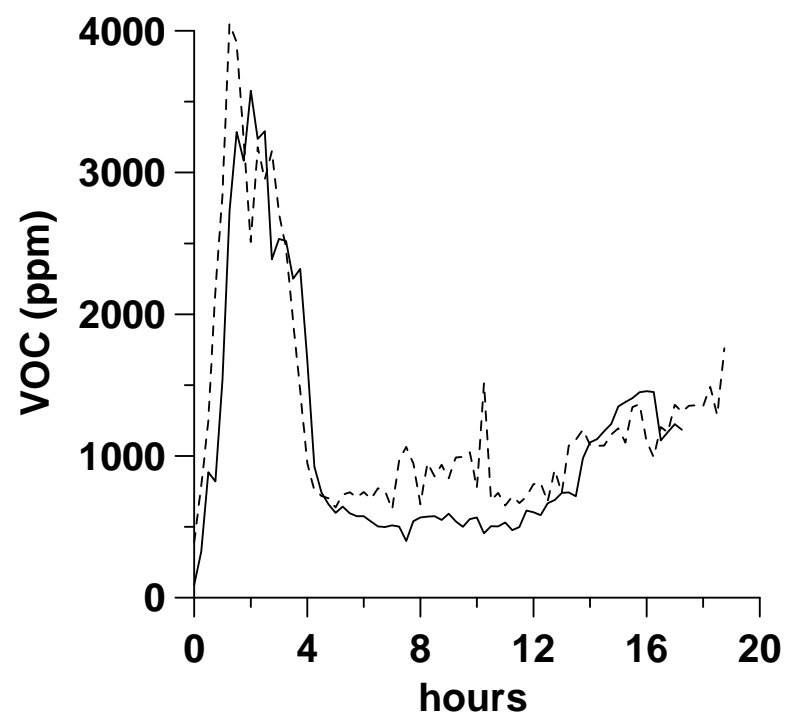

Figure 1. Method 25A profiles collected in July 2000 (bold) and November 2000 (dashed).
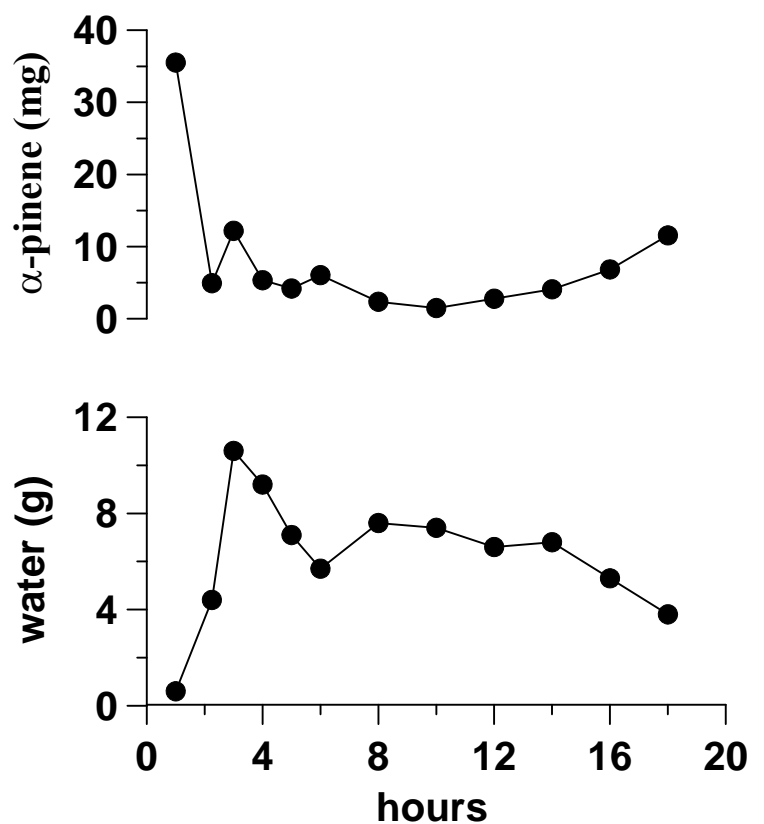

Figure 2. Pinene and water profiles collected in July 2000. 


\title{
Method for lowering the VOCs emitted during drying of wood products
}

\author{
S. Banerjee, J. Boerner W. Su, US patent 6,365,240 (2002)
}

\begin{abstract}
The present invention is directed to a method for removal of VOCs from wood products prior to drying the wood products. The method of the invention includes the steps of providing a chamber having an opening for receiving wood and loading the chamber with green wood. The wood is loaded to an extent sufficient to provide a limited headspace in the chamber. The chamber is then closed and the wood is heated in the chamber for a time and at a temperature sufficient to saturate the headspace with moisture and to substantially transfer VOCs from the wood product to the moisture in the headspace.
\end{abstract}

\section{Claims}

1. An undried, treated wood product which has a reduced level of VOCs, wherein the wood product has from about $50 \%$ to about $130 \%$ final moisture by weight.

2. A wood product in accordance with claim 1 wherein from about $20 \%$ to about $90 \%$ of the VOCs have been removed from said wood product as compared to a green wood product.

3. A wood product in accordance with claim 1 wherein said wood product is selected from the group consisting of dimension lumber, particles, oriented strand board particles and veneers.

4. A wood product in accordance with claim 3 wherein said wood product comprises dimension lumber.

5. A wood product in accordance with claim 3 wherein said wood product comprises particles.

6. A wood product in accordance with claim 3 wherein said wood product comprises oriented strand board particles.

7. A wood product in accordance with claim 3 wherein said wood product comprises veneers. 


\title{
Method for distributing chemicals through a fibrous material using low-headspace dielectric heating
}

S.Banerjee, E. Malcolm, US patent 6,436,486 (2002)

\begin{abstract}
System and method for diffusing chemicals rapidly and evenly into and through fibrous material, such as wood. Chemicals are introduced into the fibrous material by applying the chemicals to the fibrous material. After treating the fibrous material with the chemicals, the fibrous material is maintained under low-headspace conditions. Thermal energy or dielectric heating, such as microwave or radio frequency energy, is applied to the fibrous material. As a result, the chemicals are able to distribute evenly and quickly throughout the fibrous material.
\end{abstract}

\section{Claims}

1. An improved method for diffusing a chemical into a fibrous material, comprising the steps of: (a) applying a chemical to a fibrous material; (b) placing the fibrous material in a lowheadspace environment; and (c) irradiating the fibrous material with dielectric heat until the chemical is diffused into the fibrous material.

2. The method of claim 1, wherein the fibrous material is selected from a group consisting of softwood, hardwood, bamboo, papyrus, paper, and straw.

3. The method of claim 1, wherein the dielectric heat is microwave energy.

4. The method of claim 1, wherein the dielectric heat is radio frequency energy.

5. The method of claim 1, wherein the low-headspace environment inhibits evaporation of water from the fibrous material.

6. The method of claim 5, wherein the low-headspace environment allows at most about twenty percent evaporation of water from the fibrous material.

7. The method of claim 1, wherein step (a) comprises applying the chemical to at least one surface of the fibrous material.

8. The method of claim 1, wherein steps (a) and (b) comprise immersing the fibrous material in the chemical.

9. The method of claim 1, wherein step (b) comprises covering the fibrous material with an object that inhibits evaporation of water from the fibrous material.

10. The method of claim 9 , wherein the object is plastic.

11. The method of claim 1 , wherein step (b) comprises placing the fibrous material in a low- 
headspace dielectric heater.

12. The method of claim 1, wherein step (b) comprises filling a dielectric heater with the fibrous material such that the amount of space remaining within the dielectric heater inhibits evaporation of water from the fibrous material.

13. The method of claim 1 , wherein the chemical is white liquor.

14. The method of claim 1 , wherein the chemical is a catalyst used for pulping the fibrous material.

15. The method of claim 14, wherein the catalyst is a sulfur-derived compound.

16. The method of claim 15 , wherein the sulfur-derived compound is sodium sulfide.

17. The method of claim 15 , wherein the preservative is a borate compound.

18. The method of claim 15 , wherein the preservative is a chromium compound.

19. The method of claim 1 , wherein the chemical is an anthraquinone.

20. The method of claim 1 , wherein the chemical is a preservative used for preserving the fibrous material.

21. The method of claim 1 , wherein step (a) comprises spraying the chemical on the fibrous material.

22. An improved method for diffusing a chemical into a fibrous material, comprising the steps of: (a) applying a chemical to a fibrous material; (b) placing the fibrous material in a lowheadspace environment; (c) irradiating the fibrous material with thermal heat; and (d) irradiating the fibrous material with dielectric heat until the chemical is diffused into the fibrous material.

23. The method of claim 22 , wherein the fibrous material is selected from a group consisting of softwood, hardwood, bamboo, papyrus, paper, and straw.

24. The method of claim 22 , wherein the dielectric heat is microwave energy.

25. The method of claim 22 , wherein the dielectric heat is radio frequency energy.

26. The method of claim 22, wherein the low-headspace environment inhibits evaporation of water from the fibrous material.

27. The method of claim 26, wherein the low-headspace environment allows at most about twenty percent evaporation of water from the fibrous material.

28. The method of claim 22, wherein step (a) comprises applying the chemical to at least one 
surface of the fibrous material.

29. The method of claim 22, wherein step (b) comprises covering the fibrous material with an object that inhibits evaporation of water from the fibrous material.

30. The method of claim 29 , wherein the object that inhibits evaporation of water from the fibrous material is plastic.

31. The method of claim 22, wherein step (b) comprises placing the fibrous material in a lowheadspace dielectric heater.

32. The method of claim 22, wherein step (b) comprises filling a dielectric heater with the fibrous material so that the amount of space remaining within the dielectric heater inhibits evaporation of water from the fibrous material.

33. The method of claim 22, wherein the chemical is white liquor.

34. The method of claim 22 , wherein the chemical is a catalyst used for pulping the fibrous material.

35. The method of claim 34 , wherein the catalyst is a sulfur-derived compound.

36. The method of claim 35, wherein the sulfur-derived compound is sodium sulfide.

37. The method of claim 22, wherein the chemical is an anthraquinone.

38. The method of claim 22 , wherein the chemical is a preservative used for preserving the fibrous material.

39. The method of claim 22, wherein step (a) comprises spraying the chemical on the fibrous material. 


\title{
Heat transfer model for estimating pinene emissions from hot-pressing softwood flakeboard
}

This paper was published in Holzforschung, 58, 384 (2004).

Jayaprakash S. Radhakrishnan and Sujit Banerjee*

*Institute of Paper Science \& Technology and School of Chemical \& Biomolecular Engineering, Georgia Institute of Technology, 500 Tenth St NW, Atlanta, GA 30332-0620, USA. FAX: (404)894-4778. email: sujit.banerjee@ipst.gatech.edu

\begin{abstract}
A heat transfer model for estimating pinene emissions from hot-pressing strand for the manufacture of flakeboard has been constructed from first principles and validated. The model predicts $\alpha$-pinene emissions of $0.4 \mathrm{~kg} / 1000 \mathrm{~kg}$ for a 0.95 - $\mathrm{cm}$ board, which is within the $0.3-0.6$ $\mathrm{kg} / 1000 \mathrm{~kg}$ range reported for commercial operations. Most of the emissions originate from the hot 1-mm layer of wood adjoining the platen surface. As a result, residual pinene in the board is depleted at the surface for both commercial and laboratory-prepared boards. Emissions are drastically reduced when the mat is surfaced with a layer of aspen.
\end{abstract}

Keywords: aspen, emissions, flakeboard, heat-transfer, hot-pressing, model, pinene, platen, strand, surface, VOC

\section{Introduction}

Oriented strand board and particleboard are made by mixing resin with dry flakes or particle, respectively, and hot-pressing a mat prepared from the resinated wood. Terpenes, principally $\alpha$-pinene, are the main volatile organic compounds (VOCs) released from pressing softwood. Methanol, formaldehyde, acetaldehyde, propionaldehyde, and other compounds are released in much smaller quantities, but are important and are regulated separately as "Hazardous Air Pollutants" or HAPs (Jiang et al. 2002). The terpenes are lost through simple evaporation (Banerjee 2001). Hence, terpene emissions must relate to parameters such as the rate of heat transfer and wood porosity. In this paper we develop and validate a simple heat transfer model for the release of pinene during hot-pressing strand.

\section{Materials and Methods}

Green pine flakes were oven-dried at $105^{\circ} \mathrm{C}$ to a dry-basis moisture content of about $8 \%$. The flakes were trimmed to approximately $2 \times 10 \mathrm{~cm}$ and mixed with GP145C 48 core PF resin (from Georgia-Pacific) at $2.75 \%$ of oven-dried wood mass. A known weight (15 or $20 \mathrm{~g}$ ) of the dried flakes was oriented into $11 \times 11 \times 1-\mathrm{cm}$ mats containing between six and eight flakes in the $\underline{z}$ direction. Each mat was inserted into a foil bag constructed from $0.005-\mathrm{cm} 309$ highchromium stainless steel and fitted with air intake and outflow tubes as described earlier (Martino et al. 2002). The bag was sealed and placed between the heated $\left(210{ }^{\circ} \mathrm{C}\right)$ top platen $(15$ $\mathrm{x} 15 \mathrm{~cm})$ and lower cold $\left(110^{\circ} \mathrm{C}\right)$ platen of an electrohydraulic press. This arrangement simulates half of the mat in an industrial press where heat is applied from both platens. The mat was pressed at $1500 \mathrm{kPa}$ for $3 \mathrm{~min}$. The final (dry basis) moisture content (MC) was less than $1 \%$. 
Airflow of $0.3 \mathrm{lpm}$ was maintained through the bag during pressing and for 4 mins thereafter, and the emissions were vented through heated aluminum tubing $\left(165^{\circ} \mathrm{C}\right)$ into $25 \mathrm{ml}$ of chilled acetone. The trap solvent was then analyzed by gas chromatography (gc). Breakthrough was measured by placing a second trap after the first; carryover was insignificant. For the experiments with a pine core and an aspen surface, either 12 or $15 \mathrm{~g}$ of pine flakes were sandwiched between 4 or $5 \mathrm{~g}$ of aspen flakes, respectively, so that aspen constituted $25 \%$ of the total furnish.

The pinene content of the wood tissue in oriented strand board (OSB) was determined using several sheets obtained from a local hardware store and from boards pressed in the laboratory. The commercial board was very lightly sanded, and a $10 \times 10 \mathrm{~cm}$ square was cut from the center of each board. Surface and core material was filed out and the filings soaked in acetone overnight and analyzed by gc.

\section{Results and Discussion}

Modeling the release of pinene during hot-pressing

Terpenes are released from the mat during pressing due to the differential vapor pressure created by the temperature gradient. The amount of terpenes released depends on the temperature distribution within the mat, and thus on the heat transfer to the mat. The diffusion of terpenes from an OSB mat during pressing can be modeled using simple heat and mass transfer considerations. For diffusion in solids, the diffusion depth, the effective thickness of penetration of the diffusing species during time $(\mathrm{t})$, is given by Eq. 1.

$$
z_{i}=4 \sqrt{D_{i} t}
$$

where $D_{i}$ is the diffusion coefficient of the diffusing species (Bird et al.1994).

$\alpha$-Pinene is the principal terpene released from softwood (Cronn et al.1983) and is used as a representative compound in this study. Its $D_{i}$ value for diffusion in wood is not available, and the following approximations were made to arrive at an estimate. The diffusion coefficient of water vapor, $D_{w}$, has been reported to be $3.8 \times 10^{-10} \mathrm{~m}^{2} \mathrm{~s}^{-1}$ and $4.9 \times 10^{-10} \mathrm{~m}^{2} \mathrm{~s}^{-1}$, respectively for Scots pine heartwood and sapwood at $60^{\circ} \mathrm{C}$, respectively (Sehlstedt-Persson 2001). Since our mat was principally composed of sapwood, the second value is more appropriate for our application. The diffusion coefficient of a gas in a porous medium is given by Eq. (2)

$$
D_{A}=\frac{d}{3}\left(\frac{8 R T}{\pi M_{A}}\right)^{\frac{1}{2}}
$$

where $\mathrm{d}$ is pore diameter, $\mathrm{R}$ is the gas constant, $T$ is absolute temperature, and $\mathrm{M}_{\mathrm{A}}$ represents the molecular weight of the gas (Treybal 1980).

Thus, for diffusion of two different gases through the same medium we get 


$$
\frac{D_{2}}{D_{1}}=\left(\frac{T_{2}}{T_{1}} \frac{M_{1}}{M_{2}}\right)^{\frac{1}{2}}
$$

where $D_{1}$ and $D_{2}$ are the diffusivities of species 1 and 2 respectively. The diffusivity of water is $4.9 \times 10^{-10} \mathrm{~m}^{2} \mathrm{~s}^{-1}$ at $60{ }^{\circ} \mathrm{C}$ as noted above, from which we obtain $1.9 \times 10^{-10} \mathrm{~m}^{2} \mathrm{~s}^{-1}$ for the diffusion coefficient of $\alpha$-pinene in wood at $100{ }^{\circ} \mathrm{C}$. This temperature was chosen, since water from the wood matrix and the resin formulation evaporates during pressing. The actual mat temperature varies with time and location, but a small change in temperature does not materially affect the results.

Equation (1) predicts an effective diffusion depth of $0.77 \mathrm{~mm}$ for $\alpha$-pinene in wood for a three-minute press cycle, which means that most of the terpenes are lost from the surface layer. For these small depths, heat transfer is controlled by slow conduction near the surface and the mat can be assumed to be semi-infinite in our calculations. At the onset of pressing, the surface of the mat is exposed to a temperature of typically $200{ }^{\circ} \mathrm{C}\left(\mathrm{T}_{\mathrm{s}}\right)$. The temperature distribution in the mat near the surface as a function of time and depth can be obtained by solving the transient one-dimensional heat equation

$$
\frac{\partial T}{\partial t}=\alpha \frac{\partial^{2} T}{\partial z^{2}}
$$

where $\alpha$ is the thermal diffusivity of the mat $\left(1.17 \times 10^{-7} \mathrm{~m}^{2} / \mathrm{s}\right)$ (Simpson and TenWolde 1999) and $z$ is the depth from the surface in meters subject to the following initial and boundary conditions: $\mathrm{T}=\mathrm{T}_{0}$ at $\mathrm{t}=0, \mathrm{~T}=\mathrm{T}_{\mathrm{s}}$ (surface temperature) at $\mathrm{z}=0$, and $\mathrm{T}=\mathrm{T}_{0}$ at $\mathrm{z} \rightarrow \infty$. The last condition is based on the assumption that the mat is semi-infinite compared to the small diffusion depth under consideration and the time of heating in the experiment (3-minutes) is too small to cause large temperature changes inside the mat due to the low thermal conductivity of wood. A schematic is provided in Figure 1.

The temperature profile within the mat at any time, $\mathrm{T}(\mathrm{z}, \mathrm{t})$, is obtained by solving the above equation with the corresponding initial and boundary conditions using a combination of variables technique (Bird et al.1994).

$$
T(z, t)=T_{0}+\left(T_{s}-T_{0}\right) \operatorname{erf}(\eta)
$$

where $\quad \eta=\frac{z}{\sqrt{4 \alpha t}}$

The function $\operatorname{erf}(\eta)$ is the error function defined by Eq. 7.

$$
\operatorname{erf}(\eta)=\frac{2}{\sqrt{\pi}} \int_{0}^{\eta} e^{-\eta^{2}} \mathrm{~d} \eta
$$


Equation 5 is only valid for very small thicknesses near the surface and over small time intervals. The time-averaged temperature at a particular depth can be obtained by integrating the instantaneous temperatures given by Eq. 5 with respect to time, for a given value of $\mathrm{z}(0.7 \mathrm{~mm})$ over the $180 \mathrm{~s}$ time interval. The average temperature at the surface layer was found to be $169^{\circ} \mathrm{C}$ using graphical integration and assuming $\mathrm{T}_{0}=25^{\circ} \mathrm{C}$. The average diffusivity of the surface layer can be calculated from the time-averaged temperature as an approximation. The magnitude of change in diffusivity is less than the change in the temperature causing it. The change in diffusivity due to the maximum possible temperature rise (from room temperature to the peak surface layer temperature of $183^{\circ} \mathrm{C}$ ) is only $20 \%$ and thus, this assumption is valid. From Eq. 3 , the average diffusion coefficient of $\alpha$-pinene at the surface is calculated to be $2.05 \times 10^{-10} \mathrm{~m}^{2} \mathrm{~s}^{-1}$.

The pinene flux from the surface layer can be calculated by solving the one-dimensional transient mass transfer equation for a stationary medium (Fick's second law) (Bird et al. 1994) assuming a semi-infinite solid with constant surface concentration and an infinite supply of the diffusing species. These assumptions are justified because the diffusion of terpenes in wood is very slow. The mass transfer equation is solved with the necessary boundary conditions (Crank 1983). The flux (moles of terpene diffused per time per area) is given by

$$
j=\sqrt{\frac{\mathrm{D}_{\mathrm{eff}}}{\pi \mathrm{t}}}\left(c_{0}-c_{\infty}\right)
$$

where $\mathrm{D}_{\text {eff }}$ is the effective diffusivity of terpenes through the wood, $\mathrm{c}_{0}$ represents the concentration of terpenes at the layer under consideration (given by the vapor pressure), and $\mathrm{c}_{\infty}$ is the concentration of terpenes at the surface (taken to be zero). Integrating Eq. 8 over time from $t=0$ to $\mathrm{t}_{0}$, the press time, gives the total terpenes released per unit area.

$$
J_{T O T}=\sqrt{\frac{4 \mathrm{D}_{\mathrm{eff}} t_{0}}{\pi}}\left(c_{0}-c_{\infty}\right)
$$

The vapor pressure of $\alpha$-pinene is related to temperature through Eq. 10

$$
\mathrm{P}=1.578 \times 10^{10} \exp \{-5146 / \mathrm{T}\}
$$

which was fitted to experimental data (Perry and Green 1985). P represents vapor pressure in Pa and $\mathrm{T}$ is the absolute temperature $(\mathrm{K})$. The equation is nonlinear and the average vapor pressure cannot be calculated from the average temperature of the layer. Instead, instantaneous vapor pressure values were calculated at different time intervals for $\mathrm{t}=0$ to $180 \mathrm{~s}$ using the corresponding temperature values obtained from equation 5, and the average vapor pressure determined by graphical integration of the vapor pressure values. Thus, the time-averaged vapor pressure of $\alpha$ pinene is $153 \mathrm{kPa}$, which corresponds to a molar concentration of $41.8 \mathrm{~mol} \mathrm{~m}^{-3}$, assuming ideal gas behavior. Substituting this value in Eq. (9) gives a molar flux of $\mathrm{J}_{\mathrm{TOT}}=9.07 \times 10^{-3} \mathrm{~mol} \mathrm{~m}^{-2}$.

The diffusion from the interior of the mat contributes minimally to the overall pinene release due to the slow diffusion of pinene and the thickness of the mat. Diffusion from the body of 
the mat is slow, and can be approximated as a steady state process. The contributions from the surface layer and the body of the mat in terpene emissions can be modeled separately. The pinene released from the core can be estimated from the time and thickness-averaged temperature of the mat, since the temperature variation is not large. The average temperature of a mat cross-section of known thickness, subjected to constant surface temperatures on both sides, $\mathrm{T}_{<\mathrm{z}>}(\mathrm{t})$, is given by Eq. (11).

$$
T_{<\mathrm{Z}>}(t)=T_{s}-\left(T_{s}-T_{0}\right) \frac{8}{\pi^{2}} \exp \left(-\left(\frac{\pi}{2}\right)^{2} \frac{\alpha t}{s^{2}}\right)
$$

where $s$ is the half-thickness of the mat (McCabe et al 1993). The time and thickness - averaged temperature of the mat over the width $(2 \mathrm{~s})$ and duration of pressing $\left(t_{0}\right)$ is obtained by integrating equation (11) from $t=0$ to $t_{0}$, and is given by Eq. (12)

$$
T_{<z, t>}=T_{s}-\frac{\left(T_{s}-T_{0}\right)}{t_{0}} \frac{32 s^{2}}{\pi^{4} \alpha}\left\{1-\exp \left(-\left(\frac{\pi}{2}\right)^{2} \frac{\alpha t_{0}}{s^{2}}\right)\right\}
$$

The average temperatures obtained from Eq. 12 can be used to calculate the pinene flux in the body of the mat since the temperature variations inside the mat is much smaller than those near the surface. The average temperature of a $9.5 \mathrm{~mm}$ mat during a press cycle of $3 \mathrm{~min}$ is calculated to be $144^{\circ} \mathrm{C}$. The corresponding vapor pressure is $69.6 \mathrm{kPa}$ from Eq. 10. The amount of terpenes diffusing from the interior to the surface is given by

$$
J_{T O T}=\frac{\mathrm{D}_{\mathrm{eff}}\left(c_{0}-c_{\infty}\right) t_{0}}{\overline{\mathrm{Z}}}
$$

where $\bar{Z}$ is the harmonic mean thickness of diffusion from the core to the surface. It is used as an approximation for diffusion in the body of the mat and is given by

$$
\frac{1}{\bar{z}}=\frac{1}{\left(z_{2}-z_{1}\right)} \int_{z_{1}}^{z_{2}} \frac{1}{z} d z
$$

where $\mathrm{z}_{1}$ is the thickness at the surface layer $(0.7 \mathrm{~mm})$ and $\mathrm{z}_{2}$ is the thickness at the core $(\mathrm{s})$. Equation 13 gives the average amount of terpenes diffusing from the center. From the above equations, the total amount of $\alpha$-pinene diffusing from the core is found to be $3.41 \times 10^{-4}$ mol m$~^{-2}$, which is only about $4 \%$ of the total emissions.

Diffusion from the mat edges was neglected since there is no temperature gradient and thus, no concentration gradient across the horizontal axes. Thus the driving force for diffusion through the edges is much lower than that through the surfaces. For a mat density of $650 \mathrm{~kg} \mathrm{~m}^{-3}$ (Humphrey and Bolton 1989), the combined $\alpha$-pinene emission from the core and both surfaces 
is $2.56 \mathrm{~g} \mathrm{~m}^{-2}$ of wood, or $0.41 \mathrm{~kg} / 1000 \mathrm{~kg}$ as calculated from the model. The data in Table 1 are for $121 \mathrm{~cm}^{2}$ surfaces of boards weighing an average of $17.5 \mathrm{~g}$, which translates to an average $\alpha$ pinene emission of $0.8 \mathrm{~g} \mathrm{~m}^{-2}$. However, only one side of the board is heated, whereas both sides would contact the hot platen in commercial practice. The emissions should, therefore, be doubled to $1.6 \mathrm{~g} \mathrm{~m}^{-2}$, which is $63 \%$ of the model-derived value of $2.56 \mathrm{~g} \mathrm{~m}^{-2}$. The estimate also compares well with field data reported at $2 \times 10^{-3}-4.0 \times 10^{-3} \mathrm{~kg} / \mathrm{m}^{-2}$ (or $0.3-0.6 \mathrm{~kg} / 1000 \mathrm{~kg}$ ) for two southern pine strand presses (Crawford and Word 1999). Hence, our model is able to account for press emissions without using any parameters fitted to the emissions data.

It follows from our arguments that the pinene emissions should be greatly suppressed if the top layer of the mat was replaced with a hardwood such as aspen. The width of an aspen flake is approximately $0.7 \mathrm{~mm}$, which is comparable to the diffusion depth of $0.77 \mathrm{~mm}$. Hence, one layer of aspen should "insulate" the mat for terpene emissions. Table 2 lists the amount of $\alpha$ and $\beta$-pinenes released during pressing of the pine/aspen mats against an all-pine control. Emissions from the all-pine boards in Table 2 are lower than those from Table 1 because of batch-tobatch variability in the wood. Pressing mats with aspen on the surface leads to a $60-69 \%$ reduction in pinene emission. This range is much higher than the $25 \%$ reduction expected on the basis of dilution of the softwood with hardwood, and provides strong support for the importance of the surface in governing pinene emissions.

Since terpene should be preferentially lost from the surface of a board during pressing, the terpene content in the finished product should be higher in the core. Results from the analysis of four commercially prepared boards and three laboratory-pressed boards are listed in Table 3 and are illustrated in Figure 2. The pinene content in the core is consistently higher than that in the surface, but there is considerable board-to-board variability. Some pinene must have evaporated from the commercial boards during storage, but this is unlikely to be significant, since the same trends are found in boards prepared in the laboratory which were analyzed immediately upon preparation. Knots and other resinous regions could have also contributed to the variability because they are unevenly distributed in wood. However, the major source of the variability is likely to be the sampling. The pinene gradient in the surface is very steep. A simulation of the flux over depth is illustrated in Figure 3. Some of the variability in the surface samples probably originates from uneven sampling.

Our model only applies to emission of terpene and not to all VOCs released from pressing. Substantial quantities of methanol, formaldehyde and other compounds are also released. Most of these compounds derive from the added resin (Wolcott et al. 1996; Jiang et al. 2002), but wood tissue degradation is also a significant source (Su et al.1999). These compounds are transported out of wood by the steam generated from the moisture in the mat.

In conclusion, terpene emissions from pressing flakes originate predominantly from the layer of wood adjoining the hot platen surface. Other potential mechanisms of pinene release such as loss of pinene through transport by steam are evidently not significant. A simple heat transfer model based on conduction of heat from the platens is able to estimate these emissions within the uncertainty of measurement. The terpene emissions depend predominantly on press time and platen temperature. The relationships in Figure 3 suggest that any means to reduce ei- 
ther variable should lead to significant VOC reductions. These could be achieved through strategies such as steam-injection pressing or preheating the furnish, e.g. with microwave.

\section{Acknowledgements}

This study was funded by the Office of Industrial Technology of the US Department of Energy.

\section{References}

Banerjee, S. 2001. Mechanisms of terpene release during sawdust and flake drying. Holzforschung 55:413-416.

Bird, R.B., W.E. Stewart and E.N. Lightfoot. 1994. Transport Phenomena. Wiley, New York. pp $354,558$.

Crank, J. 1983. The Mathematics of Diffusion. Oxford University Press, London. p 32.

Crawford, R.J. and D.H. Word. 1999. Volatile organic compound emissions from wood products manufacturing facilities; Part V - Oriented Strandboard, NCASI Technical Bulletin, no. 772 .

Cronn, D.R., S.G. Truitt and M.J. Campbell. 1983. Chemical characterization of plywood veneer drying emissions. Atmos. Environ. 17:201-211.

Humphrey, P.E. and A.J. Bolton. 1989. The hot pressing of dry-formed wood-based composites, Part II. A simulation model for heat and moisture transfer, and typical results. Holzforschung 43:199-206.

Jiang, T., D.J. Gardner and M.G.D. Baumann. 2002. Volatile organic compound emissions arising from the hot-pressing of mixed-hardwood particleboard. Forest Prod. J., 52(11/12): 66-77.

Martino, C.J., S. Shrauti, S.Banerjee, L.P. Otwell and E.W. Price. 2002. Flake drying temperature affects mat properties during pressing. Holzforschung 56: 558-562.

McCabe, W.L., J.C. Smith and P. Harriot. 1993. Unit Operations of Chemical Engineering, $5^{\text {th }}$ ed., McGraw-Hill Inc., Burr Ridge, IL, p 301.

Perry, R.H. and D.W. Green. 1985. Perry's Chemical Engineer's Handbook", 6th ed., McGrawHill. New York. p 3-58.

Sehlstedt-Persson, M. 2001. COST Action E15. Advances in the drying of wood (1999 - 2003). 3rd Workshop on Softwood Drying to Specific End-Uses. Helsinki, Finland, June 11-13, 2001.

Simpson, W., and A. TenWolde. The US department of Agriculture's Forest Service Forest Products Laboratory, Madison, WI, Wood Handbook (Wood as an engineering material). 1999.

Su, W., H. Yan, S. Banerjee, L.P. Otwell and M.E. Hittmeier. 1999. Field-proven strategies for reducing VOCs from hardwood drying Environ. Sci. Technol. 33:1056-1059.

Treybal, R.E. 1980. Mass Transfer Operations McGraw-Hill. p 97.

Wolcott J.J., W.K. Motter, N.K. Daisy, S.C. Tenhaeff and W.D. Detlefsen. 1996. Investigation of variables affecting hot-press formaldehyde and methanol emissions during laboratory production of urea-formaldehyde-bonded particleboard. Forest Prod. J. 46(9):62-68. 


\begin{tabular}{|c|c|c|}
\hline $\begin{array}{l}\text { Table } 1 . \\
\text { Sample }\end{array}$ & $\begin{array}{l}\text { emissions } \\
\alpha \text {-pinene }\end{array}$ & $\begin{array}{l}\text { from labo } \\
\beta \text {-pinene }\end{array}$ \\
\hline 1 & 519 & 51.0 \\
\hline 2 & 787 & 118 \\
\hline 3 & 439 & 32.0 \\
\hline 4 & 409 & 57.3 \\
\hline 5 & 449 & 130 \\
\hline 6 & 807 & 259 \\
\hline 7 & 680 & 129 \\
\hline 8 & 355 & 105 \\
\hline Average & 556 & 110 \\
\hline
\end{tabular}

Table 2. Effect of a surface layer of aspen on terpene emissions ( $\mu \mathrm{g} \mathrm{g}^{-1}$ wood) during hot pressing.

\begin{tabular}{lll}
\hline & $\alpha$-pinene & $\beta$-pinene \\
\hline $\begin{array}{l}\text { 16-g mats } \\
\text { pine only }\end{array}$ & $111(129,112,95.4)$ & $25.1(35.1,27.9,12.4)$ \\
pine and aspen & $36.1(35.1,44.1,29.2)$ & $9.2(8.7,11.8,7.1)$ \\
$\begin{array}{l}\text { reduction (\%) } \\
\text { 20-g mats }\end{array}$ & 67 & 63 \\
$\begin{array}{l}\text { pine only } \\
\text { pine and aspen } \\
\text { reduction }(\%)\end{array}$ & $48.3(49.5,50.7,46.1,47.1)$ & $11.0(12.2,12.1,9.5,10.3)$ \\
\hline
\end{tabular}

Table 3. Terpene content ( $\mu \mathrm{g} / \mathrm{g}$ in wood) in commercial and laboratory-pressed board.

\begin{tabular}{lcccccc}
\hline & \multicolumn{2}{c}{ Surface } & \multicolumn{2}{c}{ Core } & \multicolumn{2}{c}{ Core : Surface } \\
Board & $\alpha$-pinene & $\beta$-pinene & $\alpha$-pinene & $\beta$-pinene & $\alpha$-pinene & $\beta$-pinene \\
\hline \multicolumn{2}{l}{ Commercial board } & & & & & \\
1 & 9.98 & 0.97 & 28.4 & 2.72 & 2.9 & 2.8 \\
2 & 14.2 & 13.0 & 29.1 & 15.0 & 2.0 & 1.2 \\
3 & 21.7 & 13.8 & 25.9 & 15.6 & 1.2 & 1.1 \\
4 & 15.4 & 6.41 & 45.7 & 17.6 & 3.0 & 2.1 \\
Laboratory-pressed board & & & & & \\
1 & 34.4 & 19.9 & 50.7 & 56.5 & 1.7 & 2.8 \\
2 & 16.4 & 14.3 & 23.5 & 14.3 & 1.4 & 1.0 \\
3 & 27.5 & 19.2 & 46.2 & 39.8 & 1.7 & 2.1 \\
\hline
\end{tabular}




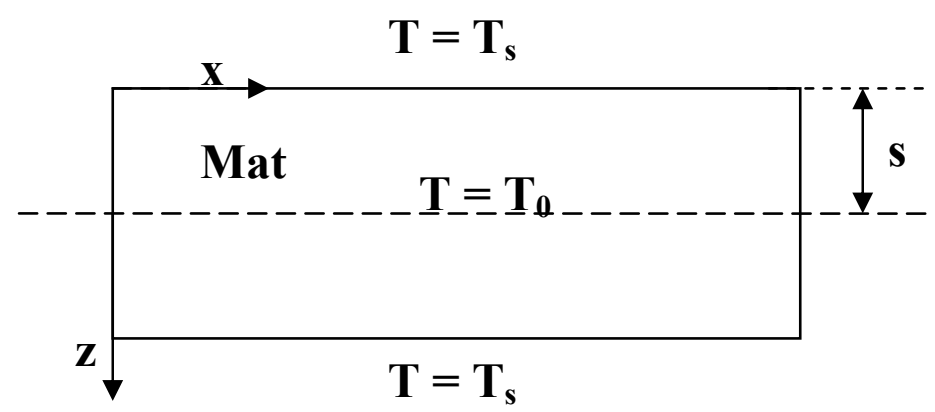

Fig. 1. Schematic of heat transfer to the mat.

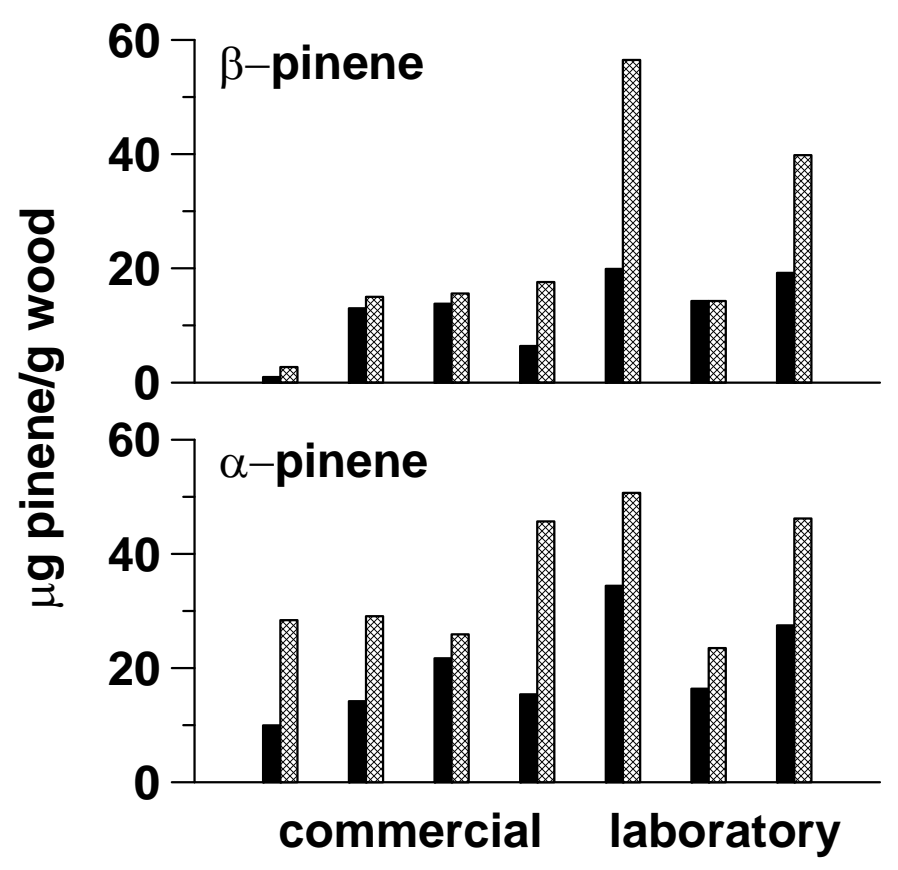

Fig. 2. Terpene content of wood after pressing. The solid and hatched bars are for the surface and core, respectively. The left four boards were obtained commercially; the three rightmost boards were prepared in the laboratory. 


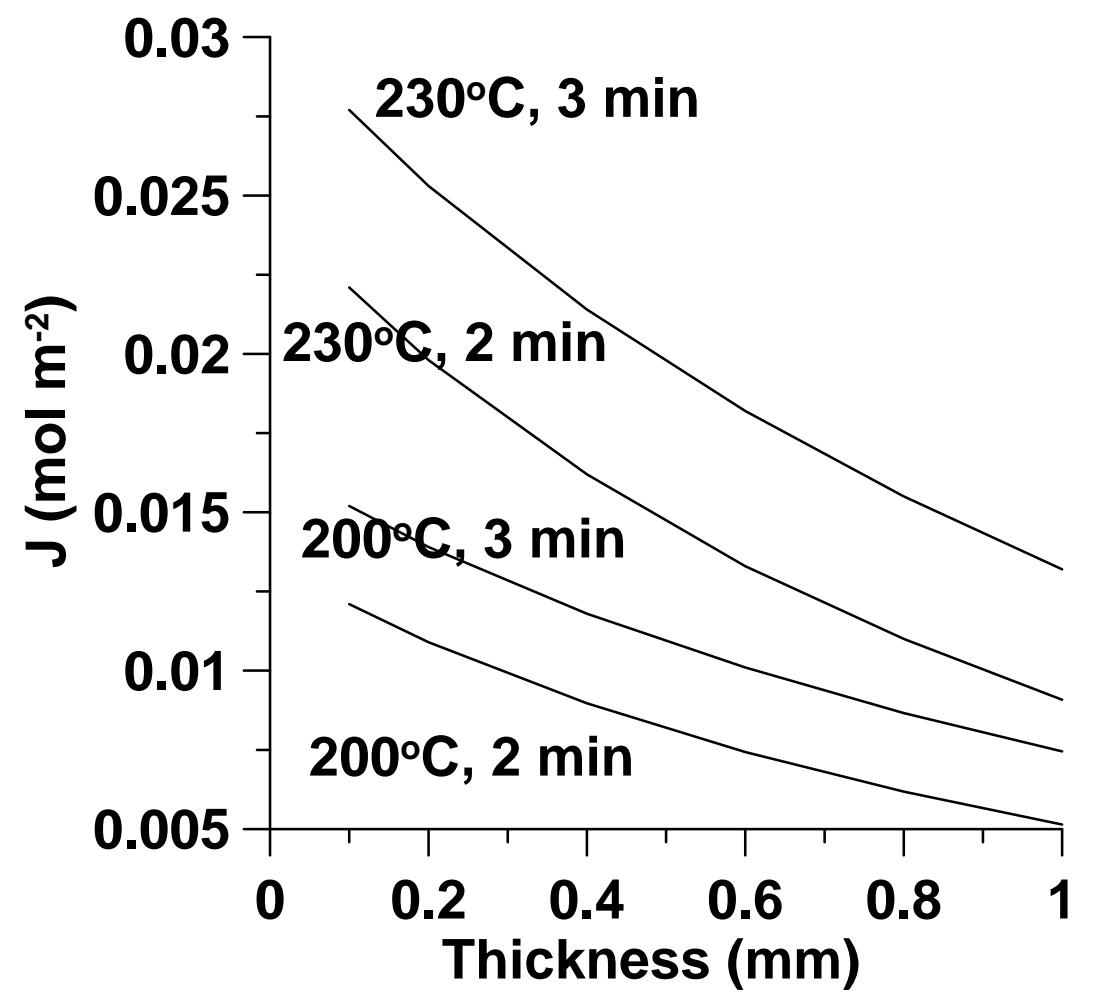

Fig. 3. Simulation of $\alpha$-pinene emissions from various depths from the surface exposed to the hot platen. 


\title{
Controlling Formaldehyde Emissions with Boiler Ash
}

\author{
Environ Sci. Technol. 39, 5101 (2005). \\ Jennifer Cowan, Malyuba Abu-Daabes, Sujit Banerjee* \\ Institute of Paper Science and Technology \& \\ School of Chemical \& Biomolecular Engineering \\ Georgia Institute of Technology \\ 500 Tenth Street NW \\ Atlanta, GA 30332-0620
}

\begin{abstract}
Fluidized wood ash reduces formaldehyde in air from about 20 to less than 1 ppmv. Methanol is removed to a much lower extent. The efficiency of formaldehyde reduction increases with increasing moisture content of the ash. Sorption of formaldehyde to ash can be substantially accounted for by partitioning to the water contained in the ash followed by ratecontrolling binding to the ash solids. Adsorption occurs at temperatures of up to $165^{\circ} \mathrm{C}$; oxidation predominates thereafter. It is proposed that formaldehyde could be stripped from an air stream in a fluidized bed containing ash, which could then be returned to a boiler to incinerate the formaldehyde.
\end{abstract}

\section{Introduction}

The engineered wood industry emits methanol and formaldehyde among other Hazardous Air Pollutants (HAPs) during drying and pressing operations and will be required to comply with the wood MACT rule (1) when it is finalized. Over one hundred relatively large facilities in the US will be subject to these regulations. Regenerative thermal (2) or catalytic (3) oxidizers are presently used to control HAPs and other VOCs. The natural gas cost of operating these units is high because the VOCs are present at low concentrations of about 20 ppmv (4) in large volumes $\left(\sim 1,500 \mathrm{~m}^{3} / \mathrm{min}\right)$ of air, which must be heated to oxidative temperatures. Biofilters (5-7) are used at some facilities (8), but they are capital- and space-intensive.

Removal of gaseous formaldehyde by adsorption has typically utilized activated carbon treated with various additives (9). Hydrophobic compounds are easily adsorbed, and a combination of adsorption and oxidation has been used to remove hydrophilic compounds such as methanol. In one example, methanol was adsorbed on nutshell carbon pre-oxidized to enhance its affinity for hydrophilic compounds (10). In another, methanol and other VOCs released from the manufacture of printed circuit boards were trapped and concentrated in activated carbon beds before being oxidized (11). VOCs have also been treated by polymer-coated zeolites (12) and polymeric membrane (13), but the large volumes of air involved in our application make these procedures cost-prohibitive.

One compliance option permitted under the proposed MACT rule (1) is to decrease either methanol or formaldehyde emissions to less than $1 \mathrm{ppmv}$. The engineered wood industry gener- 
ates energy by burning wood residues, and it seemed possible that the ash from these residues could be used to strip formaldehyde from the air stream. The ash contains unburned organic carbon (14) and it appeared likely that it would display some of the adsorptive properties of activated carbon. In this paper, we examine the feasibility of using wood ash from several facilities to remove formaldehyde from contaminated airstreams. Interest in these compounds is widespread and our findings should find application beyond the engineered wood industry.

\section{Experimental Section}

Ash was collected from the burner and the electrostatic precipitator (ESP) of the Norbord, Guntown, MS, mill. Other ash samples were provided by Bowater, Catawba, SC (bark burner), Georgia-Pacific mills at Skippers, VA (bark burner), Whiteville NC (plywood mill fly ash), and by Inland Container, Rome, GA mill (bark burner). Bulk density was determined from ash dried $\left(105^{\circ} \mathrm{C}\right)$ and sieved through a 3.4-mm screen. $\mathrm{pH}$ was measured from a settled suspension obtained by mixing $20 \mathrm{~g}$ of dry ash with $100 \mathrm{~mL}$ of water. The total carbon and inorganic carbon contents of the ashes were determined by coulometric titration (15); the organic carbon was then obtained by difference. The properties of the various ashes are summarized in Table 1 . The burner ash from Guntown was also ground in a ball mill for several hours. The particle size distribution of the ashes, determined by screening, appears in Table 2.

For the sorption experiments air was passed through ash placed in a glass bottle with a fritted glass base, which distributed the air and fluidized the ash. A cylinder of vacuum cleaner bag paper (closed at the top) was placed over the neck of the vessel to prevent fine ash particles from escaping. A stainless steel cylinder was then placed over the bag and onto a rubber spacer resting on the shoulders of the glass vessel. The cylinder was clamped to ensure a secure connection with the ash bed exhaust and was connected to the cell of an FTIR spectrometer (Midac Corporation, Irvine, CA) through a bulkhead fitting. The glass cylinder was heated to $105^{\circ} \mathrm{C}$ prior to beginning the experiment with heating tape; the temperature was controlled with a thermocouple placed between the heating tape and the glass. The stainless steel cylinder and tubing were also heat-traced to prevent condensation.

The feed solution was freshly prepared for each experiment by diluting $0.5 \mathrm{~mL}$ of formalin (an aqueous solution with 37\% formaldehyde and 15\% methanol) to $100 \mathrm{~mL}$. The solution was placed in a gas-washing bottle with a fritted glass impinger through which ultra zero grade air was passed at 2.0 L/min. Fluidized bed work was done with 150-170 g ash. The formaldehyde concentration in the feed stream was 16-21 ppmv, methanol was at 40-50 ppmv, and water constituted 3.5-3.7\%. Methanol, formaldehyde and carbon dioxide levels were continuously monitored by FTIR; the instrument was calibrated with standard permeation tubes (Precision Gas Standards Generator, Model 491M-B, Kin-Tek Laboratories, Inc, La Marque, TX). The limit of detection was about 0.1 ppmv for both methanol and formaldehyde. Spectra were acquired every 69 seconds.

Ash moisture content was measured just before each experiment. The effect of moisture on the degree of sorption of formaldehyde was studied with ash from Catawba and Guntown by adding water to the ash sample and mixing with a spatula. The wetted ash sample was sieved through a screen ( 25 mesh, $710 \mu$ openings) to break up any wet clumps and then shaken for several minutes. Some moisture loss occurred during the experiment; the moisture content of Ca- 
tawba ash $(30 \mathrm{~g})$ dropped from 2.9 to $1.3 \%$ when exposed to an $18.7 \mathrm{ppmv}$ formaldehyde feed stream at $110^{\circ} \mathrm{C}$ for 90 minutes.

The effect of temperature on desorption was determined with $30 \mathrm{~g}$ of Catawba ash preexposed to a $0.75 \mathrm{~L} / \mathrm{min} 20 \mathrm{ppmv}$ formaldehyde feedstream at $108^{\circ} \mathrm{C}$ for five hours. Clean air was then passed through the loaded ash at $0.75 \mathrm{~L} / \mathrm{min}$. The bed temperature was initially set at $116^{\circ} \mathrm{C}$, increased to $138^{\circ} \mathrm{C}$ after 48 minutes, and then to $165^{\circ} \mathrm{C}$ after 98 minutes.

\section{Results and Discussion}

The ash is ineffective for reducing methanol to our target concentration of 1 ppmv as shown by the results in Table 3. Formaldehyde is removed much more efficiently, as illustrated by the typical breakthrough curve shown in Figure 1; results for the sorption capacity of various ashes are summarized in Table 4. The relationship between initial moisture content and the sorption capacity at $105^{\circ} \mathrm{C}$ is illustrated in Figure 2. The Whiteville ash is an outlier, but this was also the only fly ash used. A complicating factor is that the ash moisture content changes over the course of the run, and any differences in the rate of moisture removal will add to the scatter. Nevertheless, moisture clearly increases the carrying capacity of the ash.

More direct evidence for the importance of water was obtained with the Guntown ESP ash. When used as received at a moisture content of $1.4 \%$ it lowered the formaldehyde concentration to $2.5 \mathrm{ppm}$. Increasing the moisture content to $4.5 \%$ decreased formaldehyde to less than 1 ppmv for nearly 40 minutes. Surprisingly, neither the carbon content nor the particle size of the ash seems to be important for trapping formaldehyde. Thus, our initial expectation that the carbon in unburned ash would mimic activated carbon was not borne out. The Skippers ash performs quite well despite its low organic carbon content of only $4.1 \%$. The carbon content of ash from Catawba and Whiteville was roughly equal, but while the Whiteville ash had the highest sorptive capacity, the Catawba ash had the lowest. Analogous results have been reported (16) in a study of formaldehyde adsorption to various activated carbons where the presence of hydrophilic $\mathrm{O}-\mathrm{H}, \mathrm{C}=\mathrm{O}, \mathrm{C}-\mathrm{O}$ groups on the surface exhibited the highest adsorption capacity for formaldehyde vapor. Activated carbon containing hydrophobic surface groups of $\mathrm{C}-\mathrm{H}, \mathrm{C}=\mathrm{C}$ adsorbed formaldehyde to a less extent. Hence, the hydrophilicity of the surface promotes the adsorption capacity, whereas the texture, surface area, and pore volume play a relatively minor role.

Consider the Figure 1 result where $150 \mathrm{~g}$ of ash at a moisture content of $1.4 \%$ reduces formaldehyde from a 20 ppmv feed stream to below the detection limit for 50 minutes. If the formaldehyde merely partitioned into the water in the ash and equilibrium is assumed, then an air:water Henry's Law Constant of $1.8 \times 10^{-6}$ atm m$~_{3}^{3} / \mathrm{mol}$ (at $105^{\circ} \mathrm{C}$ ) can be calculated if the formaldehyde is assumed to be present in air at the detection limit of $0.1 \mathrm{ppmv}$. The known Henry's Law Constant at $25^{\circ} \mathrm{C}$ is sixfold lower at $3.4 \times 10^{-7}$ atm- $\mathrm{m}^{3}$ mole (17). The disparity could derive from our assumption of $0.1 \mathrm{ppmv}$ for the concentration of formaldehyde and/or from the difference in temperature; a lower value is expected at the lower temperature. Alternatively, formaldehyde could interact differently with ash water and with pure water, giving rise to different Henry's Law Constants. Despite these uncertainties, the two values differ by less than on order of magnitude. 
The Henry's Law Constant reported for methanol is $4.6 \times 10^{-6} \mathrm{~atm} \mathrm{~m} / \mathrm{mol}(18)$, which is tenfold higher than that for formaldehyde. Hence, if stripping efficiency depended only on partitioning to the water contained in ash, then methanol should be stripped much less efficiently, as observed. The importance of water in influencing sorption has been noted by others. Gambaro (19) found that sorption of methanol to $\mathrm{V}_{2} \mathrm{O}_{5}$ only occurred when water was present in the sorbent, and suggested that the methanol was linked to the solid through water molecules.

Figures 1 and 3 profile the concentrations of formaldehyde and water, respectively, from the same experiment. The formaldehyde is retained for about fifty minutes in Figure 1, whereas the water peaks at about five minutes in Figure 3. If formaldehyde partitioning into ash water were the only process that was occurring, i.e. if the compound had no affinity for the ash itself, then its breakthrough would track that of water. Water is clearly necessary to hold the formaldehyde, as emphasized by the Figure 2 result and the other water-related measurements discussed earlier. The finding that the amount of formaldehyde removed is of the same magnitude as that expected from the Henry's Law Constant suggests that formaldehyde rapidly partitions into ash water. The observation that its breakthrough lags that of water must mean that formaldehyde binds to the ash after partitioning into the water layer. The binding to the ash solids must be ratecontrolling; otherwise the partitioning of formaldehyde to the ash water would not follow Henry's Law. Hence, it appears that formaldehyde partitions into particle-held water and then adsorbs to the surface of the ash particle while the water is being removed.

The adsorptive capacity of Catawba ash for formaldehyde at room temperature was measured to be $0.14 \mathrm{mg} / \mathrm{g}$ ash. This capacity decreased to about $0.002 \mathrm{mg} / \mathrm{g}$ ash at $105^{\circ} \mathrm{C}$. Profiles for the desorption of methanol and formaldehyde from loaded ash are shown in Figure 4; the carbon dioxide trace is illustrated in Figure 5. The carbon dioxide level rose sharply at $165^{\circ} \mathrm{C}$; it presumably came from formaldehyde which is known to thermally decompose at $150^{\circ} \mathrm{C}(20)$. No change in carbon dioxide occurred with increasing temperature when the ash alone was heated, confirming that the increased carbon dioxide in Figure 5 derived from the sorbed materials. A potential complication in interpreting the formaldehyde profiles is that the compound can be formed from the oxidation of methanol $(19,21)$. However, methanol is adsorbed to a much smaller degree than is formaldehyde (Table 3), and Figure 4 demonstrates that it is released at higher levels, so any conversion to formaldehyde should be quite small.

Our results demonstrate that boiler ash is able to remove formaldehyde from a contaminated airstream. Returning the loaded ash to the boiler would then incinerate the formaldehyde at the expense of a small increase in ash deadload. The technology should be more appropriate for press, rather than dryer emissions, because of the lower air volumes involved. The capital cost of a fluidized bed is much lower than that of a thermal oxidizer, and the cost of natural gas required to operate the oxidizer is removed. The ash handling is an additional cost, but the overall economics seem favorable. The application is not limited to the engineered wood industry but should extend to any situation where formaldehyde removal is required and ash handling facilities are available.

In conclusion, formaldehyde can potentially be stripped from an air stream through contact with boiler ash to incinerate the formaldehyde. Methanol would be removed to a much lower extent. The efficiency of collection increases with increasing ash moisture; the optimum 
moisture will probably be dictated by materials handling considerations. Typical temperatures of wood drying and pressing emissions are about $70-110^{\circ} \mathrm{C}$, so the formaldehyde would be mostly sorbed by the ash; the temperature will not be high enough to initiate oxidation. Reducing formaldehyde to below 1 ppmv would fully satisfy the regulatory limit for the proposed wood MACT rule (1).

\section{Acknowledgment}

We thank the Department of Energy for financial support under contract DE-FC36$01 \mathrm{GO} 10620$.

\section{Literature Cited}

1. U.S. EPA. National Emission Standards for Hazardous Air Pollutants: Plywood and Composite Wood Products, Effluent Limitations Guidelines and Standards for the Timber Products Point Source Category, List of Hazardous Air Pollutants, Lesser Quantity Designations, Source Category List, 2004.

2. Sauer, B.; Franklin, W.; Miner, R.; Word, D.; Upton, B. Environmental tradeoffs: life cycle approach to evaluate the burdens and benefits of emission control systems in the wood panal industry. For. Prod. J. 2002, 52, 50-59.

3. Strader, R. Selection and experience with VOC and HAPs control technologies at wood products plants. Proceedings of TAPPI International Environmental Conference and Exhibit, Portland, OR. 2003, 348-352.

4. Su, W.; Yan, H.; Banerjee, S.; Otwell, L. P.; Hittmeier, M. E. Field-proven strategies for reducing volatile organic carbons from hardwood drying. Environ. Sci. Technol. 1999, 33, 1056-1059.

5. Mackowiak, J. Removal of formaldehyde from waste gas in a biofilter. Stud. Environ. Sci. 1992, 51 (Biotech. Air Pollut. Abatement Odour Control Policies), 273-8.

6. Mackowiak, J. Large-scale process for formaldehyde removal. WLB, Wasser, Luft und Boden 1995, 39(5), 55-6.

7. Ferranti, M. M. ; Conca, A. Formaldehyde biological removal from exhaust air in the composite panel board industry from pilot tests to industrial plant. Proceedings of the Air \& Waste Management Association's Annual Conference \& Exhibition, 93rd, Salt Lake City, UT, 2000, 2037-2052.

8. Pisotti, D. A. Biofilter eliminates more than just VOCS from a press exhaust. TAPPI Environmental Conference \& Exhibit, Minneapolis, 1997, 271-275.

9. Sekine, Y.; Nishimura, A. Removal of formaldehyde from indoor air by passive type aircleaning materials. Atmos. Environ. 2001, 35, 2001-2007.

10. Bailey, A.; Williams, M.; Dunne, L.; Beames, L. Enhanced adsorption of methanol by oxidized nutshell carbon. Ads. Sci. Technol. 2000, 18, 261-266.

11. Biedell, E. L.; Buckley, W.; Altshuler, B.; Miller, B. A cost effective approach to control of VOC emissions from printed circuit board operations. Proceedings of the Air \& Waste Management Association's Annual Conference \& Exhibition, 93rd, Salt Lake City, UT, 2000, 1964-1976.

12. Bhardwaj, B.; Perera, S. P.; Crittenden, B. D. Hybrid membrane adsorbents for fluidized bed separations. Chem. Eng. Res. Des. 2000, 78, 1089-1097. 
13. Klug, A.; Pfromm, P. H.; Rezac, M. E.; Czermak, P. Selective Removal of Methanol from Humid Air Streams Using a Water-Vapor-Purged Membrane Separator. Ind. Eng. Chem. Res. 2001, 40, 2685-2692.

14. Rosenfeld, P.; Grey, M.; Suffet, M. Controlling odors using high carbon wood ash. BioCycle 2002, 43(3), 42-45.

15. Douek, M.; Ing, J. A new method for determining carbonate in samples from the pulp and paper industry. TAPPI International Process and Materials Quality Evaluation Conference, 1986, 115-122.

16. Boonamnuayvitaya, V.; Sae-Ung, S.; Tanthapanichakoon, W. Preparation of activated carbons from coffee residue for the adsorption of formaldehyde. Sep. Purif. Technol. 2005, 42, 159-168.

17. Betterton, E. A.; Erel, Y.; Hoffmann, M. R. Aldehyde-bisulfite adducts: prediction of some of their thermodynamic and kinetic properties. Environ. Sci. Technol. 1988, 22, 92-99.

18. Gaffney, J. S., Streit, G. E., Spall, W. D., Hall, J. H., Beyond acid rain. Do soluble oxidants and organic toxinsinteract with $\mathrm{SO} 2$ and NOx to increase ecosystem effects?. Environ. Sci. Technol. 1987, 21, 519-524.

19. Gambaro, L. A. Methanol adsorption-oxidation over $\mathrm{V}_{2} \mathrm{O}_{5}$-a mass spectrometry study. $J$. Mol. Catal. A, 2004, 214, 287-291.

20. World Health Organization. Formaldehyde. Environmental Health Criteria 89, International Programme on Chemical Safety, Geneva (1989).

21. Sambeth, J. E.; Centeno, M. A.; Paul, A.; Briand, L. E.; Thomas, H. J.; Odriozola, J. In situ DRIFTS study of the adsorption-oxidation of $\mathrm{CH} 3 \mathrm{OH}$ on $\mathrm{V}_{2} \mathrm{O}_{5}$. A. J. Mol. Catal. A 2000, 161, 89-97.

\begin{tabular}{|l|c|c|c|}
\hline \multicolumn{4}{|c|}{ TABLE 1. Bulk Properties of Ash. } \\
\hline \multicolumn{1}{|c|}{ ash } & dry bulk density $\mathbf{( g / \mathbf { c m } ^ { 3 } )}$ & pH in water & organic C (\%) \\
\hline Guntown burner & 0.50 & 12.1 & 16.0 \\
\hline Guntown ESP & 0.63 & 12.2 & 13.5 \\
\hline Catawba & 0.80 & 6.3 & 21.4 \\
\hline Skippers & 0.88 & 12.5 & 4.10 \\
\hline Whiteville & 0.67 & 10.8 & 19.5 \\
\hline Inland, Rome & & & 24.0 \\
\hline
\end{tabular}




\begin{tabular}{|c|c|c|c|c|c|c|}
\hline \multirow[b]{2}{*}{ percent } & \multicolumn{6}{|c|}{ particle size $(\mu)$} \\
\hline & $>710$ & $500-709$ & $250-499$ & $150-249$ & 106-149 & $0-106$ \\
\hline $\begin{array}{l}\text { Guntown, } \\
\text { burner }\end{array}$ & 47.9 & 2.8 & 5.6 & 5.6 & 3.5 & 34.7 \\
\hline $\begin{array}{l}\text { Guntown, } \\
\text { burner ground }\end{array}$ & 1.8 & 2.5 & 7.6 & 8.0 & 5.4 & 74.7 \\
\hline Guntown, ESP & 1.6 & 0.8 & 4.0 & 8.9 & 16.1 & 68.5 \\
\hline Catawba & 0 & 0 & 4.9 & 19.0 & 35.1 & 41.0 \\
\hline Skippers & 0 & 0 & 0 & 23.0 & 18.9 & 58.1 \\
\hline Whiteville & 4.3 & 7.4 & 20.9 & 20.9 & 14.7 & 31.9 \\
\hline
\end{tabular}

\begin{tabular}{|l|c|c|c|}
\hline \multicolumn{1}{|c|}{ Table 3. Removal of Methanol by Ash at $\mathbf{1 0 5}^{\mathbf{0}} \mathbf{C}$. } \\
\hline ash type & $\begin{array}{c}\text { feed methanol } \\
\text { (ppmv) }\end{array}$ & $\begin{array}{c}\text { minimum methanol } \\
\text { (ppmv) }\end{array}$ & \% reduction \\
\hline Guntown, not ground & 42.9 & 26.9 & 37 \\
\hline Guntown, ground & 44.5 & 43.6 & 0 \\
\hline Guntown, ground & 45.3 & 37.7 & 17 \\
\hline Guntown, ESP & 39.8 & 13 & 70 \\
\hline Guntown, ESP & 46 & 26 & 43 \\
\hline Catawba & 40 & 13.4 & 67 \\
\hline Skippers & 39.7 & 21.7 & 45 \\
\hline Whiteville & 49.7 & 4.7 & 90 (for 40 min) \\
\hline
\end{tabular}

\begin{tabular}{|c|c|c|c|}
\hline \multicolumn{4}{|c|}{ TABLE 4. Removal of Formaldehyde by Ash at $105^{\circ} \mathrm{C}$. } \\
\hline ash type & $\begin{array}{l}\text { ash initial mois- } \\
\text { ture content }(\%)\end{array}$ & $\begin{array}{c}\text { ash final moisture } \\
\text { content }(\%)\end{array}$ & $\begin{array}{l}\text { capacity (mg for- } \\
\text { maldehyde/g ash) }\end{array}$ \\
\hline Guntown, not ground & 2.8 & 1.4 & 0.003 \\
\hline Guntown, ground & 2.8 & 0.1 & 0.004 \\
\hline Guntown, ground & 4.4 & 2.8 & 0.002 \\
\hline Guntown, ESP & 1.4 & 0 & 0 \\
\hline Guntown, ESP & 4.5 & 1.2 & 0.015 \\
\hline Catawba $^{2}$ & 3.2 & 0.9 & 0.002 \\
\hline Skippers $^{2}$ & 8.7 & 4.9 & 0.047 \\
\hline Whiteville $^{3}$ & 6.6 & 2.4 & 0.083 \\
\hline \multicolumn{4}{|c|}{$\begin{array}{l}{ }^{1} \text { formaldehyde adsorbed while the breakthrough concentration was }<1 \mathrm{ppm} \text {. } \\
{ }^{2} \text { the portion of ash passing a } 60 \text {-mesh screen was used. } \\
\text { 3the portion of ash passing an } 18 \text {-mesh screen was used. }\end{array}$} \\
\hline
\end{tabular}




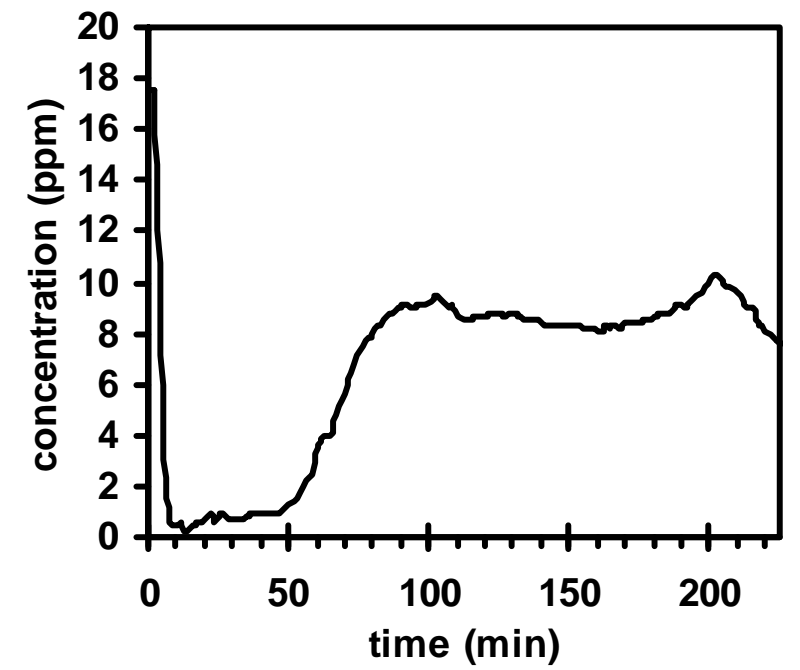

FIGURE 1. Removal of formaldehyde by Guntown ESP ash.

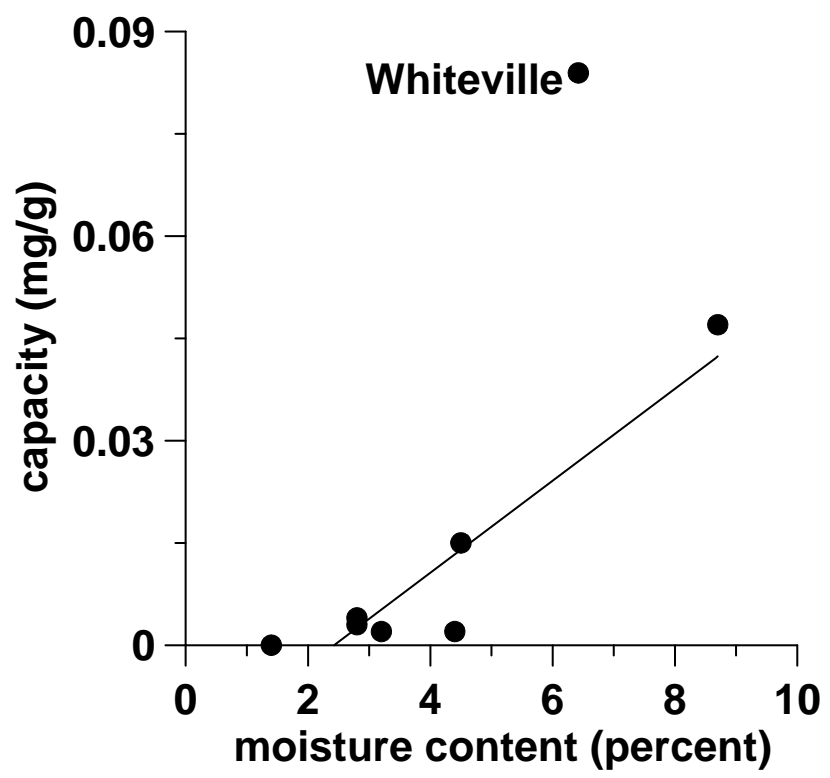

FIGURE 2. Effect of initial moisture content on the capacity of ash for formaldehyde sorption. 


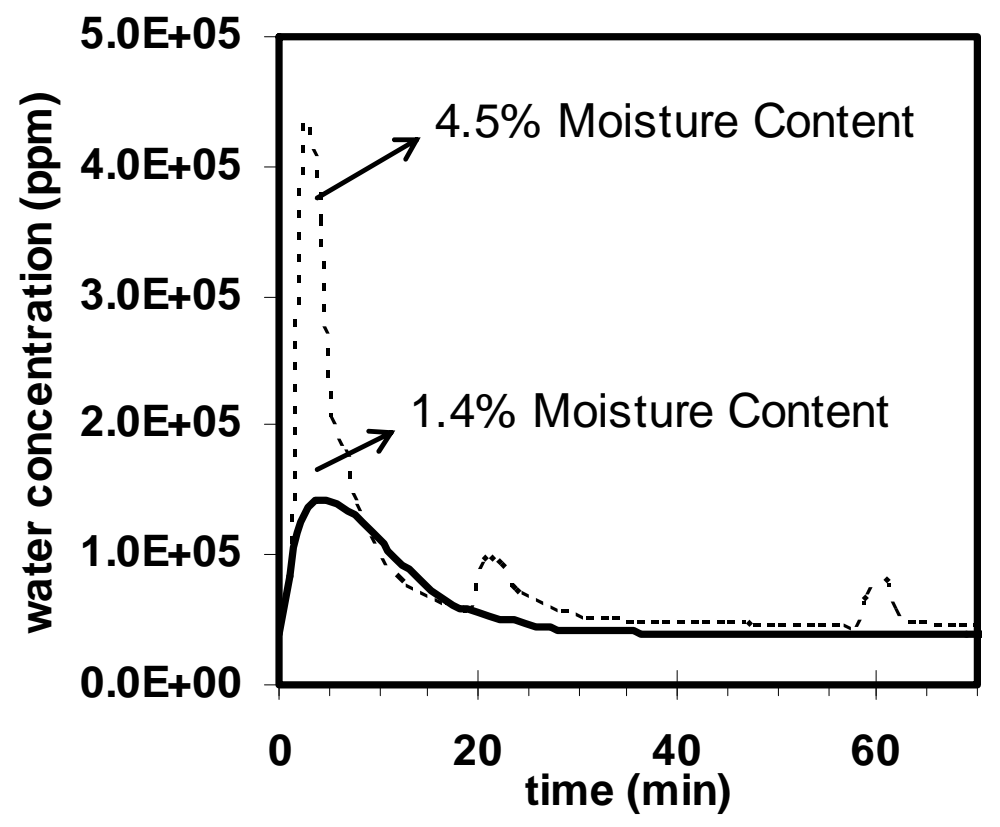

FIGURE 3. Release of water vapor from ESP ash at $105^{\circ} \mathrm{C}$ and $2 \mathrm{~L} / \mathrm{min}$.

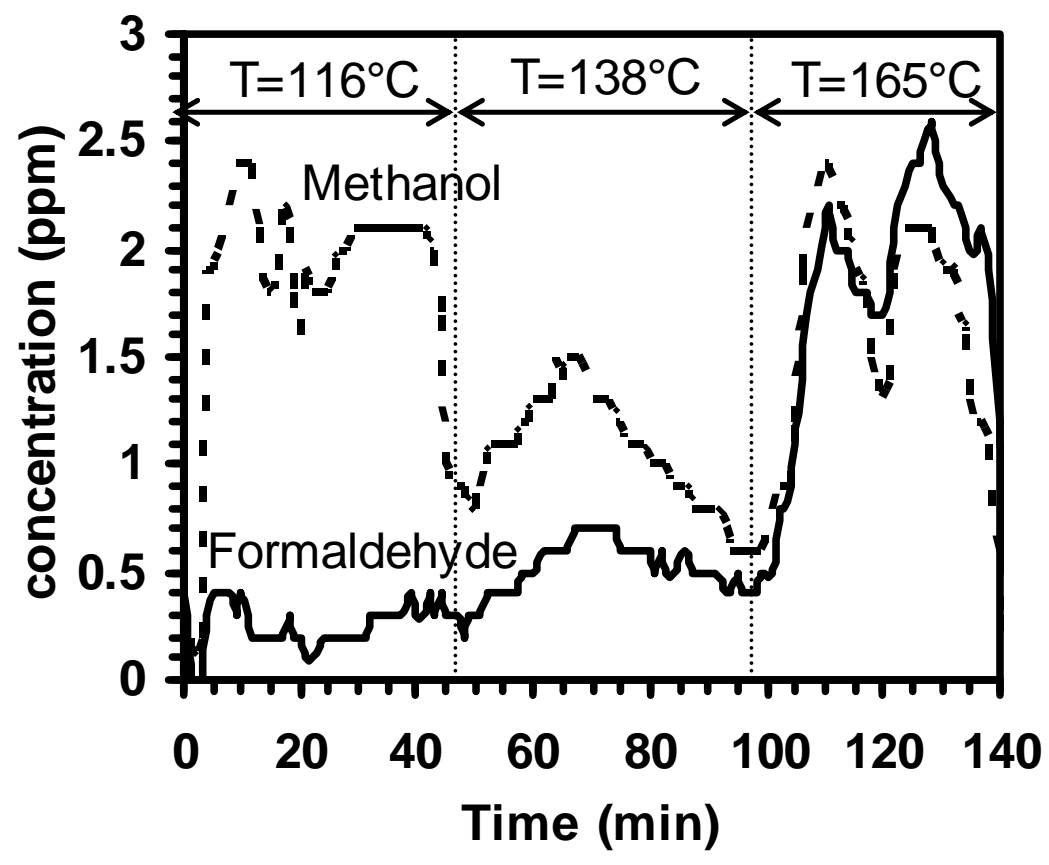

FIGURE 4. Desorption of methanol and formaldehyde from Catawba ash. 


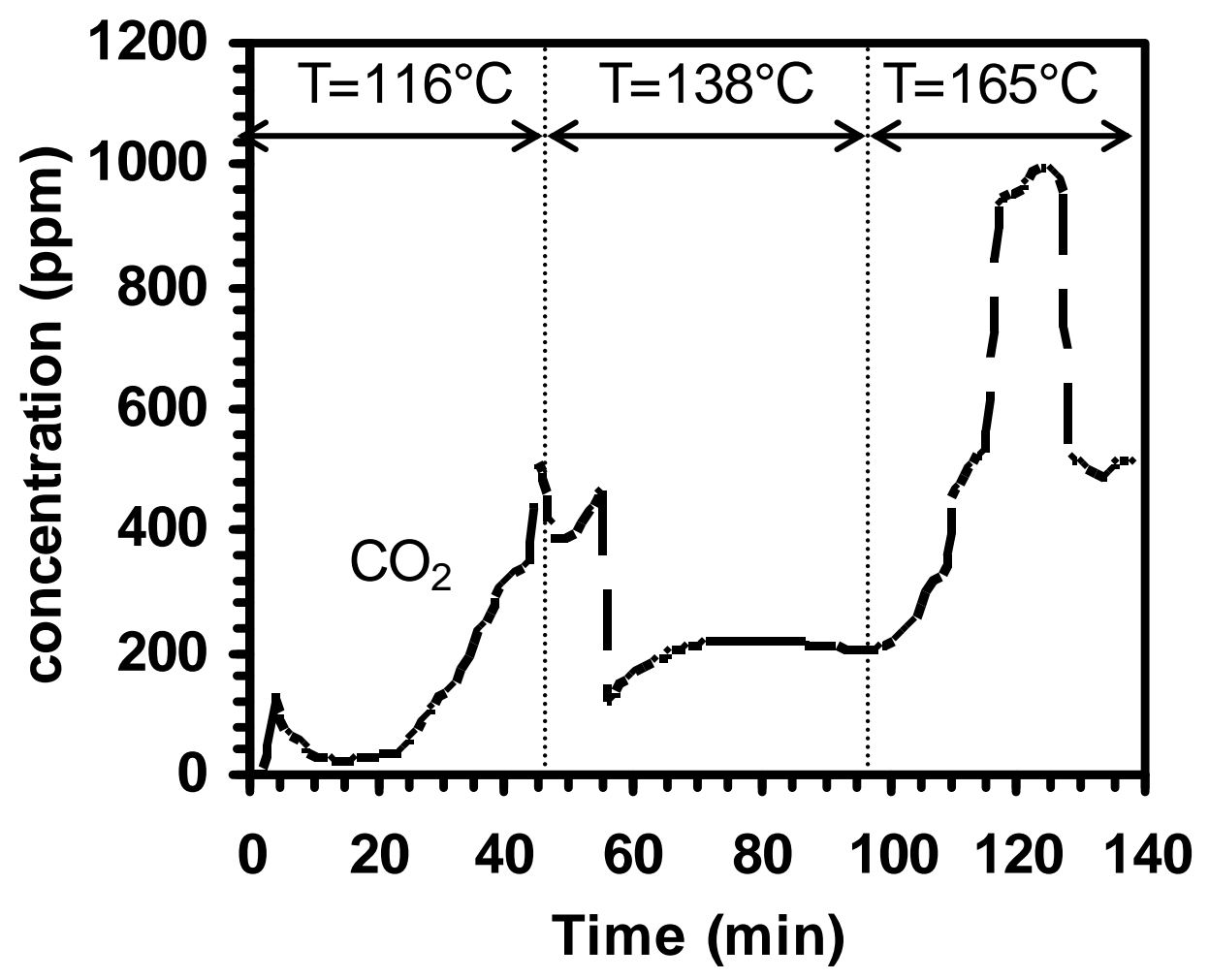

FIGURE 5. Desorption of carbon dioxide from Catawba ash by air. 


\title{
Process-Based Control of HAPs Emissions From Drying Wood Flakes
}

Environ. Sci. Technol., 40, 2438 (2006).

\author{
Sujit Banerjee ${ }^{*}$, Krishna Pendyala, Mike Buchanan, Rallming Yang, Malyuba Abu-Daabes \\ Institute of Paper Science and Technology and \\ School of Chemical \& Biomolecular Engineering \\ Georgia Institute of Technology \\ 500 Tenth Street NW \\ Atlanta, GA 30332 \\ Lawrence P. E. Otwell \\ Georgia-Pacific Corporation \\ P.O. Box 105605 \\ Atlanta, GA 30348
}

\begin{abstract}
Industrial wood drying generates methanol, formaldehyde, and other Hazardous Air Pollutants (HAPs). A simple theoretical model shows that particles smaller than $400 \mu \mathrm{m}$ will begin to thermally degrade and release disproportionately large quantities of HAPs. This is confirmed in full-scale practice where particles smaller than $500 \mu \mathrm{m}$ show visible signs of charring. Laboratory measurement of the activation energy for the breakdown of wood tissue into methanol and formaldehyde led to a value of about $17 \mathrm{kcal} / \mathrm{mole}$. The apparent activation energy measured in the field was higher. This result was obtained under non-isothermal conditions and is biased high by the fines fraction of the furnish which is exposed to elevated temperatures. It is proposed that a combination of screening out the fines fraction smaller than $500 \mu \mathrm{m}$ and reducing dryer inlet temperature will substantially reduce emissions, possibly to the point where control devices can be downsized or eliminated. Our findings allow these HAPs reductions to be semiquantitatively estimated.
\end{abstract}

\section{Introduction}

A range of volatile organic compounds (VOCs) is released from drying biomass such as biofuels (1), sludge (2), or wood (3-7). New regulations for controlling emissions from the engineered wood industry, the Plywood and Composite Wood Products (PCWP) wood MACT rule (8), are pending. This rule targets a list of six volatile organic Hazardous Air Pollutants (HAPs), namely methanol, formaldehyde, acetaldehyde, propionaldehyde, phenol, and acrolein, determined to represent the most significant HAPs emitted by this industry segment. Only the first three are commonly found in emissions from pressing and drying wood; propionaldehyde has been reported on occasion. A recent estimate has pegged the cost of compliance through current technology $(9,10)$ at several hundred million dollars $(3)$. Our general objective is to reduce emissions through process changes where possible, in order to reduce our dependence on add-on pollution control equipment that is both a capital/operating cost and an energy burden. 
Oriented strand board (OSB) is a major segment of the engineered wood industry. There are over fifty large installations in North America, and several new mills are planned. Green wood is flaked into thin strands approximately $2.5 \mathrm{~cm}$ wide and $9 \mathrm{~cm}$ long. The flaking process inevitably produces a variable quantity of smaller particles known as "fines". The green strands/fines are typically conveyed through a rotary dryer via a hot air stream generated by a direct-fired burner. HAPs released from the wood principally derive from the thermal breakdown of wood tissue, a process that accelerates sharply at wood tissue temperatures exceeding $160^{\circ} \mathrm{C}(4)$. Increasing temperature also elevates the emissions of terpenes by raising their vapor pressure (11). An obvious route to lower emissions is to decrease the dryer inlet temperature, but this would impose a penalty in dryer throughput. Another possibility is to reduce the fines fraction in the furnish entering the dryer. This fraction generates disproportionately high HAPs emissions because fines tend to lose their evaporative cooling capacity quickly and overdry on account of their high surface:volume ratio. Dried fines are used to fire the burners for the dryers so it is important to maintain an adequate supply; screening out the entire fines fraction is not an option. However, if we are able to identify the size fraction that contributes most to HAPs evolution, then we can remove only this fraction and reduce HAPs without significantly reducing the fuel supply. In this paper we establish the temperature dependence of HAPs emissions in both laboratory and full-scale settings and apply it to identify the particle size that is the largest source of HAPs emissions.

\section{Experimental}

Laboratory activation energy measurements were made with dry southern pine (Pinus spp.) flakes obtained from Louisiana-Pacific's Athens, GA, mill. Green southern pine flakes were obtained from Georgia-Pacific's Dudley, $\mathrm{NC}$, facility, and freeze-dried at $-70^{\circ} \mathrm{C}$ to a moisture content of less than 2\%. The flakes were cut into strips that were 2-6 mm wide, $4-14 \mathrm{~cm}$ long and about 2-3 mm thick. About $5 \mathrm{~g}$ of these strips were dried isothermally for 30-minutes in a tube furnace at temperatures ranging between 131 and $166^{\circ} \mathrm{C}$ under an airflow of $0.3 \mathrm{~L} / \mathrm{min}$. The exit air was passed through a chilled water impinger. Previous work (4) has shown that a single impinger captures almost all of the emissions. The impinger catch was analyzed over time, and the emission rate was found to be constant over the time frame of the measurement, i.e. it followed zero-order kinetics. The activation energy was calculated from these rate data.

Field work was done in a mill that dried predominantly southern pine in direct-fired triple-pass rotary strand dryers. The inlet temperature of the dryer was varied between 430 and $600^{\circ} \mathrm{C}$; the outlet was kept at approximately $80^{\circ} \mathrm{C}$. The inlet temperature is controlled by the outlet temperature, which is used as an indicator of wood moisture content exiting the dryer. If the outlet temperature rises beyond its setpoint, the inlet temperature falls to reverse the situation. Thus, it is not possible to simply change the inlet temperature while leaving the outlet setting fixed. We were able to overcome this hurdle by varying wood flow. Increasing wood throughput lowered the outlet temperature and the inlet temperature then rose to compensate. The furnish was dried to a moisture content of 3-5\%.

Both VOCs and HAPs were measured in stack samples with an FTIR spectrometer (model I1106) from Midac Corp., Irving, CA. The samples were drawn through heat-traced Teflon and stainless steel lines into the FTIR by a pump with heated heads to prevent condensation. In order to validate the FTIR method, samples were periodically collected in two chilled-water 
impingers arranged in series after the FTIR gas cell. The back impinger contained less than $1 \%$ of the analyte collected in the front trap, confirming that collection was substantially complete. Methanol and acetaldehyde in the impinger catch were determined by gc. The acetylacetone method (12) was used for formaldehyde. Results from FTIR and impinger analyses compared to within $30 \%$ at analyte levels of less than $10 \mathrm{ppmv}$, which was the highest value considered. Propionaldehyde was not detected at an MDL of 1 ppmv.

\section{Results and Discussion}

Consider a rectangular piece of wood undergoing drying. The resistance to mass transfer of water vapor from the wood surface to the air should be negligible as compared to the diffusion of water in the wood. For a 2-mm thick piece, the mass transfer Biot number is about 0.05 using literature values for the mass transfer coefficient (13) and diffusivity (14). The diffusion rate is given by eq (1) where $\mathrm{X}$ is the concentration of water within the wood, $D_{v}^{\prime}$ is diffusivity,

$$
\frac{\partial X}{\partial t}=D_{v}^{\prime} \frac{\partial^{2} X}{\partial s^{2}}
$$

$s$ represents the distance in the direction of diffusion, and $t$ is time (14). If the diffusivity is assumed to be constant, then the time for loss of water from $X_{1}$ to $X$ is given by equation (2). The reported value of $D_{v}$ for wood is $8.3 \times 10^{-6} \mathrm{~cm}^{2} / \mathrm{s}(14)$. If the temperature profile along the dryer

$$
t_{T}=\frac{4 s^{2}}{\pi^{2} D_{v}^{\prime}} \ln \frac{8 X_{1}}{\pi^{2} X}
$$

is assumed to decrease exponentially, then a typical residence time of two minutes leads to boundary conditions of $\mathrm{T}_{1}=593^{\circ} \mathrm{C}$ at $\mathrm{t}=0$ seconds and $\mathrm{T}_{\mathrm{f}}=82^{\circ} \mathrm{C}$ at $\mathrm{t}=120$ seconds, and equation (3) results.

$$
\mathrm{T}=593 \mathrm{e}^{-0.0165 t}
$$

We have shown earlier $(4,5)$ that HAPs emissions increase sharply when the wood moisture content drops below $5 \%$ and the tissue temperature rises beyond $160^{\circ} \mathrm{C}$. At this point the flake is no longer cooled evaporatively and it assumes the temperature of the dryer. If the dryer temperature is high enough, then the wood tissue thermally degrades and the evolution of HAPs ramps up. This situation occurs earlier with fines than with the larger flakes because of the relatively high surface area of the fines. It follows from equations (2) and (3) that under the dryer conditions described above, a $409 \mu \mathrm{m}$ thick piece of wood will reach $5 \%$ moisture content at $233^{\circ} \mathrm{C}$, the ignition temperature of wood. It is possible to confirm these results in fieldwork, since particles of this and smaller size should show visible signs of charring.

Dried furnish collected from the Georgia-Pacific mill in Fordyce, AR, was sieved into the size fractions listed in Table 1. The color of each fraction is illustrated in Figure 1; the pan fraction $(<500 \mu \mathrm{m})$ shows clear signs of early charring. Samples taken from the secondary multicyclone catch, which was comprised of much smaller particles that by-passed the primary product collection cyclone were completely charred. Hence, the experimental results agree quite well 
with the $409 \mu \mathrm{m}$ estimate from the model. Measurements were also made where the dryer inlet temperature was varied between 593 and $690^{\circ} \mathrm{C}$. The appearance of the various size fractions was very similar to those in Figure 1; i.e. the pan $(<500 \mu \mathrm{m})$ fraction was still the only material that darkened. Results from modeling support this finding. Calculations with the inlet temperature raised to $690^{\circ} \mathrm{C}$ showed that particles smaller than $424 \mu \mathrm{m}$ would begin to char, which is only slightly larger than the $409 \mu \mathrm{m}$ value estimated at $593^{\circ} \mathrm{C}$. Even so, this difference will lead to a significant increase in HAPs emissions as discussed later.

These results are broadly consistent with our earlier work in a hardwood mill where we found that removing green material that passed through a $1-\mathrm{cm}$ screen led to a $70 \%$ reduction in VOC emissions (5) from the remaining furnish. Due to the nature of hardwoods, most of the VOCs tend to be thermal decomposition products. The identification of material smaller than $\sim 500 \mu \mathrm{m}$ as the responsible fraction is important, because they represent only $5 \%$ of the total fines in Table 1. Hence, only a small loss of the fines fraction should lead to a major reduction in HAPs.

Fines are not the only source of dryer HAPs; larger particles will also release HAPs as they dry. Methanol and formaldehyde emissions were measured as a function of flake temperature. The emission rate was quite variable depending on whether the furnish was dried in the laboratory or at a mill, and for how long, which suggested that the HAPs originated from more than one precursor. Emissions were measured from two types of furnish, freeze-dried flakes, and flakes dried in a commercial rotary dryer. These furnishes represent two extremes in the sense that one had experienced no thermal stress, whereas the other had been dried aggressively. Representative Arrhenius plots are illustrated in Figure 2, and the associated data are listed in Table 2. The activation energies $\left(\mathrm{E}_{\mathrm{A}}\right)$ in Table 2 for the two furnishes are quite different for formaldehyde. The emission rate must depend upon both the degradation rate of the wood tissue as well as on mass transfer considerations. It is known that high temperature drying promotes pore closure and affects the surface properties of wood $(15,16)$. These differences may alter the mass transfer of the HAPs through the surface and lead to differences in the activation energy for their release.

The temperature dependence of HAPs was also determined in a full-scale trial at a mill in the Southeastern US. The final flake moisture was kept above 5\% to minimize overdrying of the smaller size fraction. The relationship between inlet temperature and the emissions of methanol, formaldehyde, and acetaldehyde is illustrated in Figure 3. The sum of the concentrations of all three HAPs expressed on a production-basis is plotted against inlet temperature in Figure 4. They both show that HAPs generation depends on the inlet temperature under these conditions.

The Figure 4 data cannot be directly used to obtain an activation energy because the temperature represents that of the dryer inlet and not that of the furnish. The temperature of the dryer decreases along its length, but the flake temperature does not reach that of the dryer until the moisture content drops below 5\% and the flake is no longer evaporatively cooled. Equations 2 and 3 were used to compute the temperature of the dryer at the point where a $500 \mu \mathrm{m}$ thick particle would reach a moisture content of 5\%. This should be the highest temperature experienced by the particle $\left(\mathrm{T}_{\text {particle }}\right)$. These values were calculated at several inlet temperatures $\left(\mathrm{T}_{\text {inlet }}\right)$ and 


$$
\mathrm{T}_{\text {particle }}=98.8+0.08 \mathrm{~T}_{\text {inlet }}
$$

the temperature range of $430-600^{\circ} \mathrm{C}$. Wood temperatures were calculated from eq (4) for the inlet temperature intervals used in Figure 4. These temperatures were related to the emissions data in Figure 4 and led to an apparent activation energy of $45 \mathrm{kcal} / \mathrm{mole}$, which is higher than any of the values measured in the laboratory. Assumption of a larger particle size would lead to even higher apparent activation energies since the range in $T_{\text {particle }}$ would be smaller.

The field calculation is based on a $500 \mu \mathrm{m}$ particle. However, an increasing inlet temperature would also increase the population of the fines exposed to temperatures much higher than that experienced by the flake. For example, raising the inlet temperature from 593 to $690^{\circ} \mathrm{C}$ as discussed earlier would increase the particle size subject to charring from 409 to $424 \mu \mathrm{m}$ with a concomitant increase in HAPs evolution. Thus raising the inlet temperature would increase HAPs evolution in two ways: by increasing the average temperature of the furnish and also by increasing the fraction subject to overdrying. As a result, the temperature sensitivity of HAPs generation would be higher in the field than in the laboratory and lead to a higher apparent activation energy. From an operational point of view, the result that really matters is the finding that the HAPs emissions will increase by about $0.1 \mathrm{~kg} /$ tonne for every $50^{\circ} \mathrm{C}$ rise in inlet temperature assuming a constant particle size distribution.

In summary, a model for estimating wood temperature during drying shows that particles smaller than about $400 \mu \mathrm{m}$ will thermally degrade under typical dryer conditions and give rise to disproportionately high HAPs. This projection is confirmed in full-scale work where particles smaller than $500 \mu \mathrm{m}$ show signs of charring. Fieldwork demonstrates that the HAPs emissions increase linearly with dryer inlet temperature. The activation energy for the breakdown of wood tissue in mill-dried flakes into methanol and formaldehyde was found to be about $17 \mathrm{kcal}$ in the laboratory. However, field dryer emissions were much more sensitive to temperature, probably because of emissions from overdried fines; dryer HAPs increased by about $0.1 \mathrm{~kg} /$ tonne for every $50^{\circ} \mathrm{C}$ increase in temperature. Roughly the same amount of HAPs is released from hardwood and softwood (4), so this value should be quite general and apply to most wood species. Hence, a combination of two approaches could be used to reduce HAPs. Screening out the fine particles below $500 \mu \mathrm{m}$ should reduce emissions by up to $70 \%$. A further reduction could be taken by reducing dryer inlet temperatures, although this approach must be weighed against a loss of throughput. Our results allow these reductions to be estimated a priori. The PCWP MACT rule allows industry to operate without add-on emissions controls if the overall HAPs emissions are kept below certain process-specific target levels. Adoption of the procedures described here could substantially reduce HAPs to possibly below the regulatory limit. Finally, rotary dryers are also used to dry wood particles for the manufacture of particleboard, and our conclusions should also broadly apply to particle dryers as well as to other biomass drying operations.

\section{Acknowledgment}

We thank Georgia-Pacific Corporation and the Department of Energy for financial support under contract DE-FC36-01GO10620. 


\section{Literature Cited}

1. Wimmerstedt, R.; Recent advances in biofuel drying. Chem Eng Process 1999, 38, 441-447.

2. Cusido, J. A.; Cremades, L. V.; Gonzalez, M. Gaseous emissions from ceramics manufactured with urban sewage sludge during firing processes, Waste Manage. 2003, 23, 273-280.

3. Showalter, J.; Hunt, T.; Price, E. New Direction in VOC/HAP destruction. Solutions 2005, 88(3), 37-39.

4. Otwell, L. P.; Hittmeier, M. E.; Hooda, U.; Yan, H.; Su, W.; Banerjee, S. HAPs release from wood drying. Environ. Sci. Technol. 2000, 34, 2280-2283.

5. Su, W.; Yan, H.; Banerjee, S.; Otwell, L. P.; Hittmeier, M. E. Field-proven strategies for reducing volatile organic carbons from hardwood drying. Environ. Sci. Technol. 1999, 33, 1056-1059.

6. Milota, M. R. HAP and VOC emissions from white fir lumber dried at high and conventional temperatures. For. Prod. J. 2003, 53(3), 60-64.

7. Barry A. O.; Corneau. D. Volatile organic chemicals emissions of OSB as a function of processing parameters. Holzforschung 1999 53, 641-646.

8. U.S. EPA. National Emission Standards for Hazardous Air Pollutants: Plywood and Composite Wood Products, Effluent Limitations Guidelines and Standards for the Timber Products Point Source Category, List of Hazardous Air Pollutants, Lesser Quantity Designations, Source Category List, 2004.

9. Sauer, B.; Franklin, W.; Miner, R.; Word, D.; Upton, B. Environmental tradeoffs: life cycle approach to evaluate the burdens and benefits of emission control systems in the wood panel industry. For. Prod. J. 2002, 52, 50-59.

10. Strader, R. Selection and experience with VOC and HAPs control technologies at wood products plants. Proceedings of TAPPI International Environmental Conference and Exhibit, Portland, OR. 2003, 348-352.

11. Banerjee, S.; Su, W.; Wild, M. P.; Otwell, L. P.; Hittmeier, M. E.; Nichols, K. M. Wet line extension reduces VOCs from softwood drying, Environ. Sci. Technol. 1998, 32, 1303-1307.

12. National Council for Air and Stream Improvement. Method CI/WP-98.01 Chilled Impinger Method for Use at Wood Products Mills to Measure Formaldehyde, Methanol, and Phenol. Methods Manual (03.B.004). 1998.

13. Tremblay, C.; Cloutier, A.; Fortin, Y. Experimental determination of the convective heat and mass transfer coefficients for wood drying. Wood Sci. Technol. 2000, 34(3):253-257.

14. McCabe, W. L.; Smith, J. C.; Harriott, P. Unit Operations of Chemical Engineering. Chap. 24. 5th Ed. McGraw Hill, Inc., Singapore, 1993.

15. Martino, C. J.; Shrauti, S.; Banerjee, S.; Otwell, L. P.; Price, E. W. Flake drying temperature affects mat properties during pressing. Holzforschung 2002, 56, 558-562.

16. Plagemann, W. L.; Price, E. W.; Johns, W.E. The response of hardwood flakes and flakeboard to high temperature drying. 1984, J. Adhesion 16, 311-338. 
Table 1: Size distribution of dryer fines.

\begin{tabular}{|c|c|c|c|}
\hline \multirow{2}{*}{ ID } & sieve size no. & opening size & $\begin{array}{c}\text { percent weight } \\
\text { retained on sieve }\end{array}$ \\
\cline { 3 - 4 } & & $(\mu \mathrm{m})$ & 85.8 \\
\hline 1 & 18 & 1,000 & 6.7 \\
\hline 2 & 25 & 710 & 3.4 \\
\hline 3 & 35 & 500 & 4.1 \\
\hline 4 & pan & & \\
\hline
\end{tabular}

\begin{tabular}{|c|c|c|}
\hline temp $\left({ }^{\circ} \mathrm{C}\right)$ & formaldehyde & methanol \\
\hline \multicolumn{3}{|l|}{ freeze-dried } \\
\hline 166 & 1.01 & 3.40 \\
\hline 157 & 0.70 & 3.14 \\
\hline 147 & 0.23 & 1.69 \\
\hline 140 & 0.13 & 1.52 \\
\hline 131 & 0.059 & 1.02 \\
\hline $\mathrm{E}_{\mathrm{A}}(\mathrm{kcal} / \mathrm{mole})$ & 30.4 & 12.8 \\
\hline \multicolumn{3}{|l|}{ mill-dried } \\
\hline 166 & 1.64 & 4.01 \\
\hline 157 & 1.03 & 2.69 \\
\hline 147 & 0.56 & 1.48 \\
\hline 140 & 0.40 & 1.08 \\
\hline 131 & 0.33 & 0.79 \\
\hline $\mathrm{E}_{\mathrm{A}}(\mathrm{kcal} / \mathrm{mole})$ & 17.1 & 17.0 \\
\hline
\end{tabular}

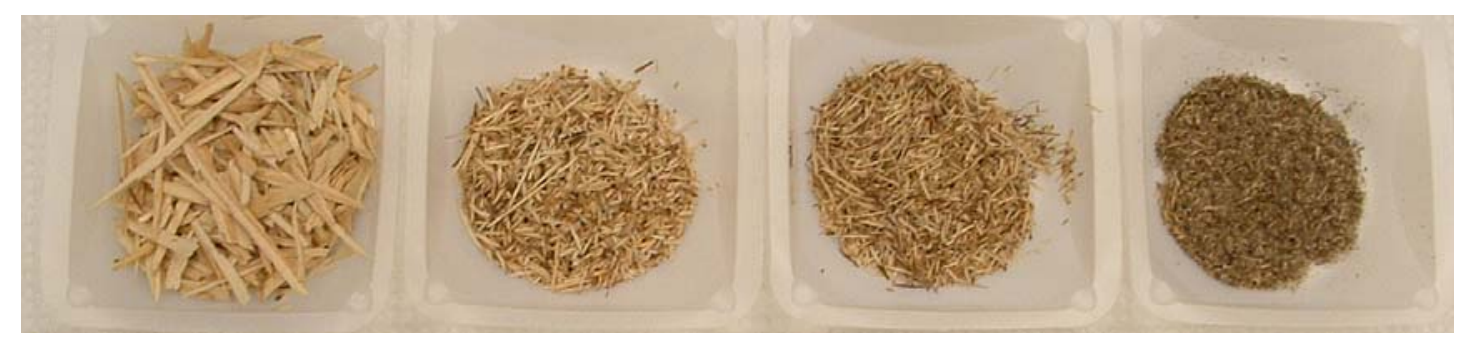

Figure 1: Photographs of fractionated dryer fines. The samples from left to right correspond to ID1-4, respectively, in Table 1. 

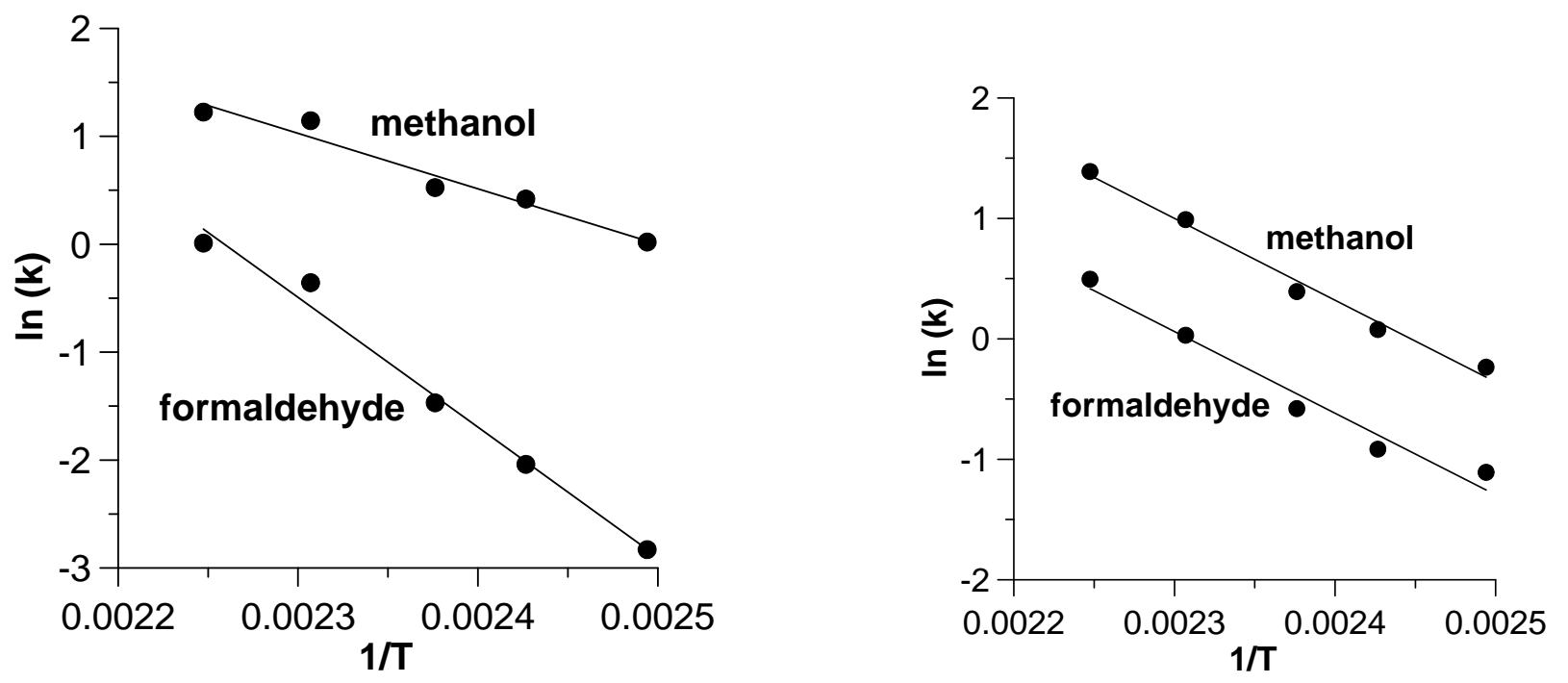

Figure 2: Arrhenius plots for freeze-dried (left) and mill-dried (right) flakes.

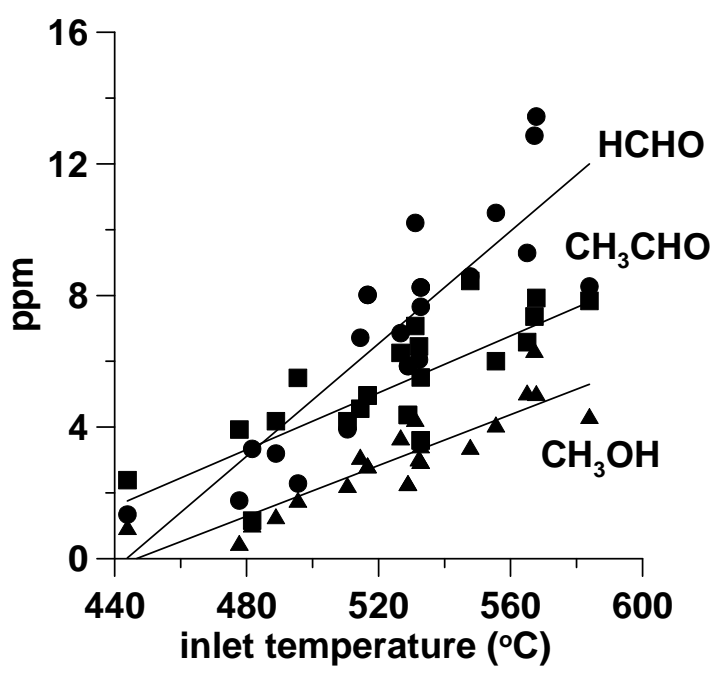

Figure 3: Relationship between HAPs and inlet temperature for individual HAPs. 


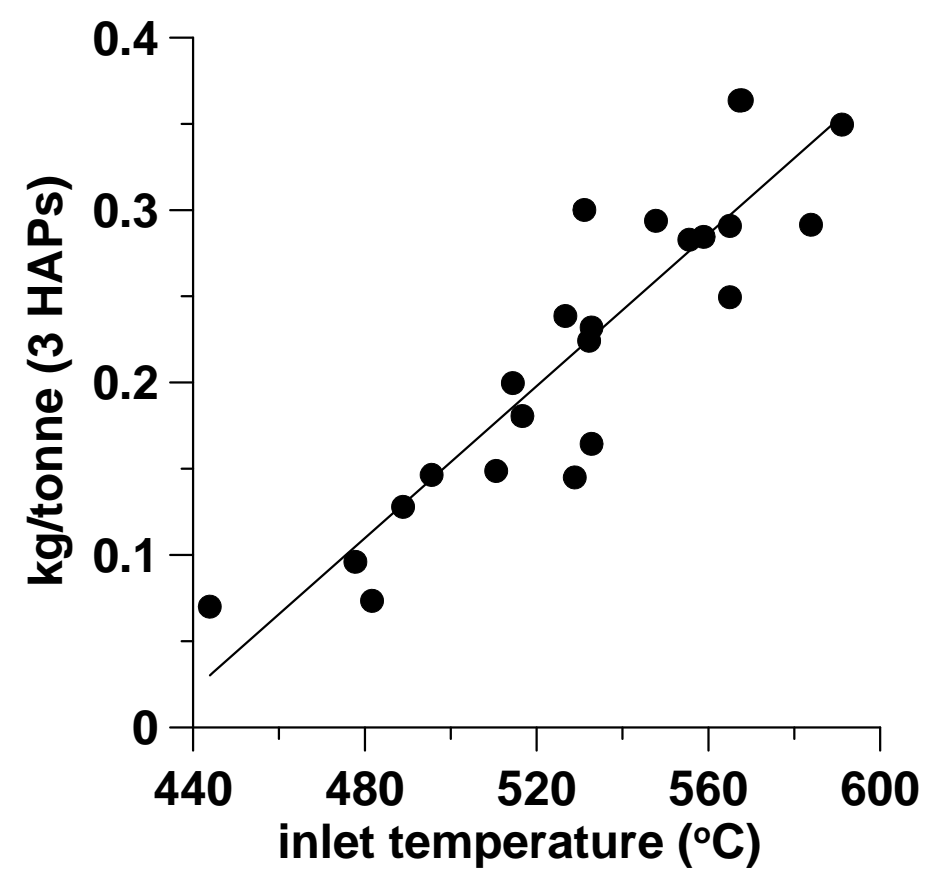

Figure 4: Relationship between the sum of three HAPs (methanol, formaldehyde, acetaldehyde) on a production basis and inlet temperature. 


\title{
Influence of Knife Angle and Ambient Temperature on Fines Generation from Flakers
}

Forest Products J., 56(10) 86 (2006).

\author{
P. Stiglbauer, T.E. Conners and S. Banerjee
}

\begin{abstract}
The production of fines from a flaker at a commercial southern pine OSB mill was found to be correlated with the log storage temperature and the cutting angle of the knife. Knife angle changes were able to significantly decrease the amount of fines produced, and the knife angle could be optimized for different wood temperatures. Twenty-nine degree knife angles produce fewer fines than knives with 26 or 31 degree knife angles when log storage temperatures are cool. Similar results were obtained using a pilot plant strander. Optimizing knife angles to reduce fines will not only increase production efficiency but will also reduce VOCs during wood drying.
\end{abstract}

\section{Introduction}

Implementation of the Clean Air Act Amendments of 1990 has resulted in the wood industry receiving increased scrutiny from the Environmental Protection Agency (EPA) regarding air quality and emissions. Particles and flakes used in the manufacture of particleboard and oriented strandboard (OSB), respectively, are usually dried at high temperatures, which promote the release of volatile organic compounds (VOCs) and hazardous air pollutants (Banerjee et al. 1995, Otwell et al. 2000). Terpenes, methanol, formaldehyde, acetaldehyde and propionaldehyde are some of the compounds emitted. Fines generated during flaking wood for OSB production are especially prone to overdrying on account of their high surface:volume ratio. Furthermore, fines consume disproportionately large amounts of resin and reduce product strength. Hence, reducing fines during flaking has environmental benefits as well as wood and resin cost savings and improved product quality.

Flaking is an interaction between a knife edge (that is prone to edge wear) and the wood itself (which varies in mechanical properties due to growth ring construction, juvenile/mature wood, etc.), so when logs are flaked it is inevitable that an assortment of flake sizes is formed. Some wood variables that are measurable and, to an extent, controllable (such as wood moisture content and temperature) can affect mechanical properties and, therefore, might be expected to have an influence on flake production. Most particles are several inches long, but a small percentage will fall through the smallest screen in a classifier. Strands are dried to target moisture contents that typically range from two to six percent, but small particles and sawdust-like fines dry faster than the larger flakes, overheat, and thermally degrade to form VOCs (Otwell et al. 2000). This paper demonstrates that the amount of fines produced at the flaker depends on both wood temperature and knife angle.

\section{Background}

To understand the dependence of fines production on wood-knife interactions we first reviewed the literature on the effect of moisture content and temperature on wood properties. 
Moisture effects on solid wood properties have been well documented; because water acts as a plasticizer, most wood mechanical properties such as the modulus of rupture and the elastic moduli decline with increasing moisture content up to the fiber saturation point (U.S. Department of Agriculture 1999). If wood is of uniform moisture content (or is at least above the fiber saturation point) throughout the production year, then moisture content and its effects on machining should not be an issue of practical importance unless mass and inertial effects can be demonstrated. Elastic and mechanical properties change with temperature, so these might be significantly affected by seasonal temperature changes and log storage conditions. At a constant moisture content and at temperatures below $150^{\circ} \mathrm{C}$, mechanical properties are inversely dependent on temperature (Kollmann 1940; Hearmon 1948; Youngs 1957; Byvshykh 1959; Gerhards 1982; Caulfield 1986; U.S. Department of Agriculture 1999; Lenth and Kamke 2001). Although the effect of temperature has long been known, its effect on wood processing is frequently neglected in the real world for ambient working temperature conditions. It is commonly known that more flaker fines are created when the wood is cold.

An inverse relationship is observed between tool force and the plasticizing influences of wood temperature and wood moisture content (Fronczak and Patzer 1982; Woodson 1979). As wood temperature increases, tool force decreases because the wood is weakened by heat. The middle lamella softens and degrades; this softening allows wood cells to be separated with less force (Koch 1972). As Koch (1972) and Woodson (1979) have demonstrated, different knife shapes produce different cleavage modes in wood and may also result in differing amounts of friction with the wood substrate if the clearance angle changes. It is well-known in the veneer industry that both wood temperature and the knife angle are critical factors in successfully peeling a veneer block with a good surface (see, for example, Spelter 1991), and it is possible that these factors are similarly important in the production of flakes.

A flaker uses pairs of counterknives and cutting knives to control flake thickness and width. A counterknife controls the flake width while the protruding cutting knife controls the flake thickness in conjunction with the flaker feed speed. These knives are set back-to-back into angled slots in the flaker disk; the slot geometry is established by the knife carrier and the knife clamp, and the resultant slot angle sets the knives' rake angle. An illustration of the knives as inset in a disk flaker is found in Figure 1.

\section{Materials and Methods}

This work was conducted during normal production runs at a cooperating OSB mill that flakes southern pine (Pinus spp.). Flake samples were collected and the fines component was quantified during seven mill trials conducted between April 2004 and July 2005. The log temperatures varied with ambient temperatures and storage conditions but were otherwise uncontrolled. Three different knife sharpness angles were used: 26, 29 and 31 degrees. ${ }^{1}$ The knife carrier angle was left unchanged for these experiments. Southern pine logs were selected by the mill in advance of the trials to ensure that they were fresh (with minimal yard storage time) and that they were free of "bug wood" that might have compromised the results of these trials.

\footnotetext{
${ }^{1}$ Measurements were made with a 32 degree knife angle in June 2004, and 31 degree knives were used beginning in December 2004 experiment. No 31- or 32-degree data were collected during the August 2004 trial due to mill constraints.
} 
Flaking was done with a CAE disk flaker (a series of knives fixed in a rotating disk): a volume of logs is held in place and the flaker is advanced into the logs; flakes are then conveyed on a belt from the flaker to another conveyor that transports them to collection bins. Samples were collected as the flakes dropped from the flaker outfeed conveyors. As samples collected from this point had the fewest mechanical carrier interactions we believe that samples collected here are the most representative of the flaker production. A schematic of the mill's flaker area is found in Figure 2. Samples were collected every 50 flaker strokes $^{2}$ from 50 to 1,000 strokes for a total of 20 samples per knife angle (per trial date), each typically between 1000 and 2000 grams green weight. It is conventional wisdom that fines production varies during a flaker stroke, so the samples analyzed in this study were collected at the mid-stroke point to ensure they were as comparable as possible. Three knife angles were tested during each trial, so there was a grand total of 60 samples collected for each trial period. Fines were separated from the rest of the undried sample using a Gilson classifier with 7/8", 5/8", 3/8", 1/4", 1/8" screens and a bottom pan. Fines were defined as particles falling through the $1 / 8$ inch screen into the pan, and the percent of fines was calculated as a percent of the original green sample weight. ${ }^{3}$ The flake moisture content was consistently $51-53 \%$ on a wet basis.

The percent fines was noted to have a seasonal variation in the mill trials, so additional pilot-scale work was done at Louisiana-Pacific Corporation's research facility in Nashville, Tennessee. The goal of this trial was to see whether the knife angle-temperature interaction observed during the mill trials for southern-yellow pine (Pinus spp.) would occur under more controlled conditions with different equipment. A laboratory-size CAE 12/48 strander was used instead of the disk flaker operated in the mill where we ran our trials.

Two knife angles (29 and 33 degrees) were used to strand the cold and warm southern pine $\operatorname{logs}$ used in the pilot trial. Short $\operatorname{logs} 18-20 \mathrm{~cm}\left(7{ }^{\prime \prime}-8\right.$ ") in diameter were conditioned for over 18 hours by submersion in water baths which were either warmed by heating elements or chilled by the addition of ice to a vat containing the logs. A thermocouple was inserted at various depths into drilled holes (approximately $20 \mathrm{~cm}$-deep)to measure the log temperature prior to stranding. The drill warmed the wood in places (presumably where it went through the denser latewood) but this was easily noticeable when the temperatures were significantly above the wood conditioning temperatures; aside from drill-induced heating the observed core and surface temperatures were similar. One log was stranded for each temperature/ knife angle combination. The strands were collected and sealed in plastic bags to prevent moisture loss while awaiting transport and screening on the following day. The identical Gilson Classifier and procedure were used to separate out the fines as before.

\section{Results and Discussion}

Most OSB mills change flaker knives on a fixed-cycle basis, and our cooperating mill normally changes knives after 1,000 flaker strokes. It was expected that fines would increase due

\footnotetext{
${ }^{2}$ A stroke is defined as the cycle of a flaker progressing through a stack of logs and back to its starting point.

${ }^{3}$ A reviewer has pointed out that the very act of classifying flakes may itself create fines. In this study, the separation of large flakes from the smaller fractions was manually assisted; the samples were typically agitated in smaller batches for a total of 7-10 minutes (depending on the sample size) to minimize the time that samples spent in this shaker-type classifier. It did not appear as though classification induced fines generation, though this was not actually measured. In any case, this effect (if present), should be insignificant, as the results are interpreted on a relative basis.
} 
to knife wear, but this was not borne out. Figure 3 illustrates fines production for one typical cycle; there was significant variability within a trial, but fines did not appear to increase with knife use. Linear regression was used to confirm that there was no significant slope for a plot of percent fines versus flaker stroke for each trial. Additionally, calculation of Durbin-Watson statistics (for serial correlation) confirmed that there was no statistically significant serial correlation (i.e., there was no change in the percent fines residual from the regression that depended on the stroke number); p-values were typically about $0.5-0.7$, but a value as small as of 0.05 or less would have been needed to demonstrate serial correlation.

A seasonal bias was expected because of wood temperature changes. The median ambient outdoor temperatures for the 24-hours preceding each trial were obtained from the U.S. National Weather Service, and limited on-site thermocouple sampling (as previously described) indicated that log temperatures were very similar. It was impractical to measure the temperature of each log that was flaked, however, and the preceding day's median temperature was used as a surrogate in subsequent analyses. Median temperatures were used instead of mean temperatures because there are differing amounts of sunlight in different seasons; dates were not used in these analyses so that these results could be more readily adapted to other regions. Results from the seven mill trials are summarized in Table 1.

Statistically significant linear relationships were observed between the preceding day's median temperature and the fines produced from all of the knife angles ( $p$-values were less than 0.05 for each regression) (Figures $4 \mathrm{a}$ and $4 \mathrm{~b}$ ). There were statistically significant differences in the slopes for the three regressions at the $99 \%$ confidence level. Due to the amount of variability in our samples throughout each trial, correlation coefficients ranged from a relatively weak 0.47 for the 29 degree knife angle to the stronger values 0.62 and 0.73 for the 31 and 26 degree knives, respectively. (As stated previously, there were no statistically significant changes in the percent of fines generated during the trials.) Linear regression lines through these data sets intersect at about $20^{\circ} \mathrm{C}$. If this temperature is set as a change-over point, by reference to U.S. Weather Service data our cooperating mill should change its customary knife angle from 29 degrees to 26 degrees for 4.5 months per year.

Results from the limited pilot studies using the strander are illustrated in Figure 5. The knife angle-temperature relationships follow the same trends observed for the mill-scale work with the 26- and 29-degree knives. One point of difference between the flaker and strander work (Figures 4 and 5) is the crossover temperature (about $20^{\circ} \mathrm{C}$ for the mill flaker data versus approximately $29^{\circ} \mathrm{C}$ for the pilot-scale work). It is likely that part of the difference might be due to the fact that the mill data were collected from different types of machines. Also, the temperature used in the mill data analysis is the previous day's median ambient temperature, whereas the actual measured log temperature was used for this pilot work. Perhaps even more importantly, this pilot work was very limited and atypical observations (from whatever cause) could bias the percent of fines observed with no way to know the measurements were unusual; additionally, these few observations cannot indicate whether the variability in the trial is different from that observed during the mill sample collection. It is impressive, however, that both pilot and mill data identify a cross-over point in the generation of fines at different sharpness angle and temperature combinations, and this would seem to indicate that a temperature-sensitive material property is being sig- 
nificantly affected by changes in wood temperature. Furthermore, the smaller knife angle produces fewer fines during warmer temperatures (and vice-versa) in both cases.

The essence of the data shown in Figure 4 is that the 29 and 26 degree knife angles are better choices for disk flakers than the 31 degree knife angle if knife angle selection is chosen according to temperature. The 29 degree knife angle produces fewer fines than the 26 degree knife angle when the median ambient temperature is below approximately $20^{\circ} \mathrm{C}$, and the 26 degree knife will produce fewer fines than the 29 degree knife angle when the weather is warmer. Based on the regression lines through all of our data points, we estimate that almost $2 \%$ more wood can be turned into flakes instead of fines if the 26 degree knife angle is used when the median ambient temperature is $27^{\circ} \mathrm{C}\left(80^{\circ} \mathrm{F}\right)$. The data collected using a 31 degree knife angle indicate that the amount of fines produced using this knife angle can always be lowered by either the 26 or the 29 degree knife angle in the defined temperature ranges. It is unlikely that the wood temperature will exceed $20^{\circ} \mathrm{C}$ for much of the year in most facilities, and the choice of knife angle for cooler temperatures is naturally of greater interest. Based on the data collected to date, a 29 degree knife is preferred if only one knife angle is to be used in a flaker. There may be an advantage to choosing the 26 degree knife at warm temperatures. It must be noted that there has been no attempt to actually determine the optimum knife sharpness angles for different temperatures and different species; other knife angles could actually be better than those used in this study.

These findings may be of value to mills in much of the United States and elsewhere. The National Oceanic and Atmospheric Administration's National Climatic Data Center publishes data on the internet that show typical temperature patterns for each state or region by month based on thirty years of data (http://gis.ncdc.noaa.gov/website/ims-climatls/index.html). Based on these data, mills in the southern states should consider knife angle changes from May through September when the mean temperature exceeds $70^{\circ} \mathrm{F}$; mid-southern states should consider knife angle changes from June through August. See the summary data map for annual temperature averages (Figure 6).

\section{Conclusions}

This research has demonstrated that fines generation can be significantly reduced at OSB flakers by adjusting sharpness angles as ambient temperature varies. The results indicate that significant linear relationships exist between the preceding day's median air temperature and percent fines for 26, 29 and 31 degree knife angles. At temperatures above $20^{\circ} \mathrm{C}$, a sharpness angle of 26 degrees generates fewer fines than either the 29 or 31 degree knife angle; conversely, sharpness angles of 29 degrees generate the fewest fines at cold temperatures. Work on determining the underlying mechanism is underway. Based on temperature data available from NOAA, OSB mills in the southern and mid-southern United States should consider making seasonal knife angle changes during the summer months. 


\section{Literature Cited}

Banerjee, S., Hutten, M., Su., W., Otwell, L., Newton, L. 1995. Release of water and volatile organics from Wood Drying. Environmental Science and Technology 29(4): 1135-1136.

Byvshykh, M.D. 1959. Influence of temperature and moisture of wood on its elastic properties. Woodworking Industry (USSR). 8(2):13-15. Translation No. 400, U.S. Department of Agriculture Forest Products Laboratory, by D. Pronin (1960).

Caulfield. D. 1986. Effect of moisture and temperature on the mechanical properties of paper. In: Solid Mechanics Advances in Paper Related Industries. Proceedings of the National Science Foundation Workshop held at the Minnowbrook Conference Center, Syracuse University, August 13-15, 1986 pp. 50-62. Published by the Department of Mechanical and Aerospace Engineering. L.C. Smith College of Engineering, Syracuse University, Syracuse, New York, May 1990. R.W. Perkins, R.E. Mark, and J.L. Thorpe, editors. 383 pages.

Fronczak, F.J. and R.A. Patzer. 1982. Influence of chuck design on spin-out torque in softwood veneer peeling blocks. U.S. Department of Agriculture Forest Service, Forest Products Laboratory Research Paper FPL 427. 14 pages.

Gerhards, C.C. 1982. Effect of moisture content and temperature on the mechanical properties of wood: An analysis of immediate effects. Wood and Fiber 14(1):4-36.

Hearmon, R.F.S. 1948. The Elasticity of Wood and Plywood. Forest Products Research Special Report Number 7, Department of Scientific and Industrial Research. H.M. Stationery Office, London. 88 pages.

Koch, P. 1972. Utilization of the Southern Pines. U.S. Department of Agriculture Forest Service. Agricultural Handbook 420. 2 vol. U.S. Government Printing Office. Washington D.C. 1663 pages.

Kollmann, F. 1940. Die mechanischen Eigenschaften verschieden feuchter Hölzer im Temperaturbereich von -100 bis $+200{ }^{\circ} \mathrm{C}$. VDI-Forschungsheft No. 403, VDI-Verlag, Berlin. Original not seen, cited in Principles of Wood Science and Technology Volume I Solid Wood by Franz F.P. Kollmann and Wilfred A. Côté, Jr. Published by Springer-Verlag New York, 1968. 590 pages.

Lenth, C.A. and F.A. Kamke. 2001. Moisture dependent softening behavior of wood. Wood and Fiber Science 33(3):492-507.

Otwell, L.P., Hittmeier, M.E., Hooda, U., Yan, H., Su, W., Banerjee, S. 2000. HAPs release from wood drying. Environmental Science and Technology 34(11), 2280-2283.

Spelter, H. 1991. Recent developments in veneer peeling confront quality variables. Panel World May 1991 pp. 54-53, continued on pp. 63-65. 
U.S. Department of Agriculture. 1999. Wood Handbook: Wood as an Engineering Material. Agricultural Handbook 72. U.S. Department of Agriculture, Washington D.C. 457 pages.

Woodson, G.E. 1979. Tool forces and chip types in orthogonal cutting of southern hardwoods. U.S. Department of Agriculture Forest Service, Southern Forest Experiment Station, Research Paper SO-146. 77 pages.

Youngs, R.L. 1957. Mechanical properties of red oak related to drying. Forest Products Journal 7(10):315-324. 
Table 1. Summary of fines data collected with various knife angles.

Percent fines (std. dev.)

Knife angle

$\begin{array}{lllcc} & \begin{array}{l}\text { Median } \\ \text { temperature }\left({ }^{\circ} \mathrm{C}\right)\end{array} & \begin{array}{c}26 \\ \text { degrees }\end{array} & \begin{array}{c}29 \\ \text { degrees }\end{array} & \begin{array}{c}31 \\ \text { degrees }\end{array} \\ \text { June 2004 } & 23.3 & 5.9(1.6) & 7.4(2.6) & 8(3.2)^{4} \\ \text { August 2004 } & 19.4 & 8.2(2.2) & 5.8(2.1) & - \\ \text { December 2004 } & 13.9 & 10.5(2.3) & 9.0(2.1) & 7.5(1.8) \\ \text { January 2005 } & 7.8 & 13.5(4.0) & 10.4(3.3) & 13.5(2.5) \\ \text { February 2005 } & 13.3 & 10.8(2.4) & 10.0(1.7) & 10.2(2.6) \\ \text { March 2005 } & 10.0 & 11.9(2.6) & 9.4(2.6) & 10.7(2.5) \\ \text { July 2005 } & 24.4 & 5.4(1.4) & 7.1(2.3) & 6.1(2.8)\end{array}$

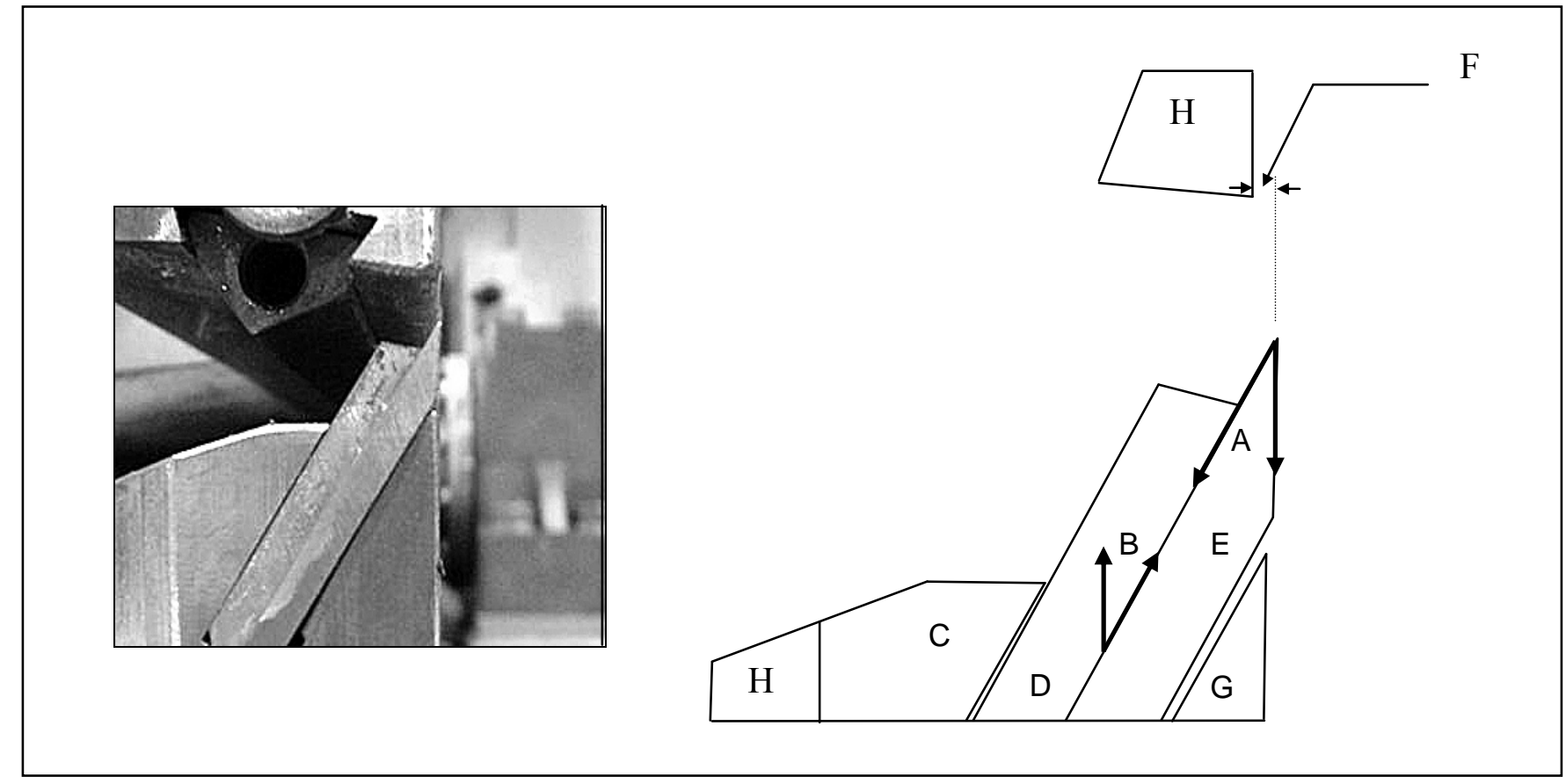

Figure 1. Flaker knife profile: $\mathrm{A}=$ knife cutting angle, $\mathrm{B}=$ knife carrier angle, $\mathrm{C}=$ knife carrier, $\mathrm{D}=$ counterknife, $\mathrm{E}=$ cutting knife, $\mathrm{F}=$ cutting knife projection, $\mathrm{G}=$ clamp, $\mathrm{H}=$ flaker disk (Photo obtained from Carmanah Design Manufacturing Inc). The knife carrier angle (B) establishes the rake angle. The cutting edge of the knife is not exactly parallel with the wood surface; there is a small clearance angle between the knife and the wood surface that is not labeled here.

\footnotetext{
${ }^{4}$ These June 2004 data were collected using a 32 degree sharpness angle.
} 


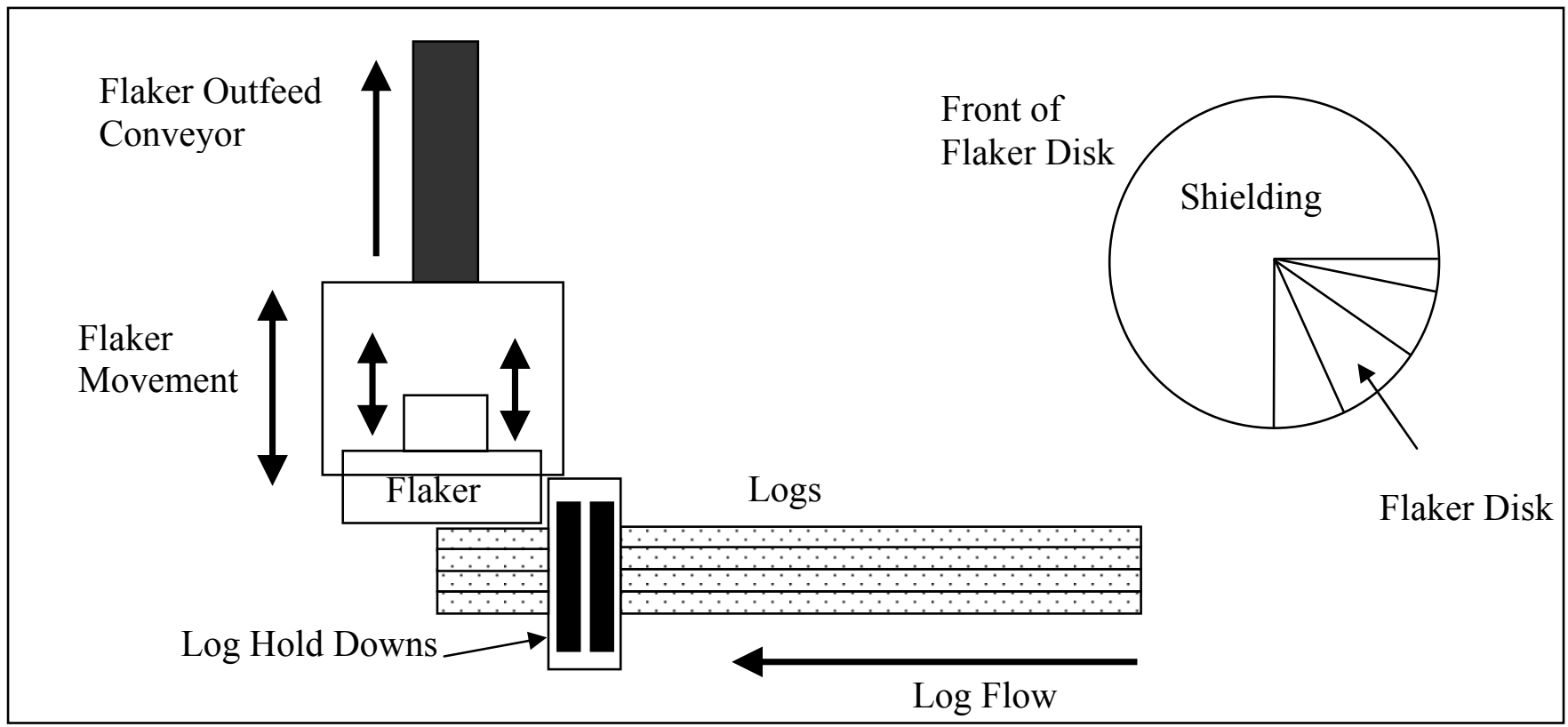

Figure 2. Schematics of flaker disk and log feed area

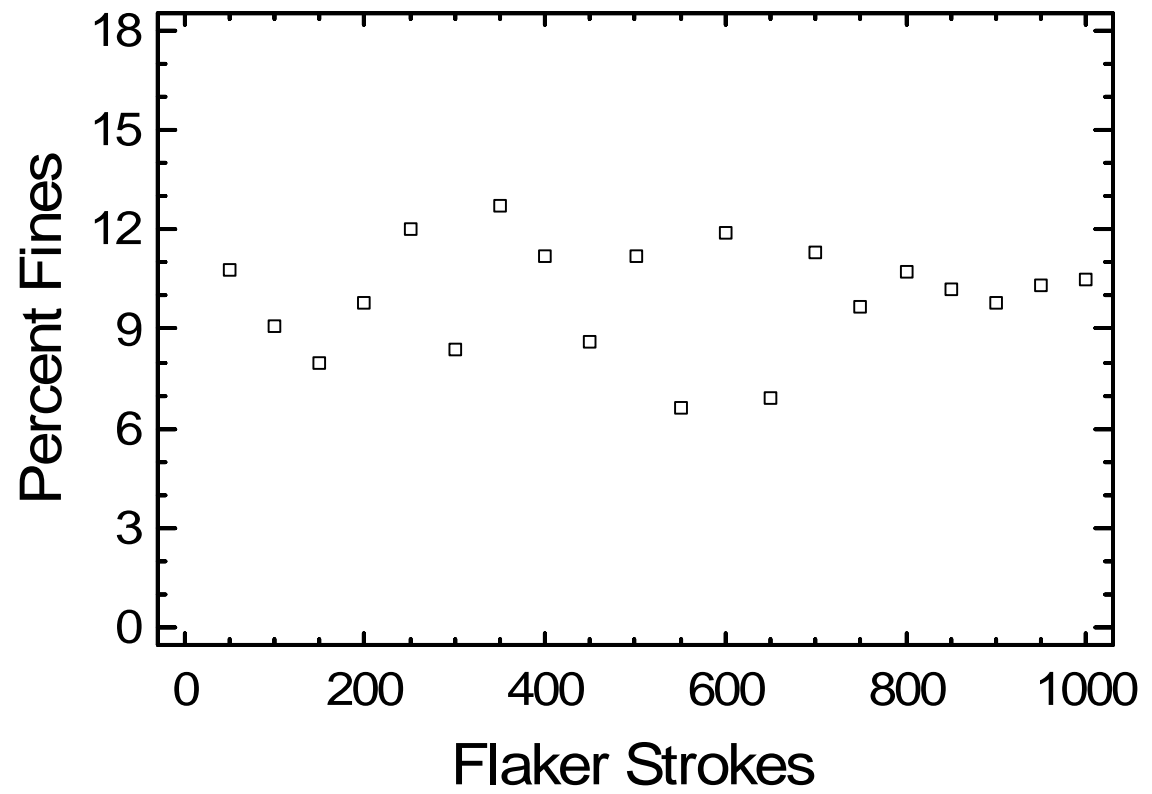

Figure 3. Fines generated as a function of flaker stroke. 29 degree knife angle example shown. 


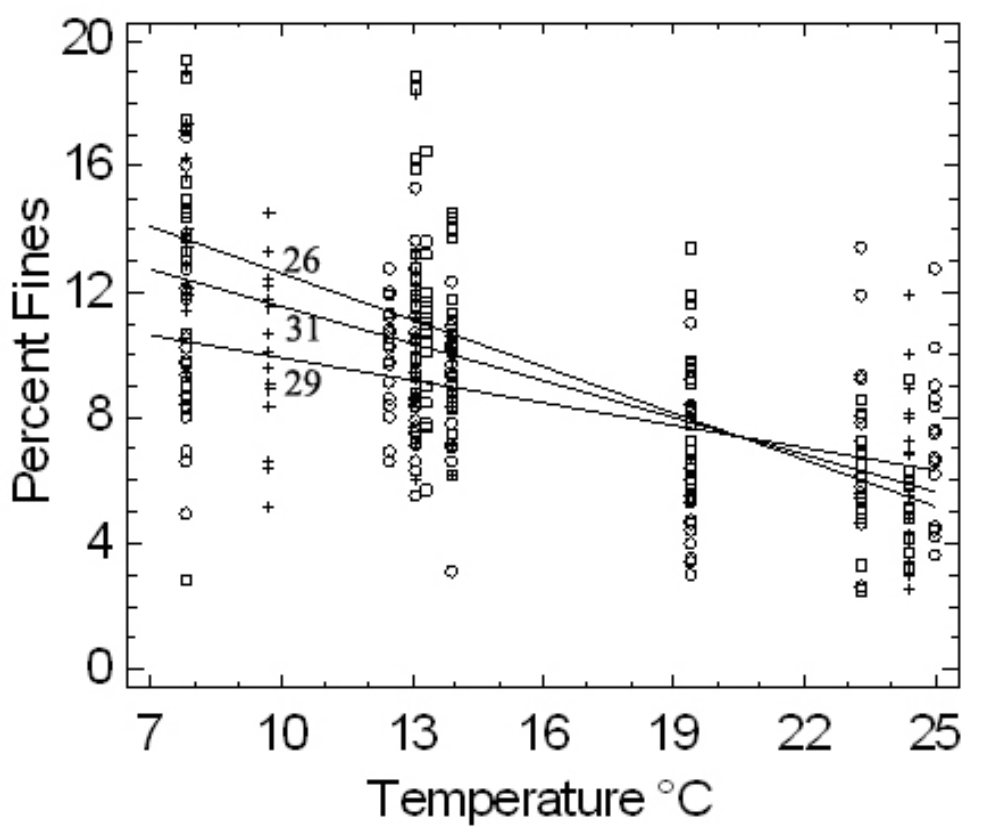

Figure 4a. Median temperature versus fines generation during full-scale flaking. Plus sign $=26$ degree knife angle data, circles $=29$ degree knife angle data, and wedge $=31$ degree knife angle data. (The 32 degree data are not plotted.). The individual regression lines are identified by the knife angles.

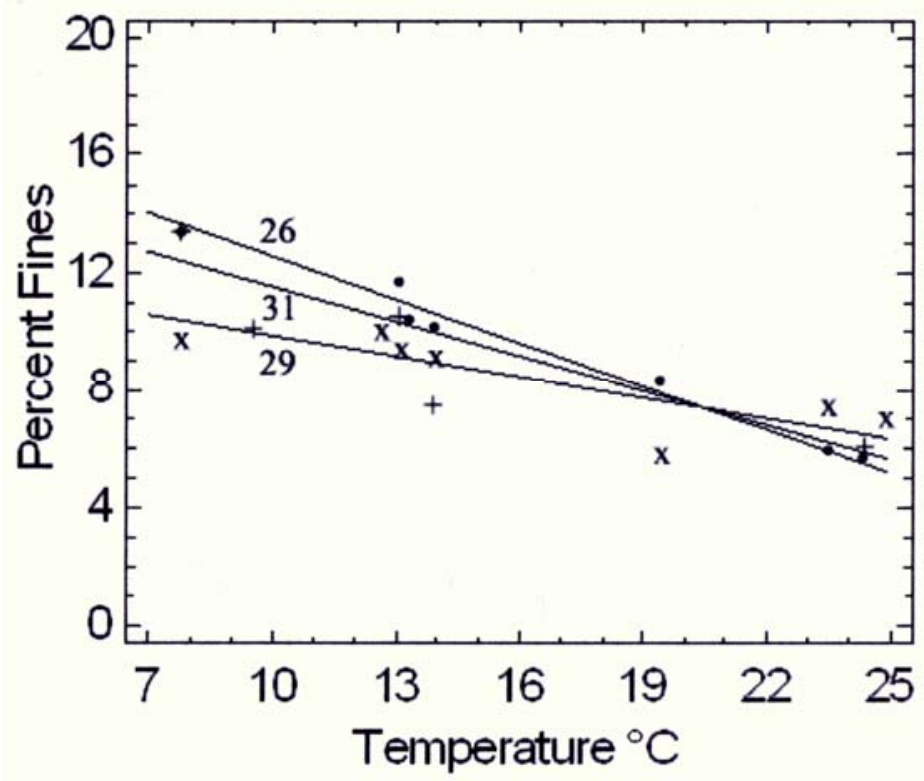

Figure 4b. Regression lines for median temperature versus fines generated during full-scale flaking plotted together with the average data for the individual trials. Black dot $=26$ degree knife angle data, $X=29$ degree knife angle data, and $+=31$ degree knife angle data. (The 32 degree data are not plotted.). The individual regression lines are identified by the knife angles. 


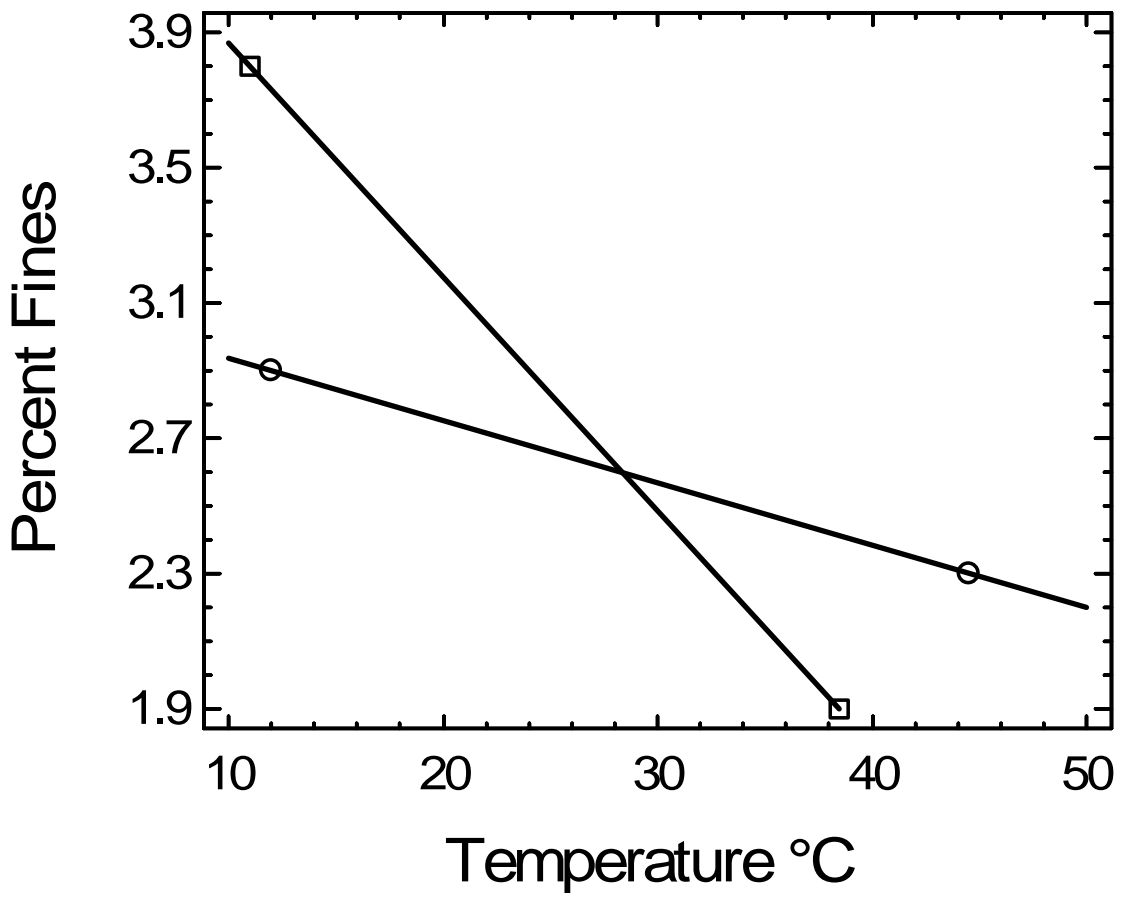

Figure 5. Median temperature versus fines generation during pilot-scale flaking. Squares $=29$ degree knife angle, circles $=33$ degree knife angle.

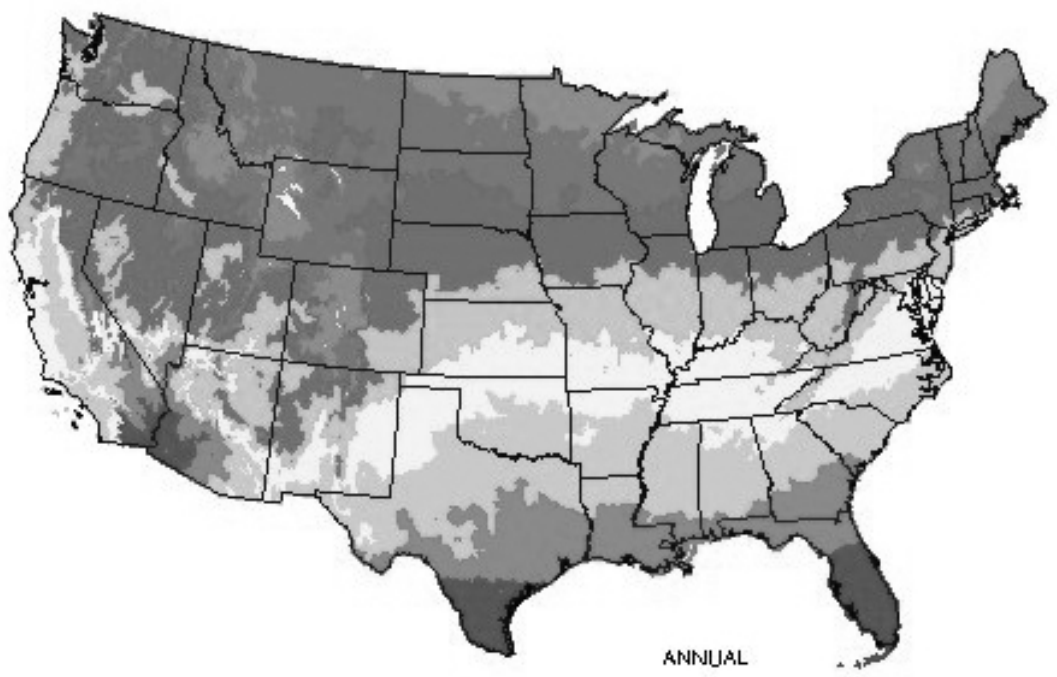

Figure 6. Average daily mean temperatures (annual basis) in the contiguous 48 states of the U.S. Temperatures are in 10 degree Fahrenheit gradations, displayed beginning with $90^{\circ} \mathrm{F}$ (and above) in southern Florida and Texas. (Map created by NOAA National Climatic Data Center, Asheville, NC. See the interactive website at http://gis.ncdc.noaa.gov/website/imsclimatls/index.html.) 


\title{
Temperature Effects on Fines Generation during Wood Flaking
}

\author{
Sujit Banerjee, Usha Hooda ${ }^{\ddagger}$, and Terrance E. Conners ${ }^{\ddagger}$ \\ Appita J., in press.
}

\author{
${ }^{\ddagger}$ Institute of Paper Science and Technology \\ School of Chemical \& Biomolecular Engineering \\ Georgia Institute of Technology \\ $50010^{\text {th }}$ Street, NW, Atlanta, GA 30332-0620 \\ "Department of Forestry \\ University of Kentucky \\ Lexington, KY 40546-0073
}

\begin{abstract}
Summary
The amount of fines produced by flaking green logs into strands for oriented strandboard depends on a combination of temperature and the knife sharpness angle. In winter, a larger knife angle reduces the fines significantly. Two conditions are necessary for this phenomenon to occur: the fines must be created by (at least) two different processes, and the two processes must have different temperature dependencies. During flaking, a piece of wood is removed from a log through a combination of splitting and cutting. Results from two full-scale facilities suggest that the splitting component is temperature-dependent because lignin softens with increasing temperature. Laboratory results indicate that the cutting action is insensitive to temperature. These data provide a working hypothesis for the practice of reducing flaker fines by adjusting the knife sharpness angle in response to log temperature. A similar approach should also apply to reducing fines from chipping wood for pulping, although the significance would be smaller given that far fewer fines are generated during chipping than in flaking.
\end{abstract}

\section{Keywords}

Fines, flaking, chipping, temperature, sharpness angle, tensile index 


\section{Introduction}

Flaking logs for the manufacture of oriented strandboard (OSB) unavoidably generates significant quantities of fines, which reduce wood yield, degrade product quality, and consume excess resin. Emissions are also increased because fines release a disproportionate quantity of formaldehyde, methanol, and other "Hazardous Air Pollutants" during drying (1). We have previously demonstrated that fines generation during commercial flaking is related to a combination of knife angle and wood temperature (2). Results collected from a full-scale facility in the Southeastern US over a year-long period (2) showed that there is a cross-over temperature at which knife angle changes should be implemented to minimize fines generation (Figure 1). Use of a larger knife sharpness angle during cooler winter temperatures significantly reduces the amount of fines produced, a practice that is now being implemented at other mills. However, the underlying mechanism is not known, and we have an unusual situation where our findings are beginning to be used in industry without its basis being understood.

Two conditions must be met for different knife angles to cause the data lines for percent fines vs. temperature to intersect as in Figure 1: (a) the fines must be created by at least two different processes, and (b) the two processes must have different temperature dependencies. We assume that the two required processes are (i) splitting along the grain, and (ii) cutting/fracturing perpendicular to the grain as illustrated in Figure 2. This is the approach conventionally used to resolve forces during engineering analyses of wood machining operations (e.g. reference 3). Different knife sharpness angles will have different amounts of force-perpendicular-to-the-grain and force-parallel-to-the-grain components. In the Figure 2 illustration, $F_{n}$ and $F_{p}$ would be principally related to the cutting and splitting components, respectively.

Splitting separates fibres held together by lignin and occurs parallel to the fibre axis through fractures in the middle lamella region where the lignin concentration is the highest. Lignin is thermoplastic, so the splitting process should be temperature-dependent. If the kinetic energy input to the system (i.e., the flaker or chipper rotation speed) is increased, then cell wall splitting may also occur parallel to the fibre axis. If the wood moisture content drops below the fibre saturation point then this too would affect fibre separation. However, other factors being equal, there should ordinarily be fewer fines and more long flakes at higher temperatures.

Cutting is a stress-induced fracture perpendicular to cell walls. This action should be temperature-insensitive by comparison and should be principally regulated by the knife angle and the flaker/chipper rotation speed. However, demonstrating that the generation of fines from cutting is independent of temperature is difficult. In principle, one could measure fines from an experiment where the blade approached the wood at a $90^{\circ}$ angle, but even here some splitting would inevitably occur. Also, the measurements would need to be very extensive to average out the inherent variability in a log. A different approach was attempted in this study. Kraft pulps with different high kappa numbers were used to make handsheets for zero-span tensile testing on the basis that the bonded pulp sheet fibres would fail through rupture across cell walls. These handsheets were conditioned and tested at different temperatures to determine whether there was a temperature dependency for this type of cell wall fracture. 


\section{Experimental}

Wet tensile measurements were made from southern pine kraft pulps at three kappa numbers: 10, 85, and 100 kappa. Each pulp was beaten in a PFI mill to at least two different freeness levels and disintegrated in a British disintegrator to provide different levels of cell wall integrity and internal bonding opportunities. Eighteen standard TAPPI handsheets were prepared from each pulp. Two strips ( $2.5 \mathrm{~cm}$ wide) were cut from each handsheet and rewetted in pans maintained overnight in temperature-controlled rooms set at $4,10,23$, and $32^{\circ} \mathrm{C}$. The strips were soaked for one hour and the excess water blotted out. The handsheets were conditioned overnight in temperature-controlled rooms and wet zero-span tensile strengths were measured at each of the four different temperatures (6). This test measures the strength of a collection of fibres. The finite-span tensile index (for the rupture of fibre network bonds) is known to decrease with increasing temperature (7), so this and other, more usual handsheet strength tests were inapplicable in this situation.

\section{Results and Discussion}

Both flaking and chipping involve splitting and cutting (although the machine geometries are different) so the trends from either operation ought to be broadly applicable to the other. We had access to data from a pulp chip operation in central Georgia (US); the data were collected over a year-long period and are illustrated in Figure 3. The trends for fines and oversize material are very different. A lower percentage of fines was produced during warm weather, while the proportion of oversize chips simultaneously increased. Analogous data obtained from a mill in eastern Georgia $200 \mathrm{~km}$ distant from the first location are provided in Figure 4. These values were averaged over 2003-2006 and show the same trend in that the fraction of large flakes increase in the summer, whereas the opposite is true for the smaller chips. This type of behavior has been noted before, but only for frozen or near-frozen wood where a phase change is involved $(4,5)$. The inverse relationship between fines and oversize material in these mills is compelling. The increase in the large chips with increasing temperature should be principally related to splitting, and is very likely a consequence of the softening of lignin at warmer temperatures. Hence, these results support our expectation that splitting is temperature dependent.

Values for the zero-span tensile index for various pulps ranging from 10-100 kappa are reported in Table 1. The 100-kappa values are also plotted in Figure 5. The zero-span index is unrelated to temperature regardless of the pulp freeness or kappa no. We recognize that the properties of a handsheet does not exactly replicate those of a log; however, a 100-kappa handsheet retains the principal components of wood, albeit at different levels and in a different form. The tensile index is independent of temperature for 10-100 kappa pulps; i.e. in the face of changing lignin content. Hence, it seems reasonable to assume that a further increase in lignin content up to the level found in a log should also not affect the temperature independence. Because zerospan tests only evaluate fibre strength properties and not fibre-fibre bonds, our results suggest that cutting is temperature-independent, whereas splitting is the temperature-sensitive component of the flaking process.

These results provide a mechanistic basis for our observation that varying knife angles with temperature minimizes fines generation (2). This practice should apply either to chipping wood for pulping or to OSB flaking operations, although demonstrating a reduction of fines in a 
chip mill would be much more difficult in view of the much lower proportion of fines that are created compared to OSB mill flaking operations.

\section{Acknowledgment}

This work was sponsored by the US Department of Energy through contract DE-FCO796ID13439 and the TIP $^{3}$ program of the State of Georgia.

\section{References}

1. Otwell, L.P., Hittmeier, M.E., Hooda, U., Yan, H., Su, W. and Banerjee, S. - HAPs release from wood drying, Environ. Sci. Technol., 34:2280 (2000).

2. Stiglbauer, P., Conners, T.E. and Banerjee, S. - Influence of knife angle and ambient temperature on fines generation from flakers, Forest Products J., 56(10):86 (2006).

3. Koch, P. - Wood Machining Processes. Chapter 3: Orthogonal Cutting. The Ronald Press Company, New York (1964).

4. Hernandez, R.E. and Quirion, B. - Effect of a chipper-canter knife clamp on the quality of chips produced from black spruce, Forest Products J. 43(9):8 (1993).

5. Hernandez, R.E. and Lessard, J. - Effect of cutting width and cutting height on the size distribution of black spruce pulp chips produced by a chipper-canter, Forest Products $J$. 47(3):89 (1997).

6. TAPPI standard methods T 279 pm-99 Tappi Press, Atlanta, GA (2005).

7. Back, E.L. and Andersson, L.I. - The effect of temperature on wet web strength properties, Tappi J., 76(5):164 (1993).

\begin{tabular}{|c|c|c|c|c|c|}
\hline \multicolumn{6}{|l|}{ Table 1} \\
\hline \multicolumn{6}{|c|}{ Effect of temperature on zero-span tensile index ${ }^{1}$. } \\
\hline kappa no. & CSF (ml) & $4{ }^{0} \mathrm{C}$ & $10{ }^{0} \mathrm{C}$ & $23^{0} \mathrm{C}$ & $32{ }^{0} \mathrm{C}$ \\
\hline 10 & 712 & $123(6)$ & $159(4)$ & $107(4)$ & $144(7)$ \\
\hline 10 & 288 & $58(1)$ & $128(4)$ & $36(1)$ & $122(4)$ \\
\hline 85 & 430 & $108(2)$ & $118(4)$ & $112(3)$ & $108(5)$ \\
\hline 85 & 370 & $136(6)$ & $149(5)$ & $138(3)$ & $107(5)$ \\
\hline 100 & 463 & $130(4)$ & $121(5)$ & $117(4)$ & $118(4)$ \\
\hline 100 & 370 & $105(2)$ & $118(5)$ & 109 (3) & $107(5)$ \\
\hline 100 & 202 & $96(4)$ & $117(6)$ & $92(2)$ & $105(4)$ \\
\hline 100 & 152 & $93(3)$ & $106(5)$ & $93(6)$ & $115(4)$ \\
\hline
\end{tabular}

${ }^{1}$ in $\mathrm{Nm} / \mathrm{g}$; the values in parentheses are standard deviations 


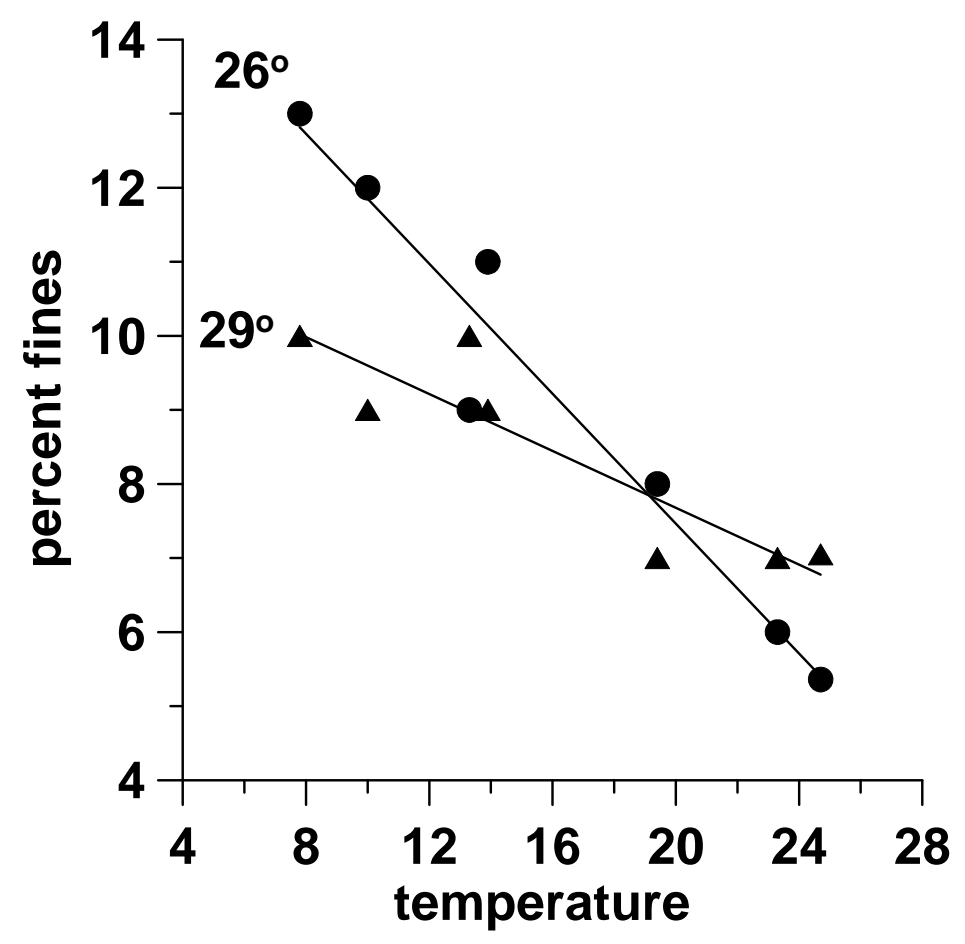

Fig. 1 Dependence on fines generation on ambient temperature $\left({ }^{\circ} \mathrm{C}\right)$ during commercial flaking.

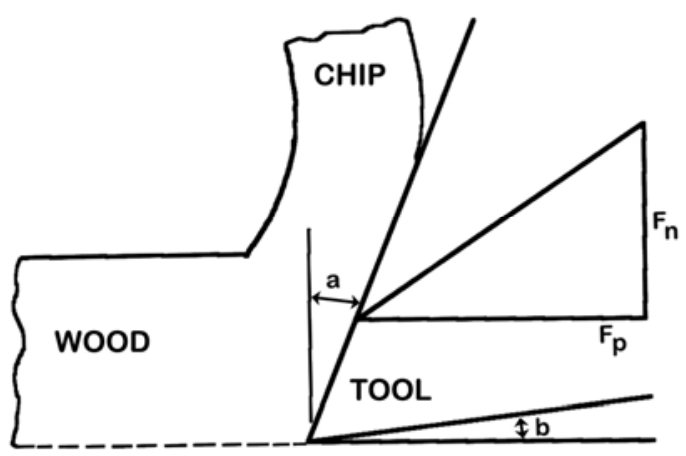

Fig. 2 Illustration of the interface between knife and wood. This diagram depicts: $a=$ the rake angle, $b=$ the clearance angle, and the included knife sharpness angle for the tool itself. $F_{n}$ represents the cutting force perpendicular to the wood grain, and $F_{p}$ represents the cutting force parallel to the grain. 


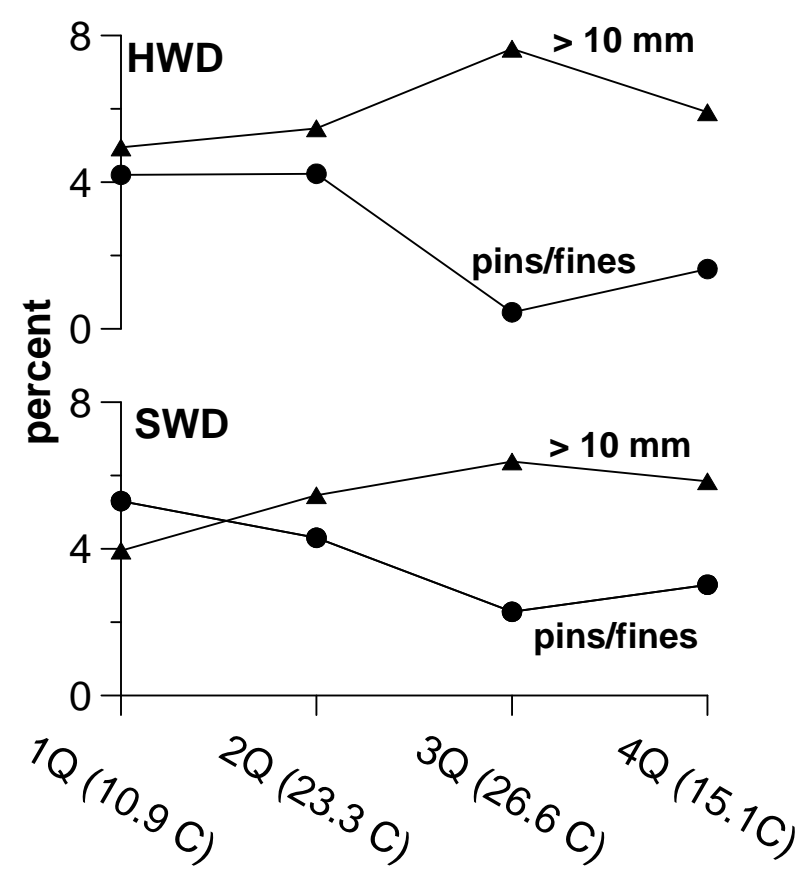

Fig. 3 Pins \& fines and oversize chips generated at a central Georgia mill. The average temperatures for $1 Q-4 Q$ are provided in the abscissa.

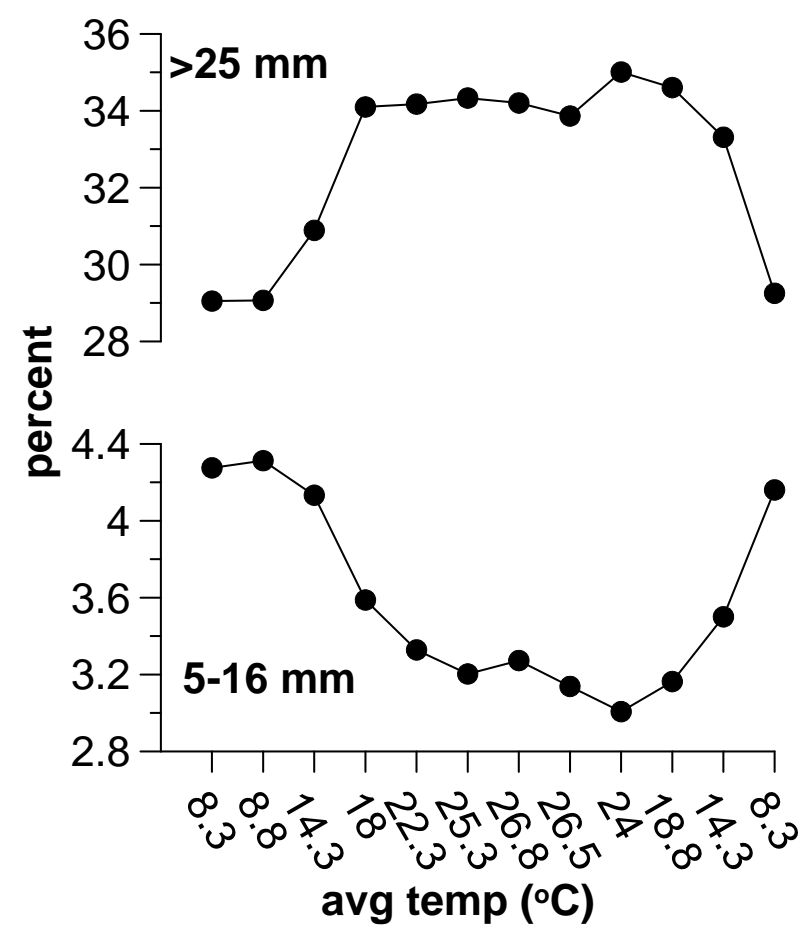

Fig. 4 Changes in yield with temperature at an eastern Georgia mill. The average temperatures are for January through December 2003-2006. 


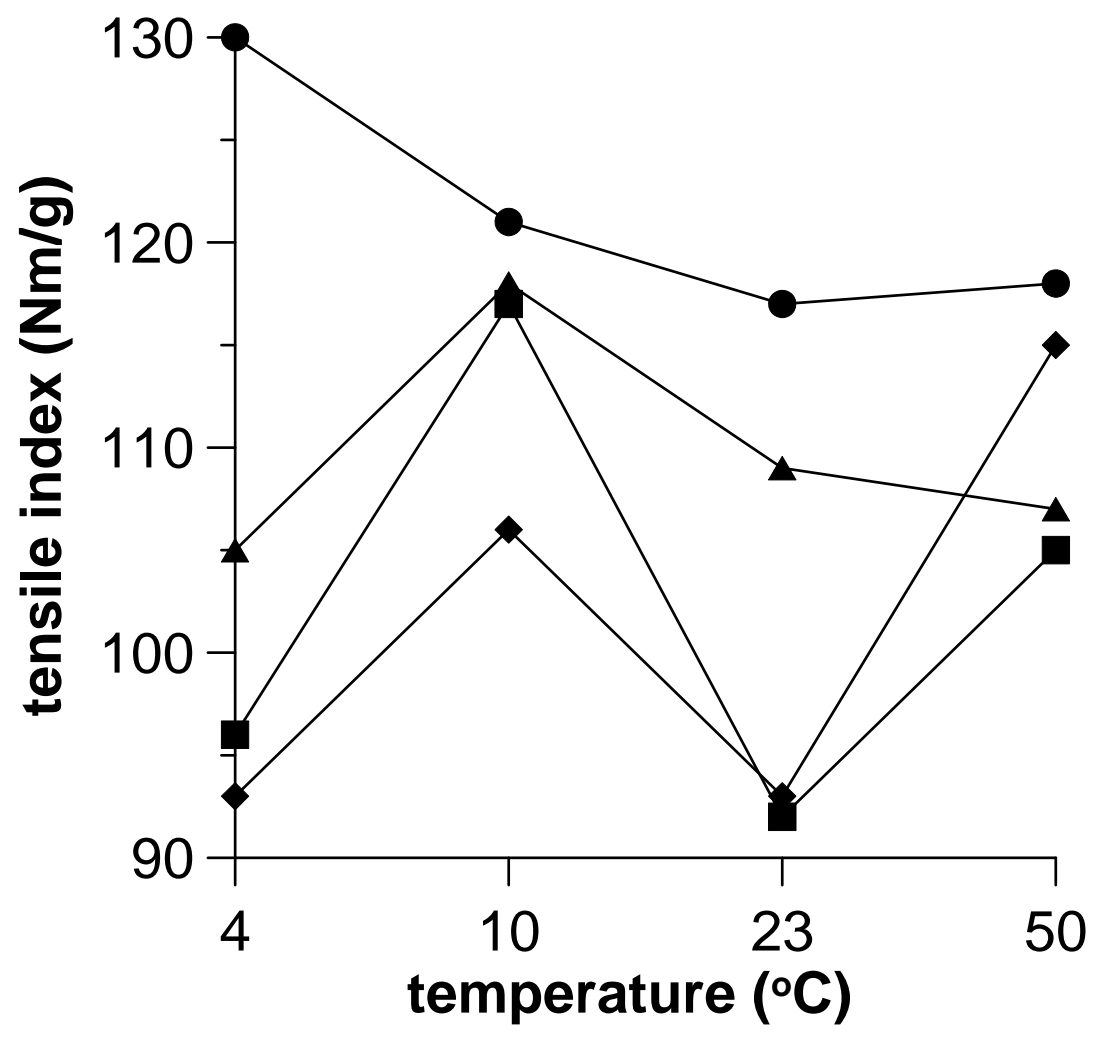

Fig. 5 Effect of temperature on zero-span wet tensile strength for 100-kappa pulp. The CSF values are as follows: • (463), $\Delta$ (370), $\square(202), \diamond(152)$. 


\section{List of Publications and Presentations}

1. W.Su, J.R. Boerner, U.Hooda, H.Yan, S.Banerjee, R.Shmulsky, L.L.Ingram, T.E.Conners, VOC extraction from softwood through low-headspace heating, Holzforschung, 53, 641 (1999).

2. U.Hooda, S.Banerjee, Microwave enhanced transport of chemicals into green wood under low-headspace conditions, Holzforschung, 54, 331 (2000).

3. L.P.Otwell, M.E.Hittmeier, U.Hooda, H.Yan, W.Su, S.Banerjee, HAPs release from wood drying, Environ. Sci. Technol., 34, 2280 (2000).

4. T.E.Conners, L.L.Ingram, W.Su, H.Yan, S.Banerjee, A.T.Dalton, M.C.Templeton, S.V.Diehl, Seasonal variation in southern pine terpenes, Forest Products J., 51(6), 89 (2001).

5. S.Banerjee, Mechanisms of terpene release during sawdust and flake drying, Holzforschung, 55, 413 (2001).

6. C.J.Martino, S.Shrauti, S.Banerjee, L.P.Otwell, E.W.Price, Flake drying temperature affects mat properties during pressing, Holzforschung, 56, 558 (2002).

7. T.E.Conners, H.Yan, S.Banerjee, Mechanism of VOC release from high-temperature Southern pine lumber drying umber kilns, Wood Fiber Sci., 34, 666 (2002).

8. S.Banerjee, J.Boerner, W.Su, Method for lowering the VOCs emitted during drying of wood products, US patent 6,029,368 (2000).

9. S.Banerjee, E.Malcolm, Method for distributing chemicals through a fibrous material using low-headspace dielectric heating. US patent 6,436,486 (2002).

10. J.Radhakrishnan, S.Banerjee, A simple heat transfer model for estimating terpene emissions from hot-pressing softwood, Holzforschung, 58, 384 (2004).

11. J.Cowan, M.Abu-Daabes, S.Banerjee, Controlling formaldehyde emissions with boiler ash, Environ. Sci. Technol., 39, 5101 (2005).

12. S.Banerjee, K.Pendyala, M.Buchanan, R.Yang, M.Abu-Daabes, L.P.E.Otwell, Process-based control of HAPs emissions from drying wood flakes, Environ. Sci. Technol., 40, 2438 (2006).

13. P.Stiglbauer, T.E.Conners, S.Banerjee, Influence of knife angle and ambient temperature on fines generation from flakers, Forest Products J., 56(10) 86 (2006).

14. S.Banerjee, U.Hooda, T.E. Conners, Temperature effects on fines generation during wood flaking, Appita J., in press.

\section{Presentations}

1. S.Banerjee, T.E.Conners, Dependence of fines generation from flaking wood on temperature and knife angle, Tenth European Panel Products Symposium, Llandudno, Wales (2006).

2. P.Stiglbauer, T.E.Conners, S Banerjee, Reducing fines generation at oriented strandboard flakers by adjusting knife angles as ambient temperature varies, Ninth European Panel Products Symposium, Llandudno, Wales, 2005.

3. P.Stiglbauer, T.E.Conners, S.Banerjee, Reducing fines generation at oriented strandboard flakers, AIChE Conf., Atlanta, GA, 2005.

4. P.Stiglbauer, T.E.Conners, S.Banerjee, Fines reduction at OSB flakers, Forest Products Society 59th International Convention, Quebec, 2005.

5. S.Banerjee, J.Yang, M.Buchanan, T.E.Conners, L.P.E.Otwell, S.Conners, HAPs generation and removal, Tappi Summit, Atlanta, GA 2004.

6. S.Banerjee, J.Radhakrishnan, M.Buchanan, T.E.Conners, K.Pendyala, J.Cowan, Use of ash in HAPs removal, Tappi Summit, Atlanta, GA 2004. 
7. S.Banerjee, Approaching the production-based limit for HAPs reduction from OSB drying \& pressing, Structural Board Association Meeting, Phoenix, AZ, 2003.

8. S.Banerjee, VOC emissions from wood dryers and presses, Georgia-Pacific corporate-wide environmental conference, Atlanta, GA, 2002.

9. S.Banerjee, Mechanism of VOC emissions from wood, AF\&PA workshop on environmental effects from wood drying, Raleigh, NC, 2001.

10. T.E.Conners, H.Yan, S.Banerjee, Release and measurement of VOC emissions from lumber kilns, TAPPI Environmental Conference, Charlotte, NC, 2001.

11. S.Banerjee, Radiofrequency enhanced diffusion of chemicals in wood, TAPPI Environmental Conference, Denver, 2000.

12. L.Otwell, S.Banerjee, Mechanism of VOC release from wood during processing at elevated temperatures, Wood Adhesives 2000, Lake Tahoe, NV, 2000.

13. T.Conners, L.Ingram, A.Thompson, M.C.Templeton, S.Diehl, W.Su, S.Banerjee, Effect of seasonal variation in southern pine terpenes on dryer emissions, TAPPI Environmental Conference, Nashville, TN, 1999.

14. S.M. Shrauti, J. Abedi. S.Banerjee, VOC reduction in plywood manufacturing by modification of drying practices, AIChE Conf., Dallas, TX, 1999.

15. S.Banerjee, VOCs from wood drying, AF\&PA workshop on Environmental Effects from Wood Drying, Raleigh, NC, 1999.

16. S.Banerjee, New developments in impulse drying sludge, EPRI Conference on Pulp and Paper Applications, San Francisco, 1998.

17. S.Banerjee, Low-VOC drying of softwood, Drying ‘98, Thessaloniki, Greece, 1998.

18. H.Yan, S.Banerjee, Extractives from softwood, ACS Conf., Boston, 1998. 